\title{
4. Bedingungen sprachlichen Handelns in der Mainzer Republik
}

Konstitutiv für die sprachpolitische Konstellation in der Mainzer Republik war der unvermittelte Herrschaftswechsel vom 21. Oktober 1792, mit dem die Machteliten, die bisher im Kurfürstentum den politischen Diskurs dominiert hatten, ihre dominante Position abrupt verloren: Der Kurfürst, große Teile der kurfurstlichen Regierung, des Adels und der Geistlichkeit, nicht zuletzt das Militär hatten die Stadt vor der anrückenden französischen Armee fluchtartig verlassen, ${ }^{180}$ und der verbliebene Rest der kurfurstlichen Regierung ${ }^{181}$ sah sich zunächst ${ }^{182}$ in indominanter Position. Ein Austausch der Machteliten hatte stattgefunden, was für die Mainzer Bevölkerung nicht nur durch die Tatsache augenfällig wurde, daß General Custine seinen Wohnsitz in den ehemals kurfürstlichen Gemächern nahm.

Anders jedoch als bei zurückliegenden Besetzungen der Stadt ${ }^{183}$ bedeutete dieser Elitenwechsel nun jedoch keineswegs eine "Kontinuität im Wandel«, das heißt keinen bloßen Austausch der Emittenten ansonsten funktionsidentischer, nämlich normativer politischer Verlautbarungen. Die Texte, mit denen die französische Besatzungsmacht sich an die Mainzer Bevölkerung wandte, trugen zwar gleichfalls zu einem gewissen Teil normative Funktion. Hinzu kamen jedoch in beträchtlichem, zeitweise uberwiegendem Umfang persuasive Texte. Dieser tiefgreifende Funktionswandel politischer Texte wird im

180 Vgl. Blisch 1992, S. 37; Scheel 1989, S. 44-48. Unter so bedenklichen Umständen, wo keine Truppen nahe sind, welche die Stadt vertheidigen können, ist die ganze courageuse Noblesse und Geistlichkeit sammt den Emigrierten und ihren Weibern gestern und vorgestern mit Sack und Pack geflüchtet. Der Churfürst kam den 4ten, sah einpacken und fuhr Abends $1 / 210$ (mit den Wappen vom Wagen abgekratzt) in der Stille davon. (Forster 1989 [1792], Bd. 17, S. 194).

181 Es handelte sich um das kurfürstliche Landesregierungskollegium, von dessen 50 Mitgliedern nur fünf in Mainz verblieben waren. Die mittleren und einfachen Beamten waren hingegen auf ihren Posten geblieben, so daß die Behorrden weiterarbeiten konnten. Vgl. Dumont 1993a, S. 117; Scheel 1981, S. 84-86; Scheel 1989, S. 57-72.

182 Unten wird gezeigt werden, daß die verbliebene kurfurstliche Rumpf-Regierung aber bald wieder bemüht war, aktiv ins sprach-politische Geschehen einzugreifen.

Vgl. Schiosser 1992, S. 9-24. 
folgenden als das Ergebnis einer ebenso tiefgreifenden Zäsur des politischen Systems zu verstehen sein.

Einen ersten Beleg für die in der Folgezeit sich häufenden persuasiven Texte stellt schon der Aufruf dar, mit dem General Custine am 23. Oktober 1792 in Mainz an die Öffentlichkeit trat:

Text 1: „Aufruf an die gedrückte Menschheit in Deutschland [...].“, Mainz, 23./25. Oktober $1792^{184}$

[1] Aufruf an die gedrückte Menschheit in Deutschland, im Namen der Franken-Republik von Adam Philipp Cüstine, Fränkischen Bürger, und General der Armeen der Republik.

[2] Als die Franken sich zum Kriege entschlossen, wurden sie dazu aufgefordert, um den ungerechten Angriff der Despoten dieser in Vorurtheilen eingewiegten Menschen zurückzutreiben, welche sich einbilden, daß die Völker des Erdbodens aus keiner andern Absicht da sind, als vor ihren Unterdrückern zu knieen, und durch ihr Gold wie durch ihren blutigen Schweis den Stolz, die Habsucht und die Wollust ihrer pflichtvergessenen Vorsteher zu sättigen.

[3] Die Nation der Franken und ihre Repräsentanten werden nach ihrer Gerechtigkeit allezeit die Völker unterscheiden, welche unglücklich genug sind, sich genöthiget zu sehen, ihre Häupter unter das entehrende Joch des Despotismus zu krümmen.

[4] Eine Nation, welche zuerst allen Völkern das Beispiel gegeben hat, zu ihren Rechten zurückzukehren, bietet Verbrüderung - bietet Ereiheit Euch an! -

[5] Euer eigener unerzwungener Wille soll Euer Schicksal entscheiden. Selbst dann, wenn Ihr die Sklaverei den Wohlthaten vorziehen würdet, mit welchem [!] die Ereiheit Euch winkt, bleibt es Euch überlassen, zu bestimmen. welcher Despot Euch Eure Fesseln zurückgeben soll.

[6] Ich werde die alten Auflagen handhaben; nur von jenen Menschen werde ich Brandschatzung fordern welche Euch drückende Lasten auflegten, denen sie sich selbst zu entziehen wußten. Ich werde alle konstituirten Gewalten bis dahin beschützen, wo ein freier Wunsch den Willen der Bürger. Beisaßen und Bauern in den Städten und Ortschaften des Erzbißthums Mainz. der Bißthümer Worms und Speier und in allen übrigen Gegenden von Deutschland, in welchen die Fahnen der Frankenrepublik aufgepflanzt wer-

184 Es handelt sich hier um eine recht freie, von Custines Sekretär, dem ehemaligen Wormser Konrektor G. W. Bohmer besorgte Übersetzung. Custines Original vom 23. Oktober 1792 (MR2, S. 84) wurde von ihm umgehend dem Pariser Nationalkonvent ubermittelt, dort am 28. Oktober 1792 verlesen und am 29. Oktober (Nr. 303, S. 322-323) im Moniteur veroffentlicht. Die hier abgedruckte Übersetzung wurde am 25. Oktober 1792 im MJK verlesen und am 26. Oktober als Plakat und als Beilage zur Mainzer Zeitung veroffentlicht. (Vgl. MR1, S. 55-56). 
den sollen, bis, sage ich, ein freier Wunsch den Willen eines jeden dieser deutschen Völker wird bekannt gemacht haben.

[7] Ich bin im Begriffe, diese Festung in den fürchterlichsten Vertheidigungsstand zu setzen, und ob man gleich unter Euch hat verbreiten wollen, daß ich die Absicht habe, sie zu verlassen, so schwöre ich doch: ich will sie behaupten! selbst dann noch behaupten, wenn das ganze Heer unsrer Feinde sich gegen dieselbe verbinden sollte.

[8] Möge sie zur Brustwehr der Freiheit aller Völker des deutschen Reiches gedeihen! Mögen aus ihrem Busen diese Grundsätze ewiger Wahrheiten hervorgehen! Möge die Klarheit dieser Grundsätze alle Menschen ergreifen, deren Nacken noch unter das Joch der Knechtschaft gebeugt ist! -

[9] Was mich betrifft, so habe ich, stolz auf den schönen Titel eines fränkischen Bürgers, all jenen Unterscheidungszeichen abgeschworen, die der Stolz der Despoten erfand. Der einzige, eines vernünftigen Menschen würdige Ehrgeiz ist dieser: In den Herzen seiner Mitbürger zu leben.

[10] Der Franken Bürger, General der Republikanischen Armeen, Cüstine.

[11] Dem Original gleichlautend, D. G. W. Böhmer.

Dieser Aufruf ist die erste, zugleich fundamentale Äußerung des Generals zu den Grundzügen seiner Besatzungsherrschaft in Mainz. Obwohl der Text durchaus Elemente regulativer Funktion enthält ${ }^{185}$ und insofern funktional keineswegs homogen erscheint, ${ }^{186}$ dominiert zweifellos die (informativ-) persuasive Funktion: Dies belegt schon die vom Emittenten gewăhlte Textsortenbenennung "Aufruf«, dies belegen die verwendeten sprachlichen Mittel, insbesondere die markante rhetorische Strukturierung, ${ }^{187}$ dies belegt aber hauptsächlich Custines explizites Angebot, die regulative Rolle an die Adressaten abgeben zu wollen (Vgl. Abs. [5].): Vor dem Hintergrund des politischen Konzeptes der Volkssouveränităt sichert Custine der Bevolkerung explizit Selbstbestimmung zu und insofern die Berechtigung, selbst die regulative Rolle zu ubernehmen. Dieses Angebot war ernst gemeint, denn Custine wartete gespannt auf die Reaktion der Bevolkerung: $J$ 'en attends l'effet ${ }^{188}$.

185 Der regierende General definiert hier die politischen Rahmenbedingungen und läßt, wie die wiederholte Verwendung der 1. P. Sg. zeigt (Vgl. die Zeilen [6,1], $[6,3],[7,1]$ und [7,4].), keinen Zweifel an seiner politischen Entscheidungskompetenz.

186 Vgl. zum Thema »Textfunktionskonflikte« Kap. 4.3.3 dieser Arbeit.

$187 \mathrm{Daß}$ der Text darüber hinaus uberwiegend aus kommissiven Sprechakten aufgebaut ist, daß auf die Person des Sprechers durchaus referiert wird und daß die eigentliche Werbebotschaft nicht expliziert wird, rückt ihn in die Năhe heutiger Wahlkampfreden.

188 Custine in seinem Brief an den Pariser Konventspräsidenten. (MR1, S. 57). 
Die große Bedeutung, die der Text für die sprachpolitische Konstellation der Folgezeit hatte, ${ }^{189}$ leitet sich jedoch weniger aus seiner spezifischen Persuasivität ab als aus der Voraussetzung, auf der diese beruht: Persuasion setzt die Annahme der Entscheidungsfähigkeit des Adressaten voraus. Insofern setzt persuasives Sprechen, das in verfassungspolitischen Fragen das Volk adressiert, die Souverănitắt des Volkes voraus. Indem Custine in dem zitierten Aufruf jede Verfassungsänderung vom Willen eines jeden dieser deutschen Völker ${ }^{190}$ abhăngig machte, ließ er die Volkssouverănität, eines der Grundprinzipien der Franzősischen Revolution, auch für die besetzten Gebiete gelten. Indem er in Anerkennung des Freiheitsprinzips dem festzustellenden Volkswillen uberdies die Qualität eines freie[n] Wunsch [es] ${ }^{191}$ verlieh, legte er sich auch schon auf ein Verfahren fest: Der Volkswille als Legitimationsinstanz sollte sich auch in den besetzten Gebieten in einem freiheitlichen Raum herausbilden und war auf freiheitlichem Wege zu ermitteln.

Der politische Raum aber, in dem ein Volkswille sich frei hătte herausbilden und artikulieren können, war im Fürstbistum Mainz 1792 keineswegs vorhanden: eine politische Öffentlichkeit. Diese konnte also nicht schon der Ort der sprachpolitischen Aktivität sein, sondern mußte erst deren Ziel werden.

\subsection{Die französische Machtübernahme in Mainz: Ein Strukturwechsel der Öffentlichkeit}

\subsubsection{Die Kommunikationsstruktur zur Zeit des »Ancien Régime«}

Von Öffentlichkeit als Instanz politischer Willensbildung konnte vor 1792 in den linksrheinischen Gebieten ebensowenig die Rede sein wie in den anderen deutschen Partikularstaaten. ${ }^{192}$ Das alles dominierende Zentrum der Politik war der Hof, und dessen Mittelpunkt der Regent. ${ }^{193}$ „Der Herrscher war noch weitgehend sakrosankt, durch das Gottesgnadentum legitimiert und somit der

189 Vgl. Dumont 1993a, S. 99-105; Schneider 1990, S. 12-18.

190 S. $51 .$, Text $1,[6,9]$.

191 S. 51., Text 1, [6,8].

192 „Kurzum, das, was wir das öffentliche Leben nennen, das war dem alten Mainzer durchaus fremd." (Bockenheimer 1902, S. 6).

193 Vgl. hierzu Bockenheimers (1902) präzise Schilderung der politischen und sozialen Verhältnisse in Mainz am Ende des 18. Jahrhunderts. 
Kritik entzogen. “194 Zwar waren die Regenten in ihren politischen Entscheidungen nicht vollkommen frei, sondern hatten mitunter Machtträger wie Kabinett, Domkapitel, Răte, Beichtvater oder auch Mätresse einzukalkulieren, jedoch handelte es sich hierbei um innerhoffische Einflußfaktoren, die fast ausschließlich von der schmalen sozialen Elite der Aristokraten ausgingen. Gegenüber den Untertanen agierten die Herrscher hingegen als Patriarchen und regierten aus einem sozialen Überlegenheitsgefuhl heraus und ohne den Versuch einer Legitimierung ihres Handelns unternehmen zu müssen. ${ }^{195}$ Die Einwohner des Landes wurden dementsprechend als Objekte, niemals als Subjekte des staatlichen Handelns betrachtet.

Politische Kommunikation fand nach diesem Herrschaftskonzept nur innerhalb des Hofes oder zwischen den Höfen statt. Da der uberwiegende Teil der Bevölkerung im Sinne der Regenten von dieser Kommunikation ausgeschlossen und lediglich mit den Ergebnissen politischer Entscheidungsfindung konfrontiert werden sollte, war der Modus der politischen Kommunikation die Geheimhaltung. Dieses Arkansystem galt nicht allein fur die Außenpolitik, wo man ohnehin eine Geheimdiplomatie betrieb, sondern auch für die Innenpolitik.

Zu einer Art Kommunikations-Macchiavellismus entwickelte sich das Prinzip, das politische Überlegen in Schweigen zu hüllen, das Reden aber in Befehle zu kleiden. Nur den Willen zu künden, nicht die Erwägung, und Fragen und Kritik von außen als autoritätsfeindlich durch die Zensur abzuwürgen, - dies ist der Kern des Arkanmodells [...]. ${ }^{196}$

Auch in Mainz war der Hof bestrebt, eine politische Partizipation der Bevölkerung durch Geheimhaltung und Kommunikationskontrolle zu verhindern. Die Praxis der politischen Kommunikationskontrolle und -verhinderung läßt sich schon an der extrem schmalen Mainzer Publizistik ablesen. Auch wenn man die von H.-J. Koppitz angemahnten, für das Jahr 1788 exemplifizierten Korrekturen ${ }^{197}$ in Rechnung stellt, erscheint Mainz im ausgehenden 18. Jahrhundert keineswegs als bedeutendes Zentrum uberregionaler Publizistik. Die Buchproduktion der vier Mainzer Druckereien hielt sich in engen Grenzen. Sie umfaßte neben den offiziellen Kalendern, dem Katechismus, dem Gesang- und Gebetsbuch, Dissertationen und Schulbüchern, Erbauungs- und Wallfahrtsbüchlein in erster Linie Nach-, auch Raubdrucke andernorts erschienener Publikationen. ${ }^{198}$

194 Dumont 1993a, S. 14.

195 Vgl. Dumont 1993a, S. 14.

196 Schneider 1978, S. 908.

197 Vgl. Koppitz 1984, S. 87-97.

198 Vgl. Koppitz 1984, S. 87-89. 
Auch die Produktion an Periodika ${ }^{199}$ war vor 1792 ebensowenig umfangreich wie ergiebig. Es herrschte, ganz im Sinne des Arkansystems, eine intendierte Durftigkeit. ${ }^{200}$ Zum Zeitpunkt der Besetzung durch die Franzosen besaß Mainz zwei Zeitungen: Zum einen das 1744 gegrundete, zweimal wöchentlich unter dem Titel Mainzisches Intelligenzblatt, mit kurfürstlichem gnädigsten Privilegium erscheinende Nachrichtenblatt. Als Regierungsorgan enthielt sich dieses Blatt keineswegs ,jeder Politik“, wie H. Roth urteilt. ${ }^{201}$ Weniger in den Nachrichten als in belehrenden Aufsätzen, die AllgemeinMoralisches, zum Teil aber auch Politisches zum Gegenstand hatten, kam eine durchaus politische Ausrichtung im Rahmen des geltenden Herrschaftsmodells zum Ausdruck: Die Obrigkeit, so das Intelligenzblatt, sei von Gott als dessen Stellvertreter in ihr Amt eingesetzt,

zum wahren Besten der Bürger, damit diese in ihren Häusern mit dem, was sie erworben haben, sicher und ruhig leben und die Früchte ihrer Arbeit in Ruhe genieBen können. ${ }^{202}$

Freudig soll daher der Bürger seine Pflichten erfüllen, vor allen Dingen den Gesetzen nachkommen und die Abgaben getreu entrichten. ${ }^{203}$

Um den Gang der staatlichen Verwaltung kümmere man sich nicht, denn dafür hat der Landesfürst Obere eingesetzt. Handlungen, die das allgemeine Wohl schädigen, bringt der brave Bürger zur Anzeige, überläßt aber alles Weitere der zuständigen Behörde. Außerdem trachtet er nicht nach öffentlichen Ämtern, wenn er nicht vom Landesherrn dazu berufen wird. ${ }^{204}$

Die zweite Zeitung war die viermal wöchentlich erscheinende Privilegierte Mainzer Zeitung, ${ }^{205}$ die 1767 ,durch die Regierung, die ein ihren Zwecken dienendes Blatt zu besitzen wünschte, "206 als Hofzeitung gegründet worden war. Auch diese Zeitung war keineswegs „völlig unpolitisch."207 Wenn beispielsweise politisch bedeutende Audienzen bei Hofe nur als gesellschaftliche Ereignisse angezeigt wurden, ihre politische Funktion aber nicht einmal

199 Vgl. Roth 1930, S. 2-14; Grab 1969, S. 122-123.

200 Vgl. Wilke/Forster 1993, S. 171; auch Bockenheimer 1902, S. 28: „Dabei darf man nicht vergessen, daß die Mainzer jener Zeit die Kenntniß politischer Vorgänge vorzugsweise aus der dreimal in der Woche erscheinenden, ihrem Inhalt und Umfange nach höchst durftigen »Privilegirten Mainzer Zeitung«, einem Regierungsblatt, schöpften [...].“

201 Roth 1930, S. 4.

202 Mainzisches Intelligenzblatt, Nr. 17 von 1788.

203 Mainzisches Intelligenzblatt, Nr. 23 von 1788.

204 Mainzisches Intelligenzblatt, Nr. 28 von 1788.

205 Vgl. oben, Fn. 21.

206 Roth 1930, S. 4.

207 Roth 1930, S. 5. 
genannt wurde, ${ }^{208}$ so reflektierte dies nicht eine unpolitische Haltung, wie Roth annimmt, sondern es war Teil des Arkansystems, das eine denkbare Öffentlichkeit politischer Entscheidungsprozesse schon dadurch zu vermeiden trachtete, daß es potentielle Gegenstände eines möglichen offentlich-politischen »Răsonnements《 verschwieg.

Auch der Bestand an Zeitschriften, die in Mainz erschienen, war gering. Zudem hatten die meisten Periodika ihr Erscheinen schon vor 1792 wieder eingestellt: Die fur die katholische Aufklärung in Mainz bedeutende moralische Wochenschrift Der Bürger hatte nur von 1765-1767 bestanden, das jesuitisch geprägte Religionsjournal erschien 1787 zum letzten Mal, 1791 stellte die von der theologischen Fakultät herausgegebene Mainzer Monatsschrift von geistlichen Sachen ihr Erscheinen ein. ${ }^{209}$ Das in Verbindung mit der Mainzer Bühne herausgegebene Periodikum Tagebuch der Mainzer Schaubühne erschien bis 1789, das Allgemeine Theaterjournal bis zur Schließung des kurfürstlichen Nationaltheaters im November 1792. ${ }^{210}$

Alles in allem läßt sich für die denkbar schmale Publizistik des kurfuirstlichen Mainz eine relativ einheitliche, politisch affirmative, keineswegs korrektive Funktion ausmachen. Sie bleibt ganz in den Grenzen eines Partikularstaates,

wo das "ancien régime" noch in voller Blüte und gerade der Versuch gemacht war, Aufklärung und geistliche Herrschaft miteinander zu verbinden, was besonders in der Mainzer Presse zutage tritt. Einzig und allein der Wille des Kurfursten war bei Gründung und Richtung der einzelnen Presseorgane maßgebend und ihre ganze Art fuhrte uns das enge an die Stănde gebundene Leben vor Augen. ${ }^{211}$

Die Kommunikationskontrolle durch die kurfurstliche Regierung bezog sich nicht nur auf die Presse, sondern auf jede Art von Publikation. Schon die kulturelle Liberalisierung im Zuge von Erthals Bemühungen um die Teilhabe von Mainz an der katholischen Spätaufklärung war zu keinem Zeitpunkt auf eine politische Partizipation außeraristokratischer Bevölkerungsanteile gerichtet gewesen. Spătestens aber mit der zu Beginn der 1790er Jahre einsetzenden Restauration, die nicht zuletzt als Reaktion auf die Franzosische Revolution und deren zunächst zustimmende Rezeption in Deutschland zu verstehen ist, wurden auch diese bescheidenen Liberalisierungsansätze wieder

$208 \mathrm{Vgl}$. Roth 1930, S. 4-5.

209 In enger Verbindung zu ihr standen die seit 1784 herausgegebenen Anzeigen von gelehrten Sachen. Vgl. Roth 1930, S. 7-10.

210 Vgl. Roth 1930, S. 6-12.

211 Roth 1930, S. 13. Allerdings handelt es sich hier weniger um eine kampferische "Einheitsfront" der „Mainzer Presse mit dem Kurfursten [...] gegen den drohenden Umsturz" (Roth 1930, S. 12), sondern um das Ergebnis energischer Kommunikationskontrolle. 
zurückgedrängt. Die nun wiedererrichtete Zensurbehörde brachte in der Folge die Schriften mehrerer Mainzer Universitătsprofessoren, die zuvor eigentlich von der Zensur ausgenommen gewesen waren, ${ }^{212}$ zur »Inquisition «: Der Priester und Philosoph Anton Joseph Dorsch beispielsweise wurde auf diese Weise in die Emigration gedrängt, die Bücher seines Kollegen Felix Anton Blau wurden verboten, und der Philosoph Andreas Joseph Hofmann handelte sich einen Verweis des Kurfursten sowie dauerhafte Überwachung ein. ${ }^{213}$

Die kurfurstlichen Versuche der Kommunikationskontrolle gingen noch weiter, indem sie sich nicht nur auf Publikationen, sondern auch auf mündliche Meinungsäußerungen der Gesamtbevölkerung richteten. Abweichend von der herkömmlichen Zensurierung bloß geschriebener Texte war auch das gesprochene Wort Gegenstand der kurfurstlichen Kontrolle gewesen:

Text 2: Verordnung der Kur-Mainzischen Landesregierung vom 10. September $1790^{214}$

[1] Wir zur Kurfürstlichen Mainzischen Landes-Regierung verordnete Präsident, Kanzlei-Direktor, Geheime-Hof-und Regierungs-Räthe.

[2] Fügen hiermit zu wissen, verordnen und gebiethen ernstlich, daß alle Reden und Gespräche gegen Religion, Sitten, Staat und Landesherrliche Verordnungen unterbleiben, und zwar um so mehr, da einem jeden unbenommen ist, seine Klagen und Anstände bey der Behörde, oder auch allenfalls bey Höchst Sr. Kurfürstlichen Gnaden anzubringen. Im Nichtbeobachtungsfalle werden Wir die Wirthe, Hauseigenthümer und Herbergsväter zur scharfen Verantwortung ziehen.

[3] Signatum unter hiebey gedrucktem Kurfürstl. Regierungs-Kanzley-Insiegel. Mainz den IOten September 1790.

[4] Freiherr von Frankenstein. Vt. J. M. Kissel, Regierungs-Secretarius.

Diese Verordnung wurde in der Praxis dann allerdings wenig strikt gehandhabt, so daß letztlich in der Zeit vor der französischen Besetzung eine „totale Überwachung im Rheinland nicht stattfand [...].“215 Aber selbst wenn harte Zwangsmaßnahmen die Ausnahme blieben, ist insgesamt doch festzuhalten, $\mathrm{da} ß$ die Intention der Regierenden auf die Verhinderung offentlich-politischer Kommunikation gerichtet war.

212 Vgl. Christ 1989, S. 228.

213 Vgl. Dumont 1993a, S. 47-50.

214 QGR, Bd. 1, S. 677.

215 Molitor 1982, S. 44. 
Vor diesem Hintergrund mag es erstaunen, daß in Mainz bis zu seiner Einnahme durch die Franzosen verschiedene aufklärerische Einrichtungen geduldet, zum Teil gefordert wurden, die zweifellos "Einfallstore" für das Gedankengut der franzősischen Revolution darstellten. Neben den auch im Linksrheinischen verbreiteten aufgeklärten Sozietäten ${ }^{216}$ ist hier an erster Stelle die Institution der Lesegesellschaft ${ }^{217} \mathrm{zu}$ nennen. Nicht nur in Mainz ${ }^{218}$ war die Motivation für die Gründung einer Lesegesellschaft das durch die Aufklärung geweckte Bedürfnis, an der kulturellen, wissenschaftlichen und politischen Diskussion der Zeit wenigstens rezipierend teilzunehmen, ein Bedürfnis, das wegen der hohen Kosten der Lekturebeschaffung individuell kaum zu befriedigen war. So wurde nach zuerst erfolglosen Anlăufen ${ }^{219} \mathrm{im}$ Jahre 1782 mit kurfurstlicher Genehmigung die Mainzer Gelehrte Lesegesellschaft mit dem Ziel gegründet,

mehrere politische, gelehrte, auch sonst interessante Zeitungen, Anzeigen, und andere dergleichen Schriften mit minderem Kösten-Aufwand, zugleich aber auch in einer vergnügten und nüzlichen Unterhaltung lesen zu können [...].

Schon seit mehrern Jahren war der beynahe allgemeine Wunsch zu Mainz rege geworden, einen gesellschaftlichen Ort zu haben, wo Männer aus allen Ständen einen gemeinschaftlichen Umgang pflegen, ihre Kenntnisse durch Lesung guter Schriften erweitern, und durch freundschaftliche Unterredungen ausbilden und wechselseitig mittheilen könnten. ${ }^{221}$

Zum Ende der 1780er Jahre waren etwa 250 Personen Mitglied der Lesegesellschaft, also etwa ein Prozent der Mainzer Bevölkerung. Fast die Hälfte der - ausschließlich männlichen ${ }^{222}$ - Mitglieder gehörten dem Adel an, rund

216 Freimaurer, Rosenkreuzer und Illuminaten waren zu verschiedenen Zeiten, mitunter mit zahlreichen Mitgliedern aus den einflußreichsten Gesellschaftsschichten, in Mainz vertreten. Vgl. Dotzauer 1984; Dotzauer 1977.

217 Vgl. Hainebach 1936; Mathy 1969b; Grus 1986; Grus 1993; Wilke 1985.

218 Man darf im ausgehenden 18. Jahrhundert in Deutschland eine Zahl von ungefähr eintausend Lesegesellschaften ansetzen. Vgl. Welke 1981, S. 45.

219 1766, im Kontext der ersten Mainzer Aufklărung wăhrend der Regierungszeit des Kurfürsten Emmerich Joseph von Breidbach-Bürresheim, hatte der Kurmainzische Hofgerichtsrat Johann Joseph Friedrich von Steigentesch in der von ihm herausgegebenen Wochenschrift Der Bürger einen erfolglosen Vorstoß zur Gründung einer Lesegesellschaft unternommen. Vgl. Grus 1986, S. 126-127.

220 BMG, S. 13. Eine ergiebige Quelle fur die Mainzer Gelehrte Lesegesellschaft ist der Bericht ihres langjăhrigen Sekretärs Johann Peter Schunk (Von der Gelehrten Lesegesellschaft zu Mainz), den dieser in seine Beyträge zur Mainzer Geschichte mit Urkunden aufgenommen hat.

221 BMG, S. 10.

222 Der Zutritt des anderen Geschlechts in diese Gesellschaft ist so, wie darinn das Spielen und Tabakrauchen, imgleichen anstößige Gespräche gegen die Religion, 
ein Viertel der Geistlichkeit und etwa zehn Prozent waren Universitătsprofessoren. Zunftburger waren in der Lesegesellschaft nicht vertreten, ebensowenig Angehörige der unteren Gesellschaftsschichten. ${ }^{223}$ Es handelte sich also „um einen sehr exklusiven Kreis von Fuhrungskräften aus Politik und Kultur", 224 der durch ein ausgeprägtes Elitebewußtsein gekennzeichnet war und der sich ,gegen die niederen Stănde scharf abgrenzte[...]." 225 Wie auch die partielle personelle Überschneidung mit dem ehemaligen, nun verbotenen Illuminatenbund zeigt, waren es ubberwiegend die Träger der Mainzer Aufklärung, die sich in der Lesegesellschaft versammelt hatten. Ehemalige Jesuiten hingegen waren aus der Lesegesellschaft ausgeschlossen worden.226

Die ausgelegte Lektüre bestand primär aus Periodika: Von sonstigen Büchern und Werken werden hauptsächlich nur Wörterbücher und solche Werke angeschaft, welche man zum Nachschlagen nöthig hat, und die sich die meisten Mitglieder nicht selbst ankauffen mögen. ${ }^{227}$ Die Gesellschaft hielt immerhin 88 Zeitungen und Zeitschriften, von denen 23 allgemeiner, auch literarischer Ausrichtung waren, 24 politisch-historischer (hierher gehörten auch Intelligenzblätter, Stadtzeitungen sowie 6 französische Blătter, ein englisches und ein italienisches) und 41 spezialwissenschaftlicher Natur. ${ }^{228}$ Sowohl die Liste der ausgelegten Zeitschriften als auch - soweit bekannt - der Buchbestand belegen ein Lektüreprogramm, das „liberalsten Charakter ${ }^{\prime 229}$

den Staat, und die guten Sitten nebst den Büchern und Schriften von solcher Art gänzlich untersagt. (BMG, S. 19).

Vgl. Hainebach 1936, S. 70; Dreyfus 1968, S. 500; Grus 1986, S. 130.

Dumont 1993a, S. 33. Die Exklusivität der Mitgliedschaft geht schon aus dem im voraus zu entrichtenden Jahresbeitrag von 12 fl. (Vgl. Scheel 1989, S. 74.) hervor, der für einen Handwerksgesellen mehr als einen halben Monatslohn ausmachte. Handwerksgesellen verdienten jährlich ca. 250 fl., Georg Forster hingegen ,rechnete nach einem Jahr in Mainz aus, daß er 3000 Gulden ausgegeben habe. Da sein kurfürstliches Salär nur 1800 Gulden betrug, mußte er 1200 Gulden auf dem Buch- und Zeitschriftenmarkt dazuverdienen.“ (Harpprecht 1987, S. 425).

225 Grus 1986, S. 125. Vgl. Scheel 1989, S. 73.

226 Vgl. Grus 1986, S. 130.

227 BMG, S. 18-19, Fn. ***.

228 Vgl. Grus 1986, S. 130-132.

229 Grus 1986, S. 132. „So ist es erstaunlich, wie selbstverständlich die Werke eines Claude-Adrien Helvetius, die gefullt sind mit atheistischen und radikal antiklerikalen Passagen, der aus Frankreich flüchten und in preußisches Exil gehen mußte, in einem katholischen Kurstaat rezipiert werden konnten. Der franzősische Abbé Raynal besuchte 1782 die Stadt Mainz. Sein Hauptwerk, die Histoire philosophique et politique des établissemente et du commerce des Européens dans les deux Indes [...] war im Jahr zuvor durch den Henker in Paris verbrannt 
hatte. Insofern stellte die Mainzer Gelehrte Lesegesellschaft für diejenige Gesellschaftsschicht, die ihr angehören konnte und wollte, ein leistungsfähiges Korrektiv furr die schmale, zudem politisch gelenkte Mainzer Publizistik dar.

Versuche von Seiten des erzbischöflichen Generalvikariats, die Auslage liberaler Veroffentlichungen zu unterdrücken, konnten immer wieder zurückgewiesen werden. Einer der interessantesten Aspekte an diesen Auseinandersetzungen ist die Tatsache, daß sie die intensive personelle Verflechtung der Lesegesellschaft mit dem Hof erhellen. Der kurmainzische Hof-, Regierungsund Revisionsrat Heinrich Wilhelm Graccher beispielsweise war nicht nur kurfurstlicher Zensor der weltlichen Schriften, sondern zeitweilig zugleich Vorsitzender der Lesegesellschaft. Erhellend ist ein Gutachten, mit dem er erfolgreich einer Anzeige widersprach, mit der das Generalvikariat, zuständig für die geistlichen Schriften, die Lesegesellschaft beim Kurfürsten verklagt hatte, der die Klage letztlich abwies:

Unmöglich sei es, die periodischen Schriften, worinn manchesmal ein und anders von dem genere prohibitum erscheint, hinwegzuthun und dadurch den Zusammenhang der Lektüre zu stören. Außerdem, und hier wird etwas von dem wachsenden emanzipatorischen Selbstbewußtsein der aufgeklärten Schichten gegenüber den alten geistlichen Autorităten sichtbar, bestehe die Lesegesellschaft nicht aus Leuten, welche noch an rohen Begriffen krank liegem, sondern aus Männern von gesunder Beurteilungskraft und guten Sitten [...]. Wenn dort staatsfeindliche Schriften gelesen würden, dann nur deshalb, um die Größe der Bosheit zu erkennen, die ein hämischer Schriftsteller gegen den einem jeden Patrioten gewiß vorzüglich werthen Staat ausspeyt. ${ }^{230}$

$\mathrm{Zu}$ einer fortschrittlichen, das "Ancien Régime« tendenziell transzendierenden Institution wurde die Lesegesellschaft jedoch nicht allein aufgrund der ausgelegten liberalen Lektüre, sondern insbesondere auch aufgrund ihrer inneren Verfassung: Nicht nur negierte die Lesegesellschaft, was die Eintrittsberechtigung anging, die sonst in Kurmainz strengen Standesgrenzen, ${ }^{231}$ sondern sie hatte auch den Modus ihrer inneren Entscheidungsfindung streng demokratisch geregelt: Die Aufnahme neuer und der Ausschluß bereits aufgenommener Mitglieder, die Bestimmung eines Direktors und des geschäftsfuhrenden Ausschusses sowie die Entscheidung von strittigen Fragen erfolgten in geheimen Abstimmungen. ${ }^{232}$ Außerdem legte die Lesegesellschaft, da

worden. Raynal [...] wurde vom Mainzer Kurfursten empfangen und hielt sich auch mehrfach in der Lesegesellschaft auf.“ (Grus 1986, S. 132). Grus 1986, S. 134-135.

231 Vgl. BMG, S. 15.

232 Zum Verfahren der "Kugelung (Ballotirung)« vgl. BMG, S. 15-18, 20-21, besonders $\mathrm{S}$. 15, Fn. *. 
sie keine Geheimnisse hat, noch haben will, ${ }^{233}$ ihre internen Vorgänge gegenüber jedermann offen: Sie war damit in mehrfacher Hinsicht ein Gegenmodell zum Hofarkanum.

Die Tatsache, daß in Gestalt der Lesegesellschaft zumindest potentiell ein Gegenmodell zum absolutistischen Herrschaftsmodell entstanden war, wurde vom Kurfürsten, der die Lesegesellschaft unter seinen vorzüglichen Schutz ${ }^{234}$ gestellt hatte, sicherlich unterschätzt, vielleicht nicht einmal erkannt. Selbst als ab 1791 offen revolutionsfreundliche Schriften in die Gesellschaft gelangten und von einem Teil der Mitglieder zustimmend aufgenommen wurden, ließen es der Mainzer Statthalter und der kurfurstliche Hofkanzler mit einer - die äußeren Umstănde in Rechnung gestellt - eher milden Ermahnung bewenden:

Text 3: Georg Karl Freiherr von Fechenbach und Franz Joseph Martin Freiherr von Albini: Ermahnung an die Mainzer Lesegesellschaft vom 13. Oktober $1792^{235}$

[1] An die Lesegesellschaft dahier

[2] Die bekannten dermaligen Zeitumstände würden zwar der kurfürstlichen Statthalterschaft hinlängliche Ursache geben, alle französischen Journale und Zeitungsblätter, welche nichts als unglücklichen Aufruhr predigen, für die Zukunft zu verbieten; da jedoch kurfürstliche Statthalterschaft vollkommen davon überzeugt ist, daß alle diese Schriften nicht vermögend sind, auf das dahiesige gutdenkende und für seine eigene Ruhe rühmlich besorgte Publikum einen widrigen Eindruck zu machen, so gedenket zwar die kurfürstliche Statthalterschaft noch zur Zeit nichts zu verfügen, was die Neugierde vieler hiesiger Einwohner beschränken könnte. Sie versiehet sich jedoch zu den Gliedern der Gesellschaft, daß dieselben als patriotisch gesinnte Männer hievon keinen andern als nötigen Gebrauch machen und sich auf der Lesegesellschaft selbst bei Lesung solcher Schriften keine applaudierenden Anmerkungen und Diskurse erlauben werden; indem kurfürstliche Statthalterschaft, falls sie von dem einen oder anderen Mitgliede dergleichen erfahren würde, eine solche Verwegenheit nicht anders als Zeichen eines obgleich ohnmächtigen, doch bösen Willens ansehen und mit aller Strenge andern Übelgesinnten zum abschreckenden Beispiel bestrafen müßte. Das Direktorium der Lesegesellschaft hat demnach diese Erinnerung in mehreren Abschriften auf dem Tische der Lesegesellschaft zu hinterlegen.

[3] Mainz, den 13. Oktober 1792. 
Der Umgang der kurfürstlichen Regierung mit der Lesegesellschaft läßt sich als Paradigma fur den Grundwiderspruch des Aufgeklärten Absolutismus lesen, ein Widerspruch, der in dem Versuch bestand, den Universalismus partikularisieren zu wollen. Das Bemuhen jedoch, die Aufklärung - als Universalismus par excellence - durch Partikularisierung domestizieren und damit als Sozialtechnik instrumentalisieren zu wollen, mußte fehlschlagen, da diese sich in das absolutistische Herrschaftssystem nicht integrieren ließ, sondern dessen Legitimitätsprinzip zur Erosion brachte.

Wenn in der Existenz und Gestalt einer Gelehrten Lesegesellschaft bereits Entwicklungstendenzen hin zu einer republikanischen Gesellschaftsform vorgezeichnet sind, dann doch nur deshalb, weil der Aufgeklärte Absolutismus Gegensătze nur zeitweise vereinigen konnte, die den Keim der eigenen Überwindung bereits in sich trugen. ${ }^{236}$

In Gestalt des »Räsonnements《 in der Lesegesellschaft und mehr noch in Gestalt ihrer demokratischen inneren Strukturen stand dem Absolutismus de facto ein diametrales Legitimitătsprinzip gegenüber: Der Zusammenhang „von Leserorganisierung und bürgerlicher Emanzipation“237 liegt auf der Hand. $\mathrm{Da} \beta$ dies nicht gesehen oder aber unterschätzt wurde, ließ die Herrschenden in Mainz die Lesegesellschaft dulden. Man war bereit, sie sogar zu unterstützen, solange Gewăhr dafür zu bestehen schien, daß sie sich strikt partikular verstand. Innerhalb dieser eng gesteckten Grenzen wurden auch weder die liberale Lektüre noch die demokratische innere Verfassung der Gesellschaft als bedrohlich empfunden. Daß der geistliche und der weltliche Zensor in Kurmainz Mitglied der Lesegesellschaft sein konnten, versinnbildlicht diese Beziehung: Eine liberale, auch intern republikanische Einrichtung konnte innerhalb des absolutistischen Systems akzeptiert werden, weil und solange sie sich als Privatgesellschaft, das heißt nicht als Modell politischer Willensbildung, sondern als Organ privater Bewußtseinsbildung verstand.

Die Einschätzung der Mainzer Lesegesellschaft durch den Hof war insofern nicht falsch, als sie den Schritt aus der bürgerlichen Privatheit in eine politische Öffentlichkeit als ganze nie vollzogen hat, sondern an dem Konflikt uber eben diesen Schritt zerbrach: Die oben angefuhrte Auslage und heftige Diskussion prorevolutionärer Propagandaschriften fuhrte nicht nur zu der genannten Ermahnung durch die Regierung, sondern auch zu einer internen Zerreißprobe, zuletzt zur Spaltung: ${ }^{238}$ Zahlreiche Mitglieder traten in eine neue, unpolitische Lesegesellschaft uber. Die alte Gesellschaft bestand zwar weiter, sah sich jedoch nach der Besetzung von Mainz 1792 in gänzlich

236 Grus 1993, S. 79.

237 Dann 1981, S. 19. Vgl. Schneider 1978, S. 909.

238 Vgl. z. B. Grus 1986, S. 136-138. 
veränderter Funktion. Die partikulare, bloß räsonnierende bürgerliche Institution, die sie dargestellt hatte, war uber Nacht funktionslos geworden, indem nun eine neue Öffentlichkeit angestrebt wurde, die von Anfang an als Modell gesamtgesellschaftlicher politischer Willensbildung angelegt war.

J. Habermas ist zuzustimmen, wenn er für das 18. Jahrhundert die Tatsache der Antizipation der politischen durch die literarische Öffentlichkeit beschreibt. ${ }^{239}$ Die Verhältnisse im Mainz des Jahres 1792 stellen jedoch insofern eine Ausnahme von dem allgemeinen Verlauf in Deutschland dar, als es hier aufgrund der spezifischen militärisch-politischen Ereignisse zu einer bemerkenswerten Beschleunigung des Prozesses kam. Mit der französischen Besetzung wurde in Mainz die Kategorie der politischen Öffentlichkeit uber Nacht Realităt, ohne daß sie zuvor als Modell sozial virulent geworden wäre. In Mainz kam es 1792 demnach weniger zu einem Strukturwandel als zu einem abrupten Strukturwechsel der Öffentlichkeit.

\subsection{2 Öffentlichkeit als Modell der Mainzer Jakobiner}

Zurecht sah der Mainzer Jakobiner Georg Wedekind die "sconditio sine qua non « von politischer Freiheit in der Existenz von Öffentlichkeit. Diese ist fur ihn ein grundlegendes Unterscheidungskriterium von "Demokratie«, auch "Republik» einerseits und »Despotie«, auch »Monarchie» andererseits, wie seine Kontrastierung der kurfürstlichen mit den erstrebten demokratischen Verhältnissen zeigt:

Von heimlichen Hinrichtungen murmelte man nicht selten - denn reden durfte man nicht. - [...] Die Leute sollten nicht klug werden, weil sie sonst es überdrüssig werden würden, in dem Narrenhause, das heißt in der Monarchie, ruhig zu bleiben und nicht für sich, sondern nur für den gnädigsten Herrn zu leben. Darum befahl ja der vorige Kurfürst in einer gedruckten Verordnung, »daß niemand über Religion, über Sitten, über Staatsverfassung auch nur reden sollte« - denkt's, über diese drei so wichtigen, jedem Menschen so angelegenen Gegenstände sollte niemand reden dürfen!!! So sehr war es Eriedrich Karl Loseph dem Letzten daran gelegen, daß Ihr dumm bliebet und seine Streiche nicht einsähet! Hätte er es vermocht, er hätte Euch auch die Gedanken gestohlen. Versucht hat er es wenigstens, soweit es möglich war; denn wo die Leute nicht frei reden und schreiben können, da denken sie auch wenig; je weniger aber der Mensch denk, um so ähnlicher wird er dem Lasttiere, welches man durch Furcht und Schläge regieren kann - und dahin hätte er es gern gebracht. Wo man frei reden und frei schreiben und drucken lassen darf, da kommen alle Schlechtigkeiten an den Tag, da muk man ehrlich zu Werke gehen, wenn man in Ansehen bleiben will. [...] In guten Demokratien wird die Freiheit, zu reden und drucken zu lassen, heilig gehalten, weil sie das Mittel

239 Vgl. Habermas $1976\left[{ }^{1} 1962\right]$. 
ist, jedem schlechten Kerl die Larve abzuziehen; weil sie das Mittel ist, die Mängel der Staatsverfassung aufzudecken, bessere Einrichtungen zu treffen und - mit einem Wort - weil es das Interesse der Demokratie erfordert, jeden Menschen so klug zu machen, als es möglich ist. ${ }^{240}$

Wedekind steht mit dieser Argumentation auf dem Boden der Aufklärung, für die das Öffentlichkeitsprinzip zentrale Forderung ist. Den Hintergrund für diese Forderung stellt das Grundprinzip der Aufklărung dar, das in der Wahrnehmung des Einzelnen als Person besteht. Die staatlichen Vorgänge mußten der Allgemeinheit deshalb zugänglich gemacht werden, damit der Einzelne am Staatsleben uberhaupt teilnehmen konnte. „Daher verwundert es nicht, daß aus der Aufklărung heraus der Gedanke der Öffentlichkeit, der »Publizität«, eine wesentliche politische Grundforderung war [...]. Öffentlichkeit als politisches Schlagwort beinhaltete die Öffentlichkeit des Regierungshandelns, der administrativen Vorgänge sowie der Judikative."241 Paradigmatisch formuliert findet sich diese Position in I. Kants Schrift "Zum ewigen Frieden «: „Alle auf das Recht anderer Menschen bezogene Handlungen, deren Maxime sich nicht mit der Publicität vertrăgt, sind unrecht."242

Vor diesem argumentativen Hintergrund der europäischen Aufklärung und unmittelbar bezogen auf das franzősische Beispiel ${ }^{243}$ forderten die Mainzer Jakobiner Öffentlichkeit auf verschiedenen Ebenen des Staates ein, wobei es ihnen jeweils darum ging, Nicht-Kommunikation und kommunikative Asymmetrien zu beseitigen und durch zumindest potentiell symmetrische, potentiell jeden Staatsbürger beteiligende Kommunikationsstrukturen zu ersetzen. Das dem Absolutismus eigene, oben als Kommunikations-Macchiavellismus $^{244}$ bezeichnete Arkansystem des Hofes sollte aufgebrochen und durch ein Modell egalitärer, symmetrischer offentlicher Kommunikation ersetzt werden.

Dieser 'Öffentlichkeits'-Begriff ${ }^{245}$ wird von den Mainzer Jakobinern durchaus noch nicht mit dem Ausdruck Öffentlichkeit bezeichnet, sondern

240 MR1, S. 118-136, hier S. 131-132. Georg Wedekind hielt am 5., 11., 12. und 15. November 1792 eine Vortragsreihe im MJK. Die Folge wurde unter dem Titel Über die Regierungsverfassungen, eine Volksrede in der Gesellschaft der Freunde der Freiheit und der Gleichheit, gehalten zu Mainz am 5. November im ersten Jahre der Republik von Georg Wedekind, Mainz 1792 schon am 17.11.1792 in der Mainzer National-Zeitung zum Kauf angeboten. (Vgl. Scheel 1984, S. 118).

241 Witzler 1993, S. 27-28.

242 Kant 1912 [1795], S. 381.

243 Vgl. Witzler 1993, S. 30-31.

244 Vgl. oben, S. 53.

245 Vgl. zur Wort- und Begriffsgeschichte von Öffentlichkeit z. B. Hølscher 1978;

Schiewe 1989, S. 169-170; Witzler 1993, S. 4-38. 
eher mit Offenheit oder mit dem Integrat Publizität. ${ }^{246}$ Insgesamt jedoch dominieren adjektivische Benennungen ${ }^{247}$ wie offen oder offentlich, letztere neben der Bedeutung 'nicht geheim' auch in der Bedeutung 'staatlich' (öffentliches $A m t)$. Daneben finden sich häufig Negationen der Antonyme geheim oder verborgen. ${ }^{248}$ Die Mainzer Jakobiner setzten die Benennungen fur das eigene Anliegen der Öffentlichkeit denjenigen der behaupteten Gegenposition oft polar entgegen, ${ }^{249}$ was kontextsemantische Analysen ermöglicht. Auf diese sehr interessanten Innovationen der Signifikanten in ihrer Relation zu den Innovationen der Signifikate wird an einer späteren Stelle dieser Arbeit noch näher eingegangen werden. . $^{250}$

Die Hauptfunktionen der konzipierten politischen Öffentlichkeit waren zum einen die Kontrolle, zum anderen die Legitimation von staatlicher Macht. Formal als Recht des allgemeinen Zugangs zu zuvor geheimen Sektoren staatlichen Handelns verstanden, sollte Öffentlichkeit zunächst Machtmißbrauch verhindern. In diesem Zusammenhang war es ein erstes Ziel der Mainzer Jakobiner, Gerichtsöffentlichkeit als Kontrollinstrument der Justiz durchzusetzen. $\mathrm{Zu}$ den Arkanbereichen des Absolutismus hatte nämlich auch die Justiz gehört. ${ }^{251}$ Die im Kurfürstentum geheim tagenden Gerichte wurden folgerichtig von den Jakobinern mit sektiererischen Geheimgesellschaften gleichgesetzt, ${ }^{252}$ deren Legitimität gerade wegen der Geheimhaltung in Zwei-

246 Wedekind beispielsweise begrußt am 16. November 1792 im MJK den Eifer für vollkommene Offenheit und Publizität, den der Jakobinerklub an den Tag lege. (MR1, S. 235).

247 Vgl. zum Nominations-Konzept Kap. 5.1 dieser Arbeit.

248 Unsere Absicht war [...] nicht, ein geheimes Manöver zu machen, wir gaben öffentlich eine Maßregel an, wodurch wir unsere Gegner nötigen wollten, unserer Publizität die ihrige entgegenzusetzen. (MR1, S. 234. [Hervorhebung J.H.]).

249 Komplotte, die gegen die Absichten der Gesellschaft im stillen geschmiedet werden, sind unsren guten Absichten, die wir öffentlich vortragen und ohne Zwang auszuführen suchen, entgegen. Nicht wir, wohl aber unsere Gegner haben also das Mittel in Händen, das Publikum zu täuschen. Wir müssen darum auf ein, und zwar unserer Art nach öffentlich bekanntzumachendes Mittel denken, um die geheimen Machinationen gegen uns zu zernichten. [...] Ihre Werke der Einsternis werden aber aufhören, und sie werden sich genötigt sehen, ebenso öffentlich wie wir zu handeln [...]. (Georg Wedekind am 16. November 1792 im MJK. (MR1, S. 234)).

$250 \mathrm{Vgl}$. hierzu in dieser Arbeit Kap. 5.

251 Ältere, im deutschen Recht verwurzelte Formen der Gerichtsöffentlichkeit waren durch den Absolutismus beseitigt worden. Vgl. Witzler 1993, S. 17-26.

252 Stellt Euch einen recht geschickten Geheimenrat oder Hofrat vor, der immer auf geheime Gesellschaften und Konventikel schimpft und sagt, daß die dem Staate so nachteilig wären. Und gleichwohl besucht derselbe Mann alle Tage eine geheime Gesellschaft - die Regierung oder wie sonst die Gerichtsstuben, wohinein 
fel gezogen wurde: Darf das aber heimlich geschehen? Nein. So was heimlich zu tun, das macht den Verdacht rege, als wolle man das Volk betrügen. ${ }^{253}$ Konsequent wurde dann auch schon am 25 . Oktober 1792 im Jakobinerklub gefordert, bei Custine um Haltung der Gerichtspflege mit offenen Türen anzusuchen [...]. ${ }^{254}$ Auch mit dieser, am französischen Vorbild orientierten Forderung waren die Mainzer Jakobiner der Diskussion im übrigen Deutschland um Jahrzehnte voraus. 255

In einem zweiten, umfassenderen Sinne war Öffentlichkeit in der Mainzer Republik aber Legitimationsprinzip politischer Macht. Sie war der Raum, in dem in der Sicht der Jakobiner und der französischen Besatzer das von ihnen vertretene Prinzip der Volkssouverănităt Gestalt annehmen sollte. Obrigkeitliche Verfugungsakte waren dafür kein Ersatz.

Obrigkeiten sind unzureichend, diese Hauptstützen der Freiheit und Gleichheit, die Freimütigkeit und die Gerechtigkeit, in republikanischen Staaten aufrechtzuerhalten. Die Schritte der Obrigkeiten sind ihrer Natur nach zu ernsthaft, zu abgemessen, und der Umfang ihrer Würksamkeit ist nicht ohne Gefahr der Freiheit selbst hinreichend zu vergrößern. Es muß deshalb zwischen die eigentlichen Obrigkeiten und zwischen Familien- und Privatgesellschaften der Bürger etwas in die Mitte treten - es muß Orte geben, wo man über öffentliches Wohl, über Politik, Gesetzgebung, Sitten etc. beratschlagt; wo man ohne allen Nachteil heute eine Sache gut finden und morgen nach reiferer Prüfung verwerfen kann; Orte, wo man den Gemeingeist bildet, wo man unter sich eins wird und so dem Gesetze vorarbeitet, und diese Orte sind - die Volksgesellschaften. Verbrechen, wogegen die Gesetze schweigen, Verbrechen, welche bloß durch die öffentliche Meinung bestraft werden können, finden hier ihre Tribunäle [...]. ${ }^{256}$

In einem allgemeinen, prinzipiell sämtliche Einwohner einschließenden Kommunikationsprozeß sollte eine "sffentliche Meinung" sich herausbilden, die dann zur Legitimationsgrundlage der angestrebten Revolutionierung der Staatsverfassung werden sollte. Für Georg Forster war die offentliche Meinung das Werkzeug der Revolution, und zugleich ihre Seele. ${ }^{257}$ Als proble-

niemand kommen darf, als der einen gewissen Eid geschworen hat, heißen mögen; das sind die wahren Konventikel! Und zwar die schlimmsten. (Georg Wedekind am 28. Oktober 1792 im MJK. (MR1, S. 76)).

253 Georg Wedekind am 28. Oktober 1792 im MJK. (MR1, S. 76).

254 MR1, S. 56.

255 Vgl. Witzler 1993, S. 31-39.

256 Hermann Peter Nikolaus Theyer [im Protokoll auch: <Deyer>] in seinem Aufruf an meine Mitbürgerinnen, gesprochen in der Gesellschaft der Volksfreunde am 19. Jänner im zweiten Jahre der Frankenrepublik Adde pulchrum bono - verbinde das Schöne mit dem Nützlichen. (MR1, S. 578-588, hier S. 585-586).

257 Georg Forster 1793 als Pariser Korrespondent der Zeitschrift Friedenspräliminarien. (Forster 1990 [1793], Bd. 10,1, S. 602). 
matisch erwies sich allerdings die oben angeführte Tatsache, daß dieses Werkzeug den Demokraten zum Zeitpunkt der französischen Besetzung von Mainz nicht zur Verfilgung stand:

[...] schon haben wir siebentausend Schriftsteller, und dessen ungeachtet, wie es keinen deutschen Gemeingeist giebt, so giebt es auch keine deutsche öffentliche Meynung. Selbst diese Wörter sind uns so neu, so fremd, daß jedermann Erläuterungen und Definitionen fordert; indes kein Engländer den andern mißversteht, wenn vom public spirit kein Franzose den andern, wenn von opinion publique die Rede ist. ${ }^{258}$

Diese Situationseinschätzung bezieht Georg Forster zurecht nicht speziell auf Mainz, sondern auf ganz Deutschland. Die bekannte politische "Verspătung" der deutschen Partikularstaaten bestand eben auch darin, daß von einer politischen Öffentlichkeit zur Zeit der Jahrhundertwende insgesamt nicht gesprochen werden kann, und daß dementsprechend auch eine durchgehende Tradition politisch-øffentlicher Sprache fehlte. Diese Verhältnisse dauerten bis weit in das neunzehnte Jahrhundert an:

Über die Zwangsverhältnisse der Napoleonherrschaft hinweg ging eine kontinuierliche Entwicklung zu den Karlsbader Beschlussen von 1819, also zur perfekten Unterdruckung offentlicher Meinung durch das Metternich-System der eigentlichen Restaurationszeit. Abgesehen von einzelnen literarischbildungsbürgerlichen Belegen seit den 1790er Jahren, sind die Begriffe $O$ Offentlichkeit und offentliche Meinung im heutigen Sinne erst im Laufe der Restaurationszeit im allgemeinen Sprachgebrauch ublich geworden [...]. Dem obrigkeitlichen Zwang entsprach das fast völlige Fehlen öffentlicher Rede in Deutschland noch uber das Jahrhundert hinaus, das Karl Moor in Schillers "Die Räuber« das tintenklecksende Säkulum genannt hat. ${ }^{259}$

In Deutschland repräsentierte der Begriff der 'Öffentlichkeit' also bis weit in das neunzehnte Jahrhundert ,gerade nicht die politische Wirklichkeit, sondern ihr Gegenbild."260 Als „Schlüsselwort einer progressiven Denkungsart, die ihre Kraft aus der Opposition zu einer als repressiv empfundenen Realität bezieht [...]", 261 entfaltete der Begriff erst 1830 und 1848 soziale Dynamik.

Die Bedeutung der Mainzer Republik für die Sprachgeschichte des Deutschen besteht zumindest darin, daß sie ein Element der Diskontinuität darstellt innerhalb dieser deutschen Tradition der Verhinderung politischer Öffentlichkeit und offentlichen politischen Sprechens. Auch wenn die Mainzer Republik aufgrund ihrer militărisch bedingten kurzen Dauer uber Ansătze

258 Forster 1974 [1794], Bd. 8, S. 365.

259 von Polenz 1994, S. 41.

260 Schiewe 1989, S. 169. Vgl. Schiewe 1989, S. 163-186.

261 Schiewe 1989, S. 169-170. 
nicht hinausgelangte, ${ }^{262}$ markiert sie doch eine bedeutende Zäsur innerhalb einer pragmalinguistisch verstandenen deutschen Sprachgeschichte: Hier wurde erstmals in Deutschland versucht, eine kritische politische Öffentlichkeit zu installieren und diese, nicht zuletzt mittels persuasiver Sprachverwendung, zu demokratischem Handeln zu motivieren. Die sprachlichen Mittel, die hier Verwendung fanden, waren zwar nicht in jedem Punkte innovativ, sondern einmal durch Frankreich beeinflußt, zum anderen nahmen sie Muster auf, die in die Reformations- und Bauernkriegspublizistik zurhckweisen. Dessen ungeachtet bleibt es aber das sprachhistorische Verdienst der Mainzer Republik, dem im 18. Jahrhundert ubiquităren Kommunikations-Macchiavellismus nicht nur das Konzept einer demokratisch intendierten, kritischen Öffentlichkeit entgegengesetzt, sondern diese auch kurzfristig realisiert zu haben.

Dies gilt auch dann, wenn man die aufklärerischen Institutionen des 18. Jahrhunderts in Rechnung stellt: Auch wenn die Lesegesellschaften, speziell die Mainzer Lesegesellschaft, in den Blick genommen werden, dominiert das Moment der Diskontinuität. War das Ziel der Lesegesellschaften - so spannungsreich sich das im einzelnen gestalten mußte - ein partikulares, nämlich die gegenseitige Aufklärung einer privilegierten Minderheit, die sich im Rahmen der politischen Verhältnisse des aufgeklärten Absolutismus bewegte, so stellt die Mainzer Republik in mehrerer Hinsicht einen Gegenpol dar: Es ging in ihr erstens nicht um Aufklärung innerhalb der bestehenden politischen Verhăltnisse, sondern um deren Ablösung durch ein ihnen polar entgegengesetztes politisches System. Zweitens war nicht eine soziale Minderheit angesprochen, sondern die Gesamtheit der Staatsbürger. Und drittens ging es nicht um einen Wissenszuwachs, sondern um einen Machtzuwachs für die angesprochenen Bürger. Tendierten die Lesegesellschaften also zu „Diskussion als Politikersatz" in "quietistischer Illusion der verstaatlichten Intelligenz" ${ }^{263}$ so war es das Ziel der Mainzer Republik, Staat und Politik durch offentliches Sprachhandeln zu revolutionieren.

Diese scharfe Diskontinuität verweist auf einen markanten Unterschied zu den Verhältnissen in Frankreich. Oben ${ }^{264}$ wurde ausgefuhrt, daß es in Frankreich zunächst kommunikative Handlungen waren, die im vorrevolutionären Zeitraum eine neue Realitătssicht vermittelten, die dann politisches Handeln auslöste. Vor diesem Hintergrund konnte J. Guilhaumou formulieren: „[D]ie Öffentlichkeit eroberte die Politik."265 Konfrontiert man dieses Verhältnis von Sprache und Politik in der Franzosischen Revolution mit dem in der

Vgl. unten, Kap. 4.1.4.

Wehler 1987, Bd. 1, S. 331. Vgl. von Polenz 1994, S. 36.

Vgl. oben, S. 32.

Guilhaumou 1989, S. 49. 
Mainzer Republik, so erscheint es zu letzterem - vergröbernd gesprochen geradezu spiegelbildlich vertauscht: In der Franzősischen Revolution waren sprachliche Äußerungen das entscheidende Movens der gesellschaftlich-politischen Entwicklung. In Mainz hingegen war bei aller Markanz der historisch-sprachpragmatischen Zäsur diese das Ergebnis der politisch-militärischen Ereignisse: Erst nach stattgehabter militärischer Aktion konnten die Jakobiner in einer Persuasionsoffensive die Bevőlkerung ansprechen. Die Konstellationen in der Französischen Revolution und in der Mainzer Republik sind beide Ausdruck der grundlegenden Analogie von Sprache und Politik, jedoch mit umgekehrter Priorităt von »Basis« und »Überbau«: In Mainz, so läßt sich Guilhaumous Diktum den Verhältnissen entsprechend abändern, eroberte nicht die Öffentlichkeit die Politik, sondern die Politik die Öffentlichkeit. ${ }^{266}$

\subsubsection{Emittenten und Adressaten politischer Texte}

Die politische Öffentlichkeit, die sich - wenn auch nur zeitweise und mit gewissen Einschränkungen ${ }^{267}$ mit dem Beginn der Mainzer Republik rasch herausbildete, war als allgemeine intendiert, das heißt, sie war im Unterschied zum vorher herrschenden Kurmainzer Arkansystem dadurch charakterisiert, daß zumindest zu Anfang weder bestimmte Kategorien von Personen noch von Situationen prinzipiell von der politischen Kommunikation ausgeschlossen waren.

Eine erste, einschneidende Veränderung der kommunikativen Bedingungen betraf die starke Ausweitung der Adressatenschaft politischer Texte. Während solche Texte zuvor nur eine schmale, innerhöfische Personenkategorie adressiert hatten und die Gesamtbevölkerung nur mit den normativ formulierten Ergebnissen politischer Entscheidungen konfrontiert worden war, adressierten politische Texte unterschiedlichster Funktion nun ohne Ausnahme sämtliche Bevölkerungsgruppen, auch die Landbewohner, auch Analphabeten und sogar die sonst vom politischen Kommunikationsprozeß ausgeschlossenen Frauen. ${ }^{268}$ Diese Tatsache der Ausweitung der intendierten Adressatenschaft politischer Texte sollte insbesondere fur das zu entwickelnde Textsortenspektrum beachtliche Konsequenzen haben. ${ }^{269}$

266 Diese Tatsache hat für die Kommunikationsstruktur innerhalb der Mainzer Republik tiefgreifende, im folgenden zu diskutierende Konsequenzen. Vgl. Kap. 4.2 dieser Arbeit.

Vgl. Kap. 4.1.4 dieser Arbeit.

268 Vgl. Fn. 256.

269 Vgl. Kap. 4.3 dieser Arbeit. 
Die zweite, zunächst noch stärker ins Auge fallende Veränderung gegenuber Kurmainz betraf die Zahl und Art der Emittenten politischer Texte in der Mainzer Republik. Waren diese in Kurmainz auf Hof und Verwaltung beschränkt geblieben, so trat in der Mainzer Republik eine Vielzahl neuer Textemittenten hervor, die die politische Öffentlichkeit durch ihr persuasiv gerichtetes Sprachhandeln prägten.

$\mathrm{Zu}$ diesen neu an die Öffentlichkeit tretenden Textemittenten gehörten als erste Gruppe diejenigen Mainzer Bürger, die mit der französischen Besetzung die Chance gekommen sahen, ihre demokratische, antifeudale Einstellung in politisches Handeln umzusetzen: Die Mainzer Jakobiner. Diese bestimmten in der ersten Phase der Mainzer Republik das sprachpolitische Geschehen, indem sie die durch die französische Besetzung ermöglichte politische Öffentlichkeit sprachlich dominierten.

$\mathrm{Zu}$ ihnen stieß als zweite Gruppe ein eigens zum Zweck der politischen Persuasion angeworbener Personenkreis: ${ }^{270}$ Schon am 26. Oktober 1792 hatte Custine dem Pariser Konvent seine Absicht der Anwerbung von Propagandaspezialisten angekündigt (Je vais chercher à engager quelques citoyens de Strasbourg, recommendable par leur vertus, leurs principes et leurs talents oratoires et leurs écrits [...].271), um dann am 31 . Oktober einen öffentlichen Aufruf an den Straßburger Jakobinerklub ergehen zu lassen:

Il me faut des orateurs ici et des orateurs allemands. Je veux faire prêcher la révolution française à Spire, à Worms, à Mayence, à Francfort. C'est une mission que je veux établir et non une croisade que je veux faire. Envoyez-moi quelques bons républicains, gens sages, nerveux, écrivant et parlant avec énergie et surtout point ambitieux, car ils perdent tout et brouillent tout, [...] il me faut des hommes pour Francfort, Worms et Spire et pour électriser les Mayençais. ${ }^{272}$

Diesem Aufruf folgten rasch mehrere Personen, unter ihnen Friedrich Christoph Cotta, Friedrich Georg Pape und Anton Joseph Dorsch, die im folgenden stärksten Einfluß auf das politische Kommunikationsgeschehen in Mainz nehmen sollten.

Die französische Besatzungsmacht unter General de Custine, die mit diesem Aufruf - als veranlassende Kraft - eher im Hintergrund wirkte, trat aber auch, als dritte Kategorie neuer Textemittenten, selbst aktiv in Erscheinung. Im Rahmen ihrer Strategie einer »expansion révolutionnaire« sahen und verhielten die Franzosen sich in Mainz als apôtres de la Liberte ${ }^{273}$ und expo-

\footnotetext{
270 Vgl. Dumont 1993a, S. 100-102.

271 MR1, S. 58.

272 UQM, S. 215, Fn. 80.

273 Vgl. oben, S. 20.
} 
nierten sich - vor dem Hintergrund mehrjahriger revolutionärer Erfahrung in Frankreich - mit einer Fulle politischer Texte.274

Besonders wichtig für die Textproduktion der Mainzer Republik wurde dann noch eine vierte Kategorie von Textproduzenten, nămlich die ab November 1792 von Custine neu errichteten und mit prorevolutionår ausgerichteten Männern besetzten Zivilverwaltungen (Allgemeine Administration und Munizipalitäten), ${ }^{275}$ deren Verlautbarungen schon aufgrund ihrer juristischen Verbindlichkeit rezipiert werden mußten und mit Autorităt versehen waren. Mit den Texten dieser neuen, revolutionär orientierten Verwaltungen erhielten die „demokratischen Ideen gewissermaßen obrigkeitliche Sanktion, was bei dem vorherrschenden politischen Bewußtsein zur Folge hatte, daß sie viel eher akzeptiert wurden, als wenn sie nur von den Jakobinern allein propagiert worden wären."'276

Diese Funktionalisierung der Verwaltungen für die revolutionäre Persuasion hatte allerdings gegen den hinhaltenden Widerstand der kurfürstlichen Landesregierung durchgesetzt werden müssen. Diese war auch während der Mainzer Republik, auf unterschiedlichen Wegen, noch immer aktiv und muß insofern zu den genannten, während der Mainzer Republik erstmals auf den Plan getretenen politischen Textemittenten als weitere Kategorie hinzugezählt werden:

Ein erster Ansatzpunkt fir die kurfürstliche Landesregierung, auch unter der französischen Besatzungsmacht noch Einfluß zu behalten, ${ }^{277}$ war Custines Aufruf an die gedrückte Menschheit in Deutschland [...], ${ }^{278}$ der offentlich ankündigte, die überkommenen politischen Institutionen vorerst respektieren zu wollen. ${ }^{279}$ Die kurfürstiche Rumpf-Landesregierung ${ }^{280}$ legte Custines

274 Da diese Texte gemäß der zu dieser Zeit geltenden franzősischen Sprachenpolitik zusammen mit einer Übersetzung oder auch ausschließlich in Übersetzung distribuiert wurden, traten zur Besatzungsmacht noch in französischen Diensten stehende deutsche Übersetzer. Diese sind gewissermaßen als sekundäre Textemittenten zu betrachten, die auf die Textsemantik und damit auf die politische Wirkung der französischen Verlautbarungen mitunter bedeutenden Einfluß nahmen. Vgl. beispielsweise die wichtige Rolle von Custines Sekretär und Übersetzer, dem ehemaligen Wormser Konrektor G. W. Bohmer. Seine freie Übertragung von Custines »Aufruf an die gedrückte Menschheit in Deutschland [...]« veränderte die Textsemantik in erheblicher, für das weitere Geschehen bedeutender Weise. (Vgl. oben, Fn. 184).

Vgl. oben, S. 18.

277 Zur staatsrechtlichen Interpretation dieses Konfliktes vgl. Schneider 1990, S. 16 18.

278 Vgl, oben, S. 50f., Text 1.

279 Vgl. oben, S. 50f., Text 1, Zeilen [6,1] und [6,3-6,4].

280 Vgl. Fn. 181. 
Aufruf nun gezielt einseitig aus, indem sie ihn strategisch auf die Erklärung einer nichtinterventionistischen Besatzungspolitik reduzierte. Schon am 24. Oktober 1792 gab sie den untergeordneten Behörden die Weisung, daß sie in ihren Geschäften, sie betreffen die Justiz, Polizei, oder Finanzen, wieder ungehindert, nach wie vor, fortzufahren, und in vorkommenden Fällen unter der gewöhnlichen Courtoisie an die einschlagenden Stellen zu berichten hätten. ${ }^{281}$ Am 27. Oktober ließ sie dann dieses und ein weiteres Reskript, das die traditionelle Machtposition der kurfurstlichen Verwaltung auch unter den Bedingungen der französischen Besatzung festschreiben sollte, im Mainzer Intelligenzblatt veröffentlichen:

Nachdem die Anzeige geschehen, daß verschiedene kurfürstl. Unterthanen verweigert, die schuldigen Zehenten, Gefälle, Zinse etc. dermalen nicht [!] weiter zu entrichten, auf die dieserwegen von den Berechtigten bei dem dahier kommandirenden französischen Herrn General Custine angebrachte Beschwerden aber die Erklärung dahin erfolgt, wie es [!] die Absicht nicht habe, an den Landes-Statuten, Rechten und Verordnungen, welche bisher bestanden, etwas abzuändern, im Gegentheil die Meinung sei, daß die Gerechtigkeit ihren stracken Lauf wieder nehme und nach wie vor, verwaltet werde, fort alle jene herkömmliche und bisher mit Recht bezogene Schuldigkeiten ihren ununterbrochenen Fortgang haben sollen; als haben sämtliche kurf. Vizedom-, Ober- und Ämter die kurf. Unterthanen hiernach anzuweisen, und denselben zu bedeuten, daß bei unverhoffendem Widersetzungsfalle, dieselben mit den zugesicherten Zwangsmitteln zu forthiniger Entrichtung dieser ihrer Schuldigkeit werden angehalten werden. ${ }^{282}$

Es lag auf dieser Linie, daß die Behörden ihre Verlautbarungen nach wie vor im Namen des Kurfürsten ausfertigten und beispielsweise das Amts- und Anzeigenblatt weiterhin unter dem Titel Mainzisches Intelligenzblatt mit kurfürstlichem gnädigsten Privilegium erschien. Diese Versuche der kurfürstlichen Regierung, dominanten Einfluß auf die politische Öffentlichkeit der Mainzer Republik zu nehmen bzw. zu behalten, mußten den Widerspruch sowohl der Mainzer Jakobiner als auch der franzősischen Machthaber erregen. Der Mainzer Mathematikprofessor und Jakobiner Matthias Metternich polemisierte in seiner Zeitung Der Bürgerfreund gegen die oben genannte Ausgabe des Mainzer Intelligenzblatts: Wir sagen zuerst das "gnädigst privilegirte $\mathrm{mu} \beta$ wegbleiben; denn alles Gnädigstprivilegirte war immerhin Eingriff in die Menschenrechte. ${ }^{283}$ Besonders kritisiert er den Versuch der kurfürstlichen Regierung, den stattgehabten Machtwechsel zu verschleiern:

281 Vgl. MR2, S. 85.

282 Abschrift kurf. Regierungs-Reskripts an sämtliche kurfürstl. Vizedom-Ober- und Ämter dd. Mainz den 24ten Oktob. 1792. Abdruck im Mainzer Intelligenzblatt vom 27. Oktober 1792, S. 681. (MR2, S. 85). 
Nun folgen zwei Regierungs- und ein Stadtgerichts-Reskript. In allen dreyen leuchtet eine Anmaßung von Herschersucht, oder eine sogenannte politische Wendung hervor, die der Burgerfreund nicht erklären mag; obschon er könnte. In allen dreyen steht: das der Geschäfsgang des Beamtenwesens vor wie nach betrieben werden solle. Wissen den die Herrn nicht was Bürger General Cüstine [...] ihnen per Reskriptum zukommen ließ?284

Custine reagierte auf diese Strategie der kurfürstlichen Landesregierung, indem er negative Sanktionen androhte ${ }^{285}$ und verordnete, alle Verwaltungsakte seien nun den neuen Machtverhăltnissen entsprechend zu zeichnen mit $A \boldsymbol{u}$ nom de la nation française, nous les municipaux provisoirement conservés etc. ${ }^{286}$ Eine wirkliche Dominanz erreichte die französische Besatzungsmacht dann aber erst, als man, wie oben erwähnt, neue, systemkonforme Verwaltungen einsetzte. ${ }^{287}$

Damit waren die Krăfte des 》Ancien Régime« jedoch als Emittenten oppositioneller Texte in der Mainzer Republik durchaus noch nicht ausgeschaltet. Im Gegenteil, die gegenrevolutionären Kräfte verstärkten ihre Textproduktion sogar, je länger die Mainzer Republik andauerte. Allerdings mußte man, nachdem der eher legalistisch angelegte Versuch gescheitert war, die Verwaltungshierarchie in der Hand zu behalten, andere, indirekte Methoden der Einflußnahme entwickeln, zum Beispiel die persuasive Einwirkung auf die öffentliche Meinung. Insofern waren es nicht nur die Demokraten, die mit der Etablierung einer politischen Öffentlichkeit ein sprachliches Repertoire zu deren Beeinflussung entwickeln mußten und konnten, sondern in gleicher Weise ihre konservativen Gegner. Diese profitierten in beträchtlichem Maße von dem hohen Stellenwert, den die Institution einer kritischen Öffentlichkeit für die demokratisch-revolutionäre Seite besaß: Die neue Qualităt der politischen Öffentlichkeit, die in der Mainzer Republik entstand, resultierte ja nicht allein aus der auffälligen Tatsache, daß neue Textemittenten dominant

284 In: Der Bürgerfreund, H. 3 vom 2. November 1792, S. 14. (MR2, S. 86).

285 J'apprends avec étonnement, Messieurs, qu'après avoir reçu de moi la permission de continuer provisoirement l'administration de la police du pays pour la nation française, vous vous permettez d'en intituler les actes au nom de l'Électeur. Je vous préviens, que si vous continuez à donner une telle preuve d'éloignement à la nation, je ne tarderai pas à vous faire éprouver le poids de son ressentiment. Tous vos actes seront intitulés désormais: Au nom de la nation française, nous les municipaux provisoirement conservés etc. Schreiben Custines an den Mainzer Stadtrat vom 30. Oktober 1792. (MR2, S. 86).

286 Schreiben Custines an den Mainzer Stadtrat vom 30. Oktober 1792. (MR2, S. 86).

287 Damit hatte man allerdings den in Text 1 (Vgl. oben, S. 50f.) formulierten Kurs verlassen und war zur Praxis einer interventionistischen Besatzung abergegangen. 
wurden, sondern besonders auch daraus, daß - hauptsächlich zu Beginn kommunikative Symmetrie intendiert wurde. Das Volk als Adressat der revolutionären Texte sollte nicht passiv bleiben, sondern seinerseits zu Äußerungen angeregt werden. Diesem Ziel dienten beispielsweise auf Dialog hin ausgerichtete Persuasivtexte, auch revolutionäre Feiern und Feste, nicht zuletzt aber auch die systematisch angelegten Volksbefragungen wie die Auslage eines "Roten Buches« oder die Verfassungsbefragung der Mainzer Zünfte. Bei diesen Aktionen hoffte man zwar darauf, revolutionsfreundliche Reaktionen zu erlangen und so zu dem gewünschten "voeu librement émis" der Bevölkerung zu gelangen, jedoch wurde nicht etwa nur prorevolutionären, sondern auch kritischen Stimmen Rederecht eingeräumt. In diesem Recht auf freie, auch kritische Meinungsăußerung sahen sowohl Franzosen als auch Mainzer Jakobiner ein zentrales Kennzeichen einer demokratischen Verfassung:

Wir können den Gedanken so wenig wehren wie den Bewegungen unsers Herzens und unserer Schlagadern. Ist aber freies Denken natürlich, so ist es auch die Mitteilung der Gedanken, wozu wir alle angeborne Neigung haben, ohne welche wir alle unglücklich sein würden. So müssen wir uns mithin wechselseitig in der menschlichen Gesellschaft diese Freiheit verbürgen. ${ }^{288}$

Mag nun die Einrichtung des Staates beschaffen sein, wie sie immer wolle, so kann keinem Bürger verboten werden, seine Meinung über dieselbe zu äußern. Im Gegenteile ist es Pflicht für jeden Bürger, daß er die Fehler, die er an den Gesetzen $z u$ bemerken glaubt, bekanntmache, weil es Pflicht jedes Bürgers ist, für das Beste des Staats aus allen seinen Kräften zu sorgen. [...] In Republiken, die eine demokratische Verfassung haben, muß jeder über die Gesetzgebung frei urteilen dürfen. Allen ist hier daran gelegen, daß die Gesetze die gemeinschaftliche Glückseligkeit der Bürger möglichst befördern. Wie können aber die Gesetze vollkommen werden, wenn sie nicht frei von jedem untersucht werden dürfen?289

Diese liberale Theorie, der in der ersten Zeit der Mainzer Republik auch die Praxis folgte, stellte für die revolutionskritischen oder -feindlichen Kräfte, die dabei waren, eine Gegenstrategie zu entwickeln, geradezu eine Aufforderung dar, als Textemittenten in Erscheinung zu treten. Diese Kraffte nahmen denn auch das demokratische Prinzip der Meinungsfreiheit beim Wort, um ihre

288 MR1, S. 762. Die Textstelle ist Georg Wedekinds Erklärung der Rechte des Menschen und der Natur entnommen, die ab dem 26. Februar 1793 im MJK vorgetragen wurde. Der Text erschien im März 1793 als selbstăndige Flugschrift unter dem Titel Die Rechte des Menschen und Bürgers, wie sie die französische konstituierende Nationalversammlung 1791 proklamierte, mit Erläuterungen von Georg Wedekind, Mitgliede des Nationalkonvents der freien Deutschen zu Mainz. Mainz im zweiten Jahr der Freiheit und der Gleichheit 1793. Vgl. MR1, S. 738767.

MR1, S. 761. Vgl. auch Fn. 288. 
demokratiefeindliche politische Haltung offentlich zu propagieren. Sie nutzten damit also die eben im Entstehen begriffene demokratische Institution einer politischen Öffentlichkeit dazu, gegen dieselbe zu polemisieren. Mit dem erklärten Ziel, das Publikum auch in den Gegengründen zu belehren, ${ }^{290}$ ließ sich beispielsweise schon am 27. Oktober 1792 der kurfurstliche Gefallverweser Erasmus Lennig in den Jakobinerklub aufnehmen. ${ }^{291}$ Am 31. Oktober hielt er dort eine revolutionskritische Rede, wobei er sich dem versuchten Wortentzug erfolgreich mit dem Hinweis widersetzte, "daß er nach den(en) von der Gesellschaft selbst(en) aufgestellten Grundsätzen der Freiheit und Gleichheit alles sprechen könne, was er nur immer wolle«. ${ }^{292}$ Tatsächlich argumentierte er in seiner Rede dann vehement gegen die Position der Mainzer Jakobiner ${ }^{293}$ Lennigs Rede war kein Einzelfall, sondern fand Nachfolge beispielsweise in den von Daniel Dumont, Sprecher des Mainzer Handelsstandes, verfaßten moderantistischen ${ }^{294}$ Reformvorschlägen ${ }^{295}$ oder dem gleich-

290 Hoffmann 1793/94, S. 141-142. Vgl. MR1, S. 61-62.

291 Dies war keine isolierte Vorgehensweise, sondern wurde bei Hofe zeitweise als Strategie diskutiert. Am 3. November 1792 fragte beispielsweise der Hof- und Regierungsrat Anton Moritz von Kalckhoff, ob man den MJK ohne Widerstand soll fortarbeiten lassen oder ob gutgesinnte Bürger eintreten und ihre Grundsätze bestreiten [...] sollten. (MR1, S. 67) Lennig selbst gab später an, durch den geistlichen Rat Johann Valentin Schumann zum Klubeintritt bewogen worden zu sein. Vgl. MR1, S. 88.

292 MR1, S. 87.

293 Das Manuskript der Rede ist verschollen, jedoch ist durch den revolutionsfeindlich eingestellten Autor Anton J. Hoffmann der Inhalt überliefert (Vgl. Hoffmann 1793/94, S. 177-178): Mainz könne sich bei einer reichswidrigen Konstitution nicht halten; Mainz, im Stande der Freiheit, müßte mit dem wärmsten Patriotismus schon im ersten Winter erfrieren; Mainz würde, im Fall es sich von dem teutschen Reiche losriß, ohne die Pfalz, die darmstädtischen und andere umliegende teutsche Länder verhungern müssen; Mainz würde auch bei einer vorzunehmenden Revolution das für Teutschland werden, was Paris für Frankreich ist, und also auch der Schauplatz jener Schreckenszenen für Teutschland sein, so man in Paris so vielfältig gesehen, und die freien Mainzer Bürger würden gar zu viel an ihrer Nahrung leiden, wenn der Adel und die Geistlichkeit, die den größten Teil ihres Vermögens im Ausland hätten, aus ihrer Existenz kämen. (MR1, S. 86-87).

294 Vgl. Fn. 300.

295 Vgl. MR1, S. 153-158. Metternich las einen hier herumgehenden Aufsatz vor voll aufrührerischer Gedanken, worin der hiesige Handelsstand dem General Custine vorstellen will, daß die fränkische Konstitution auf das teutsche Phlegma und geringe Kräfte(n) des mainzischen Staates nicht passe. (MR1, S. 153) Vgl. hierzu auch Buddrus 1984/85. 
falls gegenrevolutionär ausgerichteten Promemoria der Niederen Geistlichkeit vom November 1792.296

Beriefen sich solche Autoren, die in ihren Texten eine gemäßigt-revolutionskritische Position vertraten, noch auf das Recht der Meinungsfreiheit, so versuchte das eine letzte Gruppe von Textemittenten gar nicht erst: Die kurfurstliche Exilregierung. Nachdem deren legalistisch orientierter Versuch, die Zivilverwaltungen in den Händen zu behalten, gescheitert war, verlagerte sie im Verlauf der Jahre 1792/93 ihre Aktivitäten immer mehr auf anonyme gegenrevolutionäre Agitation, die ihre Wirkung auf die Mainzer Bevölkerung nicht verfehlte.

Dabei fiel es „den alten Souverannen schwer, sich appellierend ans Volk zu wenden, das sich in Frankreich schon zum neuen Souverăn gemacht hatte." 297 Indem man nämlich mit Druckschriften an das Volk appellierte und bemüt war, die Öffentlichkeit zu beeinflussen, akzeptierte man faktisch, was man zugleich bekämpfte: Den Volkswillen als politische Instanz. Gerade indem anonyme, antirevolutionäre Autoren sich mit Veröffentlichungen wie Schöne Raritäten zum Zeitvertreib des Mainzer Bürgers beim troknen Brod und am leeren Kruge [...]. oder Etwas über die mainzische Konstitution in einem Sendschreiben des Doktor Gottlob Teutsch an den Verfasser des mainzischen Bürgerfreundes, Frankfurt und Leipzig 1792.298 an die Gesamtbevölkerung wandten, bestätigten sie - unabhängig von ihrer gegenrevolutionären

296 Vgl. MR1, S. 359-361. Auch in diesem Text beriefen sich die Verfasser geschickt auf die von den Mainzer Demokraten selbst vertretenen Prinzipien: Die Mainzer niedere Geistlichkeit [...] weiß, daß ihr großmütiger Überwinder und Beschützer in einem gedruckten Blatte, betitelt: Aufruf an die gedruckte Menschheit etc. dem Mainzer Volke freigelassen hat, sich nach seinem ungezwungenen Willen sogar einen Despoten und also vielmehr eine andere als französische Konstitution zu wählen, und daß also die Äußerungen der Gesellschaft der Freunde der Freiheit und Gleichheit mit den Gesinnungen ihres Überwinders und Beschützers nicht in der vollkommensten Übereinstimmung stehen [...]. [D]ie niedere Mainzer Geistlichkeit [muß] ihren großmütigen, nur Wahrheit und Freiheit auf alle[n] Wege[n] begünstigenden Überwinder und Beschützer bitten, eine vollkommene Prekfreiheit, als welcher die beiden edelsten Töchter der Gottheit, Wahrheit und Ereiheit, ihr Dasein zu verdanken haben, durch eine zu erlassende Proklamation zu gestatten und gegen jeden direkten oder indirekten Eingriff nachdrucksamst zu schützen, indem Freiheit ohne Wahrheit nicht bestehen und Wahrheit nicht statthaben könne, solange es nur den geringsten Anschein hat, als wollte man mur einer Partei alles frei zu reden und zu drucken verstatten und jedem andern mündliches und schrifliches Stillschweigen auferlegen. (MR1, S. 360).

298 Schon der Name war Programm. Verfasser war der geflohene kurmainzische Hofkanzler Franz Joseph Freiherr von Albini. 
Intention - das Ziel der Revolutionăre indirekt: Indem man nun versuchte, die öffentliche Meinung im eigenen Sinne zu beeinflussen, hatte man die aus dem Prinzip der Volkssouverănităt resultierende Bedeutung der politischen Öffentlichkeit de facto akzeptiert.

Das Neue, die Zeitenwende Markierende, ist aber gewesen, daß die alten Gewalten im Rheinland, die die Einwohner ihrer Lande immer als Objekte, nie als Subjekte, geschweige denn als souverăn handelnde Subjekte, angesehen hatten, nun ihrerseits Propaganda inszenierten, um ihre alten Untertanen zu Aktionen gegen die neuen Herren aus Frankreich zu veranlassen. 299

Es würde also insgesamt zu kurz greifen, die Textproduktion der Mainzer Republik auf die - freilich zuerst ins Auge springenden - Äußerungen der prorevolutionären Textemittenten reduzieren $\mathrm{zu}$ wollen. Die politische Öffentlichkeit, die sich entwickelte, war hingegen von oft kontroversen Beiträgen unterschiedlichster Textemittenten teils revolutionärer, teils "moderantistischer" ${ }^{300}$ teils entschieden antirevolutionärer Orientierung geprägt.

So aßen die Bürger und Bauern nicht nur bei den Jakobinern vom »Baum demokratischer Erkenntnis«, sondern in gewisser Weise auch bei deren Gegnern; denn sie wurden nun publizistisch mit Fragen befaßt, die bisher nur den »Geschäftsmännern «, den Politikern also, vorbehalten waren. Insofern war selbst die Abwehr der Mainzer Republik ein Schritt in Richtung auf eine »Demokratisierung der politischen Kultur« [...]. ${ }^{301}$

Die Tatsache freilich, daß auch die Gegenrevolution - allein durch das Faktum des Appells an das Volk - die demokratischen Prinzipien unterschwellig beförderte, konnte den Zeitgenossen schwerlich bewußt werden: Sowohl für die gegenrevolutionären Kräfte selbst als auch für die Mainzer Jakobiner, die durch die feindliche persuasive Aktivität alarmiert waren, standen weniger die genannten hintergründigen Sekundäreffekte im Blickpunkt, sondern die unmittelbare antidemokratische und antirepublikanische inhaltliche Ausrichtung der gegenrevolutionären Aktivităt. Letztere bestimmte die Qualităt der öffentlichen politischen Auseinandersetzung in der Mainzer Republik.

299 Molitor 1982, S. 35.

300 "Gemeint sind die Anschauungen und Bestrebungen, die auf eine konstitutionelle Monarchie hinausliefen [...].“ (Träger 1963a, S. 602. Vgl. von Polenz 1988, S. 184.) G. Forster wandte sich am 15. November 1792 in seiner Rede Über das Verhältnis der Mainzer gegen die Franken [...] (MR1, S. 219-232) entschieden gegen moderantistische Reformvorschläge: Das ist das Ziel und Ende des Moderantismus, der immer nur mit einschläfernden Worten, mit sanfter Stimme, mit Engelsblicken Euch einzuwiegen sucht, um Euch hernach desto bequemer mit Haut und Haar zu verschlingen. (MR1, S. 228). 


\subsubsection{Die Realität politischer Öffentlichkeit}

Nicht nur zur Zeit der Französischen Revolution, sondern bis weit ins neunzehnte Jahrhundert hinein nimmt die Mainzer Republik fur den deutschen Sprachraum insofern eine Sonderstellung ein, als praktisch nur hier furr einige Zeit eine wirkliche kritische politische Öffentlichkeit mit demokratischen Zügen existierte. ${ }^{302}$ Die Bevolkerung war in kurzester Zeit durchgängig politisiert worden und nahm in unterschiedlicher Weise und mit unterschiedlicher Motivation am offentlichen Diskurs teil. Diese Außenperspektive, die die Mainzer Republik den Verhăltnissen in den übrigen, vergleichsweise rückständigen deutschen Staaten als Avantgarde voranstellt, darf aber nicht vergessen machen, daß es sich in Mainz zu keinem Zeitpunkt um eine demokratisch-pluralistische Öffentlichkeit moderner westlicher Prägung handelte, wo politische Meinungsunterschiede vor dem Hintergrund eines verfassungsmäBigen Basiskonsenses ausgetragen werden. Im Gegenteil, im Mainz des Jahres 1792 war eben dieser Basiskonsens strittig.

Aus der Innenperspektive der Mainzer Republik sahen sich die an der politischen Öffentlichkeit Partizipierenden viel eher in einer Situation des Kampfes: Zunächst um diesen Basiskonsens, dann um die Macht, zuletzt um's Überleben. Dieser Kampf wurde zwar auch mit sprachlichen Mitteln ausgetragen, gleichzeitig aber mit außersprachlichen, nicht zuletzt mit Mitteln militärischer Gewalt. Die politische Öffentlichkeit, die auf diesem Hintergrund entstand, war eine instabile, dynamisch sich verändernde, die von mehreren Machtzentren mit wechselnder Dominanz geprägt wurde. $\mathrm{Zu}$ dieser Dynamik trug nicht wenig bei, daß, wie oben herausgestellt wurde, ${ }^{303}$ mehrere der beteiligten Machtzentren vor dem Hintergrund in sich widersprüchlicher Motive agieren mußten.

Insbesondere fur die Motive der Mainzer Jakobiner ergab sich das Problem einer Polarität zwischen ihrem aufklärerisch motivierten Konzept einer demokratischen Öffentlichkeit und den Erfordernissen des Machterhalts in auch militärisch - massiv bedrohter Lage. Wie nicht anders zu erwarten, verschoben die Gewichte sich besonders in der autoritären und schließlich in der Kriegsphase ${ }^{304}$ zunehmend in Richtung auf zunächst restriktive, dann repressive Machterhaltstechniken. Zu Beginn jedoch, in der liberalen Phase bis zum Jahresende 1792, setzte der Jakobinerklub noch ganz und gar auf „die Macht der Vernunft, auf d[ie] Wirkung der Aufklärung allein “, ${ }^{305}$ so daß in der po-

\footnotetext{
302 Vgl. von Polenz 1994, S. 40.

303 Vgl. oben, S. 28f.

304 Vgl. oben, S. 28.

305 Scheel 1989, S. 96.
} 
litischen Öffentlichkeit durchaus „eine relativ freie und politische Diskussion" ${ }^{\text {306 }}$ konstatiert werden kann.

Was die mundliche politische Auseinandersetzung anging, deren zentraler Ort der Jakobinerklub war, so läßt sich für die Anfangszeit feststellen, daß hier ein allgemein zugängliches Forum politisch-kritischer Öffentlichkeit geschaffen worden war, in dem auch kontrovers argumentiert werden konnte. Neben Auseinandersetzungen innerhalb der Jakobinerschaft ist ein Beleg hierfür die Tatsache, daß man beispielsweise gegenrevolutionäre Äußerungen wie die oben genannte des Erasmus Lennig ${ }^{307}$ durchaus zuließ. Auch daß gegenrevolutionäre Redner in der Anfangszeit der Mainzer Republik offen das Wort nahmen, ist ein Beleg dafür, daß sie auf sprachlich, nicht gewaltsam reagierende Gegner setzten.

In der Tat reagierten die Mainzer Jakobiner auf gegenrevolutionäre Äußerungen zunăchst mit dem aufklärerisch-diskursiven Verfahren der verbalen Entgegnung, meist als Widerlegung bezeichnet, das - in Abhebung von der zurückliegenden Kommunikationskontrolle - als Errungenschaft der eben erreichten demokratischen Öffentlichkeit angesehen und verteidigt wurde:

allein laßt sie kommen, die frechen Wahrheitsschander, sie sollen itzt besser als damals, wo man nicht widerlegen durfte und Wahrheit Verbrechen war, überführt werden $[. . .]^{308}$

Gegen Versuche, unliebsame Meinungsäußerungen im Jakobinerklub mit administrativen Mitteln zu unterbinden, ${ }^{309}$ wurde der Eigenwert einer offenen politischen Auseinandersetzung betont:

[...] nachher wurd beschlossen, daß alle Schriften ohne Unterschied sollen abgelesen werden, weil man jede Sache auch von ihrer schlechten Seite müsse kennenlernen. 310

Ein zweiter Bruder erinnerte da[r]gegen, daß man die Freiheit, zu reden, nicht wohl einschränken könne, auch wären solche Reden da[r]zu gut, um daraus die Meinungen der Widersacher zu kennen, um sie desto sicherer zu widerlegen. ${ }^{311}$

306 Dumont 1993a, S. 288.

307 Vgl. oben, S. 74.

308 Andreas Joseph Hofmann am 12. November 1792 im MJK. (MR1, S. 213).

309 Der erste Bruder sagte, daß eine solche Sprache, wo nichts als Gemeinsprüche, kein Faktum, kein Raisonnement und kein Menschenverstand, aber viel Verteidigung - freilich auch nur in klingenden Worten - für die Despoten des Hofes wäre, [...] daß solch aristokratisches Zeug nicht mehr auf diese Rednerbühne gebracht werden solle; daher jeder Redner, der künftig hier diesen Ton anstimmen würde, sogleich zur Ordnung verwiesen werden solle. Anton Fuchs am 14. Dezember 1792 im MJK. (MR1, S. 378-379).

310 Protokoll des MJK vom 8. November 1792. (MR1, S. 153). 
Wiederholt wurden im Jakobinerklub solche Widerlegungen eingefordert, wenn Äußerungen im Publikum auf Widerspruch stießen. ${ }^{312}$ Diese Widerlegungen wurden nicht nur im Jakobinerklub mündlich vorgetragen, ${ }^{313}$ sondern mitunter uber verschiedene Druckmedien verbreitet. ${ }^{314}$ Bemerkenswert ist es dabei, daß in mehreren Fällen nicht nur die jakobinischen Widerlegungen durch den Druck verbreitet wurden, sondern auch die Texte, denen der Widerspruch galt.

Metternich las einen hier herumgehenden Aufsatz [...] vor voll aufrührerischer Gedanken, worin der hiesige Handelsstand dem General Custine vorstellen will, daß die fränkische Konstitution auf das teutsche Phlegma und geringe Kräfte[n] des mainzischen Staates nicht passe. Hierauf macht Metternich den Vorschlag, daß man die Verfasser dieser Schrift als Volksverfïhrer brandmarken und, wenn der Verfasser ein Mitglied der Gesellschaft sei, ihn als unwürdig ausschließen solle. [...] Häffelin begehrt, daß dieser Aufsatz öffentlich durch den Druck beantwortet und widerlegt werde, welches mit allgemeinem Beifall aufgenommen worden. [...] Hierauf wurd votiert und beschlossen, daß diese Schrift gedruckt und widerlegt werden solle. 315

Mit diesem Verfahren, auch den inkriminierten Text abzudrucken, wollte man zeigen, daß man die öffentliche politische Auseinandersetzung nicht scheute, sondern auf die Durchschlagskraft der Argumente vertraute. ${ }^{316}$ So wurde beispielsweise die gegenrevolutionäre Satire Schöne Raritäten zum Zeitvertreib des Mainzer Bürgers beim troknen Brod und am leeren Kruge [...] in Mainz von jakobinischer Seite unverändert nachgedruckt, damit dergleichen Verfasser, welche sich nicht getrauen, ihren Namen vorzusetzen, sehen, daß uns an ihren Lügen und Geschmier nichts gelegen ist. ${ }^{317}$ Auch im Falle der von Daniel Dumont maßgeblich formulierten, gerade aufgrund ihrer moderantistischen ${ }^{318}$ Orientierung in Mainz höchst wirkungsvollen Consti-

311 Anton Fuchs am 14. Dezember 1792 im MJK. (MR1, S. 379).

312 Ein Mitglied machte diese Motion, die Schrift des Präsidenten zu widerlegen. (Protokoll des MJK vom 30. November 1792. (MR1, S. 317)).

313 Beispielsweise antwortete Mathias Metternich schon am 1. November auf die von Erasmus Lennig am 31. Oktober 1792 im MJK vorgetragene gegenrevolutionäre Rede. (Vgl. MR1, S. 87, 90-96.) Auch andere Widerlegungen wurden regelmäßig im MJK vorgetragen, so am 12. November 1792, am 2. Dezember 1792, am 3. Dezember 1792, am 14. Dezember 1792 und am 25. Dezember 1792.

314 Metternichs Rede wurde schon am 17. November 1792 in der Mainzer NationalZeitung zum Kauf angeboten.

315 Protokoll des MJK vom 8. November 1792. (MR1, S. 153).

316 Vgl. Dumont 1993a, S. 148.

317 Mainzer Intelligenzblatt vom 23. Februar 1793, S. 100. Vgl. Dumont 1993a, S. 148, Fn. 229.

318 Vgl. Fn. 300. 
tutions-Vorschläge des Handelsstandes zu Mainz wurde der vollständige Text publiziert, jedoch mit einer nachfolgenden Widerlegung durch Karl Joseph Schweikhard Boost versehen. ${ }^{319}$ Ebenso verfuhr man bei der von Peter Adolf Winkopp verfaßten gegenrevolutionären Schrift Über die Verfassung von Mainz oder Vergleich des alten und neuen Mainz von einem Mainzer, die zusammen mit einer Widerlegung von Mathias Metternich (Der Aristokrat, auf Seichtheiten und Lügen ertappt [...].). ${ }^{320} 1793$ gedruckt wurde. Die gegenrevolutionäre Flugschrift Etwas über die mainzische Konstitution in einem Sendschreiben des Doktor Gottlob Teutsch an den Verfasser des mainzischen Bürgerfreundes, Frankfurt und Leipzig $1792^{321}$ des kurmainzischen Hofkanzlers Franz Joseph Freiherr von Albini wurde zwar nicht vollständig nachgedruckt, dafür aber war sie Gegenstand mehrerer ausgiebiger Widerlegungen, ${ }^{322}$ die ihrerseits wieder von Albini beantwortet wurden. ${ }^{323}$

319 Constitutions-Vorschläge des Handelsstandes zu Mainz, beantwortet von $K$. Boost, Bürger, Mitglied der Gesellschaft der Freiheit und Gleichheit in Mainz, Mainz 1792. (MR1, S. 155-158, 189-191; MRS, S. 205-213) Eine zweite $W i$ derlegung erschien unter der Autorenschaft von Andreas Joseph Hofmann: Über Fürstenregiment und Landstände bei Gelegenheit der Bittschrift des Mainzer Handelsstandes an den Frankengeneral Custine, gesprochen vor dem Volke, den 16. und 18. November, von Andreas Joseph Hofmann, Professor der Geschichte der Philosophie und des Naturrechts auf der Universität zu Mainz. (MR1, S. 192-214).

320 Vgl. MRS, S. 260-282.

321 Zur Auflösung des sprechenden Synonyms vgl. Weller 1963 [1886], S. 554. Zu Franz Joseph Freiherr von Albini vgl. Menzel 1974. Zu Albinis Schrift vgl. Fuchs 1973; Scheel 1984, S. 329-330; Scheel 1989, S. 130; Dumont 1993a, S. 247248.

322 Zunächst antwortete Georg Wedekind in seiner Zeitschrift "Der Patriot« (Nr. 3 vom 28. November 1792, S. 12-32: Über Staatsumwälzung und beiläufig über Hrn Doktor Gottlob Teutsch. (MR1, S. 330-336)). Die Herausgeber der jakobinischen Zeitschrift Der fränkische Republikaner, Kaspar Hartmann und Johann Dominik Meuth, antworteten in ihrem Blatt mit einer Artikelfolge, die auch als selbständige Flugschrift herausgebracht wurde (Nr. 3, S. 20-23, Nr. 4, S. 25-31, Nr. 5, S. 33-39 und Nr. 6, S. 42. Vgl. Scheel 1984, S. 329-330.) Ein weiteres Mal antwortete Kaspar Hartmann ab dem 30. Dezember 1792 mit einer Rede im MJK, die auch als selbstăndige Flugschrift erschien (Etwas über das Etwas des Dr. Gottlob Teutsch an den Verfasser des mainzischen Bürgerfreundes über die mainzische Konstitution von einem Bürger auf dem Lande, Mainz 1792, im ersten Jahre der Freiheit und der Gleichheit. (MR1, S. 442-456).

323 Ein paar derbe Worte des Dr. Gottlob Teutsch an seinen tapferen Widerleger, den vormaligen $k$ mainzischen Hofgerichtsrat, nunmehr fränkischer Republikaner Kaspar Hartmann. Mit einem Sendschreiben an den getreuen Schildknappen des Generals Custine, Daniel Stamm. Frankfurt und Leipzig 1793. Verfaßt Nimwegen, 2.1.1793. 
Diese Widerlegungen stellen nicht nur insofern eine interessante Quelle dar, als sie symptomatisch sind für das Verständnis von Öffentlichkeit, das bei den Mainzer Jakobinern in der ersten, liberalen Phase der Mainzer Republik vorherrschte. Sie sind auch deshalb furr den historischen Sprachwissenschaftler von Nutzen, weil diese eng aufeinander bezogenen Texte $^{324}$ einerseits Analysen intertextueller Strukturen ermöglichen, zum anderen aber auch eine höchst ergiebige Grundlage für die Analyse politisch konfrontativer Wortsemantik und Nomination darstellen.

Die sich stetig intensivierende, bei der Bevölkerung nicht folgenlos gebliebene Aktivităt gegenrevolutionärer Krăfte ließ allerdings noch in der liberalen Phase der Mainzer Republik Zweifel an einer bloß diskursiven Auseinandersetzung mit den Revolutionsgegnern aufkommen. ${ }^{325}$ Restriktivere Maßnahmen, auch solche der Kommunikationskontrolle und des unmittelbaren Zwanges, wurden erwogen. ${ }^{326}$ Custine drohte Ende 1792 gar, wer von einer Übergabe der Festung Mainz auch nur redete, solle auf der Stelle gehanget werden. ${ }^{327}$

Es standen verschiedene Konzepte von Öffentlichkeit im Widerstreit, was sich exemplarisch an der im November 1792 gefuhrten Auseinandersetzung um die Natur des nach französischem Vorbild eingerichteten wachthabenden Ausschusses (auch: Sicherheitsausschuß, Wachsamkeitsausschuß, comité de surveillance) des Jakobinerklubs ablesen läßt, eine Debatte, die sowohl ihres Inhalts wegen als weil sie auf den Geist unserer Gesellschaft schließen ließ,

324 Um eine Folge ăhnlich dicht aufeinander bezogener konfrontativer Texte handelt es sich auch bei der "Pressefehde«, die sich der - durch Frankfurter Bürger ermöglichten - Wiedereinnahme von Frankfurt durch preußische Truppen Anfang Dezember 1792 anschloß. Vgl. Scheel 1984, S. 355, 357.

325 „Der aufklärerische Grundgedanke, der bei der Bildung des Mainzer Klubs Pate gestanden hatte, erwies sich je länger je mehr als ein Hemmnis bei der Bewältigung der Forderungen, die der politische Alltag an den Klub mit gutem Grund zu stellen gezwungen war." (Scheel 1989, S. 103).

326 So forderte Metternich in der oben, S. 79 zitierten Debatte den Ausschluß bestimmter Mitglieder aus dem MJK aufgrund ihrer unliebsamen Äußerungen.

$327 \mathrm{Zu}$ dieser Drohung sah sich Custine nach der Wiedereinnahme von Frankfurt durch preußische Truppen veranlaßt, als die Auseinandersetzungen sich verschärften. Der Beleg entstammt einem Brief G. Forsters an seine Frau vom 19. Dezember 1792: Strenge Maasregeln gegen Spione, Aristokraten, Verräther u. d. gl. werden täglich unvermeidlicher. Der General droht in einer Proklamation, wer von Übergabe von Mainz oder Kassel reden würde, solle auf der Stelle gehangen werden, und die Administration hat heut beschloßen, der Beamte, der einer Treulosigkeit gegen die Franken überwiesen und deshalb abgesetzt wird, solle zugleich aus der Stadt und Land verwiesen werden. (Forster 1989 [1792], S. 276) Vgl. Scheel 1984, S. 403-404. 
dem Zuhörer interessant werden mußte. ${ }^{328}$ Gegenstand der Debatte war das Ziel einer Gruppe von Jakobinern, zum Zweck der Bekämpfung der Gegenrevolution in den wachthabenden Ausschuß auch geheime Glieder aufzunehmen, die - ähnlich wie in der Gegenwart ein V-Mann oder in der jüngeren Vergangenheit ein $I M-$ die gegnerischen Zirkel unterwandern sollten. Der hohe Rang des Öffentlichkeitsprinzips für die Jakobiner kommt in dieser Debatte in der Tatsache zum Ausdruck, daß man - in früh-dialektischer Argumentation - selbst den Einsatz von Geheimagenten mit dem Öffentlichkeitsprinzip glaubte rechtfertigen zu müssen [Hervorhebungen J.H.]:

Komplotte, die gegen die Absichten der Gesellschaft im stillen geschmiedet werden, sind unsern guten Absichten, die wir offentlich vortragen und ohne Zwang auszuführen suchem entgegen. Nicht wir, wohl aber unsere Gegner haben also das Mittel in Händen, das Publikum zu täuschen. Wir müssen darum auf ein, und zwar unserer Art nach offentlich bekanntzumachendes Mittel denken, um die geheimen Machinationen gegen uns zu zernichten. Ein solches Mittel wäre, wenn der wachthabende Ausschuß autorisiert würde, gute Patrioten als geheime Glieder von sich aufzunehmen, welche nach Ablegung des Eides, den jedes Mitglied schwören muß, dem wachthabenden Ausschuß zur Erreichung seiner Absichten behülflich wären, indem sie ihm von den geheimen Machinationen der Feinde der guten Sache benachrichtigten. [...] Unsere Absicht war also im mindesten nicht, ein geheimes Manover zu machen, wir gaben offentlich eine Maßregel an, wodurch wir unsere Gegner nötigen wollten, unserer Publizität die ihrige entgegenzusetzen. 329

Der Vorschlag war im Jakobinerklub heftiger Gegenrede ausgesetzt und wurde zuletzt abgelehnt:

Dieser Vorschlag wurde durch folgende Einwendungen der Gesellschaft als unerlaubt, gefährlich und ihrer Würde entgegenlaufend vorgestellt - und von ihr verworfen. Nämlich: 1) er ziele auf Einführung einer Staatsinquisition ab, 2) er mache die Gesellschaft gehässig, und er gebe dem Ausschusse ein zu großes Gewicht, wodurch dieser selbst der Gesellschaft gefährlich werden könne. ${ }^{330}$

Wenn hier auch mit der Motivation, die im Entstehen befindliche demokratische Öffentlichkeit nicht durch die Installation von Geheimorganisationen selbst zu gefährden, noch eine liberale Entscheidung getroffen wurde, so zielte die weitere Entwicklung, spätestens nach dem Bekanntwerden des Dezemberdekrets, ${ }^{331}$ aber ganz in Richtung auf administrative Kommunikationskontrolle, die zuletzt in unmittelbaren Zwang überging. Zwar war auch in

328 In der Zeitschrift „Der Patriot« veröffentlichter Bericht Georg Wedekinds über die Diskussion im MJK am 16. November 1792. (MR1, S. 233-235, hier S. 233).

329 Vgl. Fn. 328. (MR1, S. 234).

330 Vgl. Fn. 328. (MR1, S. 234).

331 Vgl. oben, S. 24. 
der autoritären Phase der Mainzer Republik unverăndert ein hoher Politisierungsgrad einer allerdings immer weniger liberal strukturierten Öffentlichkeit gegeben. Diese Öffentlichkeit war nun aber bestimmt von der, quasi offiziellen, Persuasionskampagne von Jakobinern, Militär- und Zivilverwaltungen. Revolutionskritische Stimmen artikulierten sich zwar nach wie vor, konnten jedoch nicht mehr mit Toleranz rechnen. Unabhängig davon, ob man dies positiv oder negativ bewerten will, ${ }^{332}$ ist festzustellen, daß die Repräsentanten der Mainzer Republik um so intoleranter agierten, je weiter diese zeitlich fortschritt. Die Freiheit des Einzelnen, seine Meinungen anderen mitzuteilen, galt nun nur noch, wenn er dadurch die öffentliche Ruhe nicht stört! ${ }^{333} \mathrm{Re}-$ volutionsgegner wurden als Aufwiegler oder Ruhestörer verfolgt. ${ }^{334}$ Es wurde nun angedroht, Personen, die die abzuhaltenden Wahlen durch öffentliche oder heimtückische Vorkehrungen und Reden zu hindern suchen $[. .],.{ }^{335}$ als Feinde der fränkischen Nation und als Ruhestörer zu züchtigen. 336

Schon das fehlende positive Bekenntnis zur Republik wurde in der autoritären und erst recht in der Kriegsphase der Mainzer Republik zum Ausweisungsgrund: $\mathrm{Da}$ alle Bürger schwören müssen, den Grundsätzen der Freiheit und Gleichheit getreu zu sein, daß die nicht Schwörenden des Landes verwiesen, als Feinde der Republik behandelt und deren Vermögen in Beschlag genommen werden. ${ }^{337}$ Es wurde verfügt, daß alle, die diese göttlichen Grundsätze nicht öffentlich anerkennen wollen, als Feinde zu betrachten und wegzuschaffen ${ }^{338}$ seien. Um diese Maßnahmen durchzusetzen, wurde wiederholt auch zur Denunziation aufgerufen:

332 H. Scheel bewertet die zunehmende Härte der Auseinandersetzung entschieden positiv: „Nun ist die Revolution allerdings eine zu ernste Sache, als daß man der Konterrevolution mit so viel blauăugiger Ahnungslosigkeit begegnen darf.“ (Scheel 1989, S. 104) F. Dumont neigt eher einer kritischen Bewertung desselben Sachverhalts zu: „Aufgrund enttăuschter Erwartungen wurde aus der anfangs praktizierten Überredung, die auf wirkliche Selbstbestimmung abzielte, schließlich bloße Unterwerfung, die auf Fremdbestimmung hinauslief.“ (Dumont 1993a, S. 602).

333 Protokoll des MJK vom 3. Mărz 1793. (MR1, S. 710).

334 Bei dieser Unordnung verlangte ein Mitglied, daß in Zukunft die Commissaires aus eigner Autorität befugt seien, im Namen der Gesellschaft ohne alle Anzeige die Ruhestörer arretieren zu lassen [...]. (Protokoll des MJK vom 15. Februar 1793. (MR1, S. 792)).

335 Proklamation der Nationalkommissäre vom 18.2.1793 zu ihrem Auftrag und zu den bevorstehenden Wahlen. (MR2, S. 236-237).

336 Proklamation der Nationalkommissäre vom 18.2.1793 $\mathrm{zu}$ ihrem Auftrag und $\mathrm{zu}$ den bevorstehenden Wahlen. (MR2, S. 236).

337 Protokoll des MJK vom 15. Februar 1793. (MR1, S. 791).

338 Neue Mainzer Zeitung vom 8. März 1793, S. 115-116. (MR2, S. 279). 
Wir rufen daher alle guten Bürger auf. [...] Leute, die sich durch Reden oder Taten verdächtig machen, uns oder den von uns abgesandten Deputierten anzuzeigen. Wenn wir sodann auf ihr sämtliches Vermögen einen Beschlag legen müssen, so ist es auf der andern Seite des Generals Pflicht, das Land in Kriegs-oder Belagerungszeiten von dergleichen verdächtigen oder gefährlichen Leuten zu reinigen. ${ }^{339}$

Das von den Mainzer Jakobinern proklamierte, aufklärerisch motivierte Modell einer kritischen politischen Öffentlichkeit, die als Garant der Demokratie angesehen worden war, war somit nach wenigen Monaten gescheitert. Die breitgefächerten Aktivitäten der gegenrevolutionären Krăfte hatten die Jakobiner und die französische Besatzungsmacht zur Reaktion herausgefordert. Diese Reaktion erfolgte zunächst innerhalb des selbst gesetzten, als zentrale Errungenschaft der Revolution bewerteten Rahmens der kritischen, politischen Öffentlichkeit. Spăter dominierte der Kampf gegen die Gegenrevolution über das Öffentlichkeitsprinzip, womit dann aber gerade dasjenige Ziel preisgegeben wurde, um dessentwillen man den Kampf nicht zuletzt gefuhrt hatte.

\subsubsection{Pressefreiheit in der Mainzer Republik}

Die Freiheit der Presse ist nur eines unter mehreren Merkmalen einer umfassenderen Meinungsăußerungsfreiheit, ${ }^{340}$ die ihrerseits als zentrales Kennzeichen einer demokratisch-freiheitlichen Öffentlichkeit gelten kann. Da aber der Begriff der 'Pressefreiheit' - dem der 'Zensur' polar entgegengesetzt im historischen Prozeß der Durchsetzung von politischer Freiheit und Demokratie nicht ein Element unter mehreren war, sondern geradezu die Chiffre von Demokratie und Aufklärung darstellte, soll auf seine Position innerhalb der Debatten der Mainzer Republik kurz eingegangen werden. Anhand einiger weniger Dokumente wird gezeigt, daß die Einstellung der Jakobiner zur Pressefreiheit einerseits im Rahmen dessen steht, was oben zu Theorie und Praxis des Konzeptes einer demokratischen Öffentlichkeit in der Mainzer Republik ausgeführt wurde. Andererseits, so wird sich zeigen, belegt die ambivalente, sich rasch verändernde Haltung, die Jakobiner und Franzosen gegenüber der Pressefreiheit einnehmen, ein Spannungsverhältnis, das im Konzept 'Pressefreiheit' selbst angelegt ist.

339 Proklamation der Nationalkommissäre vom 18. Februar 1793. (MR2, S. 238).

340 Auch die Freiheit des gesprochenen Wortes wäre zu nennen, dann die Freiheit der Verwendung nonverbaler Kommunikationsmittel wie politischer Symbole, nicht zuletzt die Versammlungsfreiheit. 
Seit 1772 als materiales Integrat des englischen freedom of press im Deutschen belegt, ${ }^{341}$ "entwickelte sich 'Pressefreiheit' (meist als Preßfreiheit) schnell zu einem vielgebrauchten Ausdruck mit schlagwortartiger Wirkung, der in Titeln von Abhandlungen uber Zensurprobleme häufig Verwendung findet. "342 In seiner Lesart als 'Menschenrecht' war der Begriff aufklärerisches Gemeingut, erhielt jedoch durch die Französische Revolution neue Dynamik, indem er einerseits in die Menschenrechtserklärung Eingang fand, zum anderen in den Bereich des politisch Realisierbaren gerückt wurde. „Eine neue Begriffsbedeutung der Pressefreiheit brachte die Französische Revolution zwar nicht, wohl aber für die politisch periodische Presse ein neues Verständnis ihrer politischen Macht. ${ }^{\text {"343 }}$ Als gegen staatlichen Machtexzeß gerichtetes Konzept war der Begriff der 'Pressefreiheit' ein leistungsfähiges Instrument der von staatlicher Machtausübung Ausgeschlossenen. Indem er gegen das Arkansystem des "Ancien Régime» gerichtet wurde, klagte er ein universal verstandenes Menschenrecht gegen staatliche Willkür ein.

So leistungsfăhig das Konzept 'Pressefreiheit' in instrumenteller Funktion, für den Kampf »von unten« gegen die etablierte Macht, war, so schwer taten sich seine Verfechter, es in ein Herrschaftsmodell überzufuhren, wenn der politische Kampf Erfolg gehabt hatte und es zum Machtwechsel gekommen war. Dies zeigt sich an der Realităt der Menschenrechte, besonders auch der Pressefreiheit, nach der erfolgreichen Französischen Revolution. Es läßt sich jedoch auch an den Schwierigkeiten der Mainzer Jakobiner zeigen, diesen Zentralbegriff aufklärerischer politischer Argumentation ins politische Handeln einzuführen, als die Macht errungen worden war.

Auch fur die Mainzer Jakobiner war Pressefreiheit das zentrale antiabsolutistische Aufklärungsinstrument:

[D]er Adel [muß] alles anwenden, um die Untertanen nicht zu der Bewußtwerdung ihrer Rechte kommen zu lassen; weil, sobald das geschieht, die Staatsverfassung nicht länger sich halten kann. [...] Man unterdrückt sorgfältigst die Preßfreiheit, damit nicht durch gedruckte Schriften das Volk über seine Rechte aufgeklärt werde, ja, man untersagt sogar jede freimütige Äußerung über Staatsangelegenheiten, damit weder durchs Lesen noch durch Gespräche vernünftige Gedanken mitgeteilt werden können, welche das betrogene Volk aufzuklären vermöchten. Darum hat man in allen Aristokratien, wenngleich nicht eben immer dem Namen, doch der Sache nach, eine Staatsinquisition, deren Hauptbeschäftigung es ist, das Volk vom Bewußtsein seiner Rechte und seiner Kräfte abzuhalten. ${ }^{344}$

341 Vgl. Abdelfettah 1989, S. 218.

Schneider 1978, S. 913.

343

Schneider 1978, S. 919.

344

Georg Wedekind am 5. November 1792 im MJK. (MR1, S. 125). 
Folgerichtig wurde die Pressefreiheit nicht nur als Gegenbegriff zum »Ancien Régime« angesehen, sondern gleichzeitig als Kennzeichen, ja geradezu als Garant der Demokratie:

In guten Demokratien wird die Freiheit, zu reden und drucken zu lassen, heilig gehalten, weil sie das Mittel ist, jedem schlechten Kerl die Larve abzuziehen; weil sie das Mittel ist, die Mängel der Staatsverfassung aufzudecken, bessere Einrichtungen zu treffen und - mit einem Wort - weil es das Interesse der Demokratie erfordert, jeden Menschen so klug zu machen, als es möglich ist. ${ }^{345}$

Es ging den Mainzer Jakobinern nach der Einnahme von Mainz zunächst darum, das zuvor gegen das kurfüstliche Arkansystem eingeklagte Konzept 'Pressefreiheit' durch die Franzosen in politische Wirklichkeit überzuführen. Noch in der ersten Woche der französischen Besetzung von Mainz wurde im Jakobinerklub der Antrag auf Pressefreiheit gestellt:

Am Donnerstag machte der ehemalige Hofrat Wedekind im Klub den Vorschlag, bei dem General Custine um Pressefreiheit und Haltung der Gerichtspflege mit offenen Türen anzusuchen [...]. ${ }^{346}$

Die Jakobiner machten von dieser Freiheit auch regen Gebrauch und begannen sofort nach der Besetzung von Mainz mit dem Druck und der Distribution von Flugschriften. Allerdings zeigte sich bald, daß man nicht daran dachte, Pressefreiheit als allgemeine zu verstehen und sie auch gegenrevolutionären Autoren einzurăumen. Zwar waren die Jakobiner, wie gezeigt, in der ersten Phase so liberal, bestimmte gegenrevolutionăre Schriften - oft mit Widerlegungen versehen - selbst drucken zu lassen, jedoch wurde dieses Recht den gegenrevolutionären Autoren selbst von Anfang an nicht eingeräumt. Der geplante Druck der gemäßigt-gegenrevolutionären Rede Johann Erasmus Lennigs ${ }^{347}$ wurde schon im Oktober 1792, noch in der liberalen Phase der Mainzer Republik, unterbunden. ${ }^{348}$

Eine solche Haltung zur Pressefreiheit prägt dann auch die offizielle Weisung der Allgemeinen Administration vom 21. November 1792, die diese zur Sicherung der Pressefreiheit an die Munizipalităten von Mainz, Worms und Speyer richtet (Vgl. Text 4.) Es läßt sich an diesem Text das Konzept von 'Pressefreiheit', das die Mainzer Jakobiner in der autoritären Phase der Mainzer Republik in die Tat umsetzten, unmittelbar ablesen: In Absatz [1] wird emphatisch uneingeschränkte Pressefreiheit verkundet, in Absatz [2] hingegen die administrative Kontrolle der Presse und die negative Sanktionierung inhaltlich mißliebiger Druckwerke angeordnet. Pressefreiheit, nach wie

345 MR1, S. 118-136, hier S. 131-132. Vgl. hierzu auch Fn. 240.

346 Protokoll des MJK vom 25. Oktober 1792. (MR1, S. 56).

347 Vgl. oben, S. 74.

348 Vgl. Scheel 1984, S. 512. 
vor ein kritisches, tendenziell herrschafts-destabilisierendes Instrument des Machterwerbs, war nach stattgehabtem Machtwechsel nicht mehr gefragt.

Text 4: Weisung der Allgemeinen Administration vom 21.11.1792 an die Munizipalităten von Mainz, Worms und Speyer zur Sicherung der Pressefreiheit ${ }^{349}$

[1] Da die Preßfreiheit die wahre Schutzwehr freier Völker gegen alle Arten des weltlichen und geistlichen Despotismus ist, so können wir nach den Grundsätzen der Rechte des Menschen, auf welche die freie Verfassung der Frankenrepublik gegründet ist, nicht säumen, die sämtlichen Einwohner der Städte und des Landes, welche unserer Allgemeinen Administration untergeordnet sind, an dieses unverweigerliche Recht zu erinnern und alle desfalls noch vorwaltenden $Z$ weifel und Bedenklichkeiten, welche noch von dem sonst eingerissenen Mißbrauche der willkülichen Gewalt in ihren Gemütern haften möchten, gänzlich aus dem Wege zu räumen.

[2] Gleichwie es aber jedermann freistehen muß, seine Meinungen öffentlich durch den Druck an den Tag zu legen, so darf dennoch diese Freiheit keineswegs dahin ausgedehnt werden, daß die öffentliche Sicherheit der Person und des Eigentums darunter leiden oder gar beide dadurch in Gefahr geraten können. Demzufolge hat die Allgemeine Administration beschlossen, Sie, Bürger Maires, aufzufordern, und Sie werden hiedurch aufgefordert, dahin zu sehen, daß keine Schrift gedruckt werde ohne Beifügung des Namens des Druckers, an welchen man sich heften wird, falls in derselben Grundsätze und Äußerungen vorkommen, welche die allgemeine Ordnung und Sicherheit stören, welche dem allgemeinen Wohl als dem höchsten Gesetze eines Staates zuwiderlaufen und das Volk über seine so lange geraubten Rechte oder auch uber seine Pflichten aufrührerisch irrefihren könnten. Zugleich hat die Munizipalität zu wachen, daß dergleichen volksfeindliche Schriften, sie mogen herkommen, woher sie immer wollen, nicht verkauft und verbreitet werden, und die Verkäufer und Verbreiter derselben als Feinde des allgemeinen Wohls anzusehen und zu bestrafen.

[3] Mainz, den 21. November 1792, im ersten Jahre der fränkischen Republik.

[4] Dorsch, Prasident

[5] J. M. Kissel, Selretär ${ }^{350}$

Es zeigt sich hier, daß die regulative und die poskative Sprachfunktion einander prinzipiell entgegengesetzt sind. Während regulatives sprachpolitisches Handeln eher auf Kontrolle der Presse aus ist, wird poskatives Sprachhandeln immer Pressefreiheit als Instrument des Machterwerbs einfordern. Während

Veroffentlicht im Mainzischen Intelligenzblatt vom 24. November 1792, S. 741.

(MR2, S. 144). 
dieses Spannungsverhältnis in modernen Demokratien institutionell geregelt ist, konnte man von den Mainzer Jakobinern in einer revolutionären Kampfsituation jedoch kaum erwarten, daß sie in liberaler Gelassenheit auch dem politischen Gegner, ja Feind, freien Zugang zur Presse ermöglicht hătten. $\mathrm{Daß}$ sie damit allerdings auch ihre eigenen Werte verrieten und damit nicht glaubwürdiger wurden, muß ebenfalls eingerăumt werden.

Die Konstellation in der Mainzer Republik offenbart im ubrigen auch ein begriffliches Problem des 'Pressefreiheit'-Konzeptes: Wie schon im Freiheitsbegriff selbst eine inhärente Begrenzung der Freiheit darin angelegt ist, daß jede Freiheitsausübung ihre Schranken in der Freiheit des Anderen findet, so sind auch im Begriff der 'Pressefreiheit' inharente Schranken in den Rechten des Anderen gegeben. Schon in der Formulierung der Menschenrechte - auch in den zeitgenössischen Wörterbüchern - wird 'Pressefreiheit' als inhärent begrenzte gefaßt, ist sie die Freyheit, alles drucken zu dürfen, was nicht wider den Staat und gute Sitten anstößt. ${ }^{351}$ Die Problematik der Handhabung des 'Pressefreiheit'-Konzeptes durch die Mainzer Jakobiner war die, daß die internen, formal definierten Restriktionen des Begriffs in zunehmendem Maße inhaltlich verstanden wurden. Dadurch wurde aus einer allgemein verstandenen Pressefreiheit, der nur dort Grenzen zu setzen gewesen wären, wo Freiheitsrechte Anderer tangiert sind, die Freiheit des Druckens revolutionsfreundlicher Schriften.

Symptomatisch hierfür ist es, daß ausgerechnet die Mainzer Geistlichkeit in ihrem gegenrevolutionären "Promemoria« vom November 1792 Pressefreiheit als unumschränkte einfordert:

[D]ie niedere Mainzer Geistlichkeit [muß] ihren großmütigen, nur Wahrheit und Freiheit auf alle[n] Wege[n] begünstigenden Überwinder und Beschützer bitten, eine vollkommene Preßfreiheit als welcher die beiden edelsten Töchter der Gottheit, Wahrheit und Ereiheit ihr Dasein zu verdanken haben, durch eine zu erlassende Proklamation zu gestatten und gegen jeden direkten oder indirekten Eingriff nachdrucksamst zu schützen, indem Freiheit ohne Wahrheit nicht bestehen und Wahrheit nicht statthaben könne, solange es nur den geringsten Anschein hat, als wollte man nur einer Partei alles frei zu reden und zu drucken verstatten und jedem andern mündliches und schriftliches Stillschweigen auferlegen. ${ }^{352}$

Es muß die Mainzer Revolutionäre tief getroffen haben, daß gerade die Anhänger des "Ancien Régime« den aufklärerischen Begriff der Pressefreiheit höhnisch gegen die Aufklärer selbst wenden konnten. In der Reaktion jedenfalls bestätigte man die Verfasser indirekt, denn dem Klerus wurde „der Druck dieses Memorandums verboten [...]. ${ }^{\text {(3353 }}$

351 Roth 1791, s.v. Preßfreyheit.

352 MR1, S. 360.

353 Scheel 1984, S. 359. 
Text 5: Dekret der Allgemeinen Administration vom 17.4.1793 über die Einstellung des Zeitungs- und Flugschriftendrucks ${ }^{354}$

[1] Im Namen des souveränen Volkes

[2] Da in gegenwärtigen kritischen Zeitläuften in dem dermaligen Belagerungszustande von Mainz zur Aufrechterhaltung der öffentlichen Ruhe die strengste Polizeiaufsicht über alle und jede Druckschriften und Zeitungen um so mehr nötig ist, als dadurch die Gemüter der guten Sache noch zur Zeit abgeneigten Personen gar leicht dagegen noch mehr eingenommen werden können, so wurde beschlossen:

[3] daß den sämtlichen Buchdruckern befohlen werde, bei gegenwärtigen Belagerungsumständen der Stadt Mainz keine Zeitung noch andere Schriften in Druck zu nehmen, wovon aber die fernere Auflegung des Intelligenzblattes jedoch mit dem Vorbehalte ausgenommen bleibt, daß dasselbe dem Comité de police zur vorherigen Durchsicht jedesmal zugestellt werde.

[4] Idque intimitetur der hiesigen Munizipalität zur schleunigen Bekanntmachung.

[5] Mainz, am 17. April 1793, im zweiten Jahr der Frankenrepublik

[6] Die Mitglieder der provisorischen Allgemeinen Administration

[7] A.J. Hofmann, Präsident

[8] Degenhard, Secretarius generalis

Die weitere Entwicklung in der Mainzer Republik fuhrte dann, auch was die Pressefreiheit anging, zur Restriktivierung. Unter dem Eindruck der militärischen Ereignisse, ${ }^{355}$ aber auch, um offentliche Kritik aus den eigenen Reihen zu unterbinden, ${ }^{356}$ verbot schließlich die Allgemeine Administration mit ihrem Dekret vom 17. April 1793 den Druck fast sămtlicher Presseerzeugnisse und führte fur das einzig noch erlaubte Amtsblatt sogar die Vorzensur ein. Damit hatte man zwar die innere Widersprilchlichkeit des eigenen Pressefreiheit-Konzeptes uberwunden, war aber zugleich noch hinter die kurfurstlichen Zustände zurückgefallen:

Auch wenn dieses Dekret die fruheren Freiheitszusagen der Mainzer Jakobiner Lügen zu strafen scheint, sollte doch das rezente Bild der Kommunika-

354 MR2, S. 594-595.

355 Vgl. Scheel 1981, S. 595.

356 Georg Wilhelm Bohmer hatte die Allgemeine Administration am 16. April 1793 ultimativ aufgefordert, ein an den Rheinisch-Deutschen Nationalkonvent gerichtetes, die Gewaltenteilung durchbrechendes Dekret zurückzuhalten: Wo nicht, so werde ich laut ans Publikum, unsern allgemeinen Souverän, appelieren. (MR2, S. 586) Vgl. Scheel 1981, S. 584-586, 595. 
tionsstruktur in der Mainzer Republik nicht von diesem Tiefstand politischer Kommunikation in der Kriegsphase dominiert werden. Denn nicht diese Phase des - nach außen - militărischen Kampfes und der - nach innen - autoritären Kommunikationskontrolle (auch des unmittelbaren Zwanges) hebt die Mainzer Republik aus den kommunikativen Verhältnissen ihrer Zeit heraus, sondern der innerhalb der deutschen Sprachgeschichte weit vorzeitige, wenn auch letztlich erfolglose Aufbruch zu Pressefreiheit und demokratischer Öffentlichkeit, der ihre Anfangsphase prägte. ${ }^{357}$

\subsection{Kanäle politischer Kommunikation}

Sprache ist ein hervorgehobenes Mittel politischen Handelns, doch ist sie bei weitem nicht das einzige. Gerade angesichts des hier behandelten Gegenstandes »Mainzer Republik« wird man zunächst nicht ubersehen können, daß die Mittel der Politik „Swords and Symbols ${ }^{\text {“358 }}$ sind, daß der physische Zwang nicht minder wichtig sein kann als die Interaktion mittels Zeichen. ${ }^{359}$ Aber auch für den Fall der Zeichenkommunikation ist die (Verbal-)Sprache nur eine Kodierungsmöglichkeit unter mehreren. ${ }^{360}$ Sie kann durch nonverbale Kommunikationsformen uberlagert, in bestimmten Fallen sogar ersetzt werden. Bevor im folgenden also auf die Wege verbaler politischer Kommunikation eingegangen wird, sollen die Erscheinungsformen nonverbaler Kommunikation in der Mainzer Republik kurz angesprochen werden. Sie waren 1792 in Mainz nicht minder innovativ als die verbalen.

\subsubsection{Nonverbale Zeichen: Die politische Symbolik}

Wenn die politische Kommunikation in beachtlichem Umfange auch nonverbale Zeichen nutzt, so ist hier in erster Linie an die politische Symbolik zu denken. Eine der wichtigsten Funktionen der politischen Symbolik ist es, die Identität politischer Gruppierungen nach innen und außen $\mathrm{zu}$ markieren. „Fahnen, Wappen, Hymnen; Pfahle, Stangen, Schlagbäume; Krone, Zepter,

357 Vgl. von Polenz 1994, S. 40.

358 Marshall 1939. Vgl. hierzu Dieckmann 1975, S. 28; Kopperschmidt 1976, S. 7072.

359 Vgl. aber Grünert 1974, S. 1: „Wo Politik sprachlos wird, ist sie keine Politik mehr."

360 Vgl. Resnikow 1968, S. 40-43, 178-184. 
Schwert; Adler, Lowe, Stern, Kreuz ${ }^{6361}$ sind insofern leistungsfähige Instrumente politischer Kommunikation, als sie Zusammengehörigkeit und Abgrenzung, Herrschaft und Widerstand markieren, ohne auf den Austausch von Texten angewiesen zu sein. Anders als die Sprache, die Inhalte diskursiv nur sukzessiv vermitteln kann, sind Symbole durch die Fähigkeit der ,simultanen, integralen Präsentation ${ }^{\text {“362 }}$ gekennzeichnet:

Wo Sprache oder Schrift nicht ausreichen, greift man zum Symbol. Im Symbol können die vielfaltigsten, rational nicht auflosbaren Bedeutungen und Zusammenhănge zu einem Ganzen zusammenfließen, während Sprache oder Schrift das gleiche nur nacheinander ausdrücken kőnnen. ${ }^{363}$

Die aktive Verwendung, die Tolerierung oder die Zurückweisung politischer Symbole stellt - oder beantwortet - in einem politischen Verband die Machtfrage: Herrschaftswechsel bedeutet stets Symbolwechsel, denn wer Herrschaft in Frage stellt, greift auch deren Symbole an, und eine neue Herrschaft setzt Zeichen, deren Anerkennung sie einfordert. ${ }^{364}$

Es gehört zur Ausübung einer neuen Herrschaft, das Zeichen- und Symbolsystem der alten Herrschaft zu beseitigen bzw. semantisch umzustrukturieren. Herrschaftswechsel ist mit Symbolwechsel, Symbolumkehr verbunden. ${ }^{365}$

Dies gilt auch fur die Franzosische Revolution: Sowohl die innere Dynamik der Revolution in Frankreich wie auch ihre Aufnahme im Ausland waren eng mit der Ablösung absolutistischer und mit der Durchsetzung eigener, neuer politischer Symbole verbunden. Die Rolle der politischen Symbole ist in wachsendem Maße erkannt worden, so $\mathrm{daB}$ sie nach gegenwärtigem Forschungsstand als „die Leitinstanzen und Schlüsselkräfte der Französischen Revolution uberhaupt [...]" erscheinen. ${ }^{366}$

Wie R. Reichardt jüngst in uberzeugender Analyse gezeigt hat, bedeutete die Adaption dieser Symbole in Deutschland nicht nur eine Verbreitung der inhaltlichen politischen Konzepte der Französischen Revolution, sondern daruber hinaus einen wirksamen und tiefgreifenden französisch-deutschen „Kulturtransfer“" ${ }^{367}$ Der sprachliche - uberwiegend lexikalische - Transfer, der für die Revolutionsepoche konstatiert worden ist, bildet insofern nur ein Element dieses Kulturtransfers. Wenn es auch im Rahmen dieser Arbeit nicht moglich ist, auf die politische Symbolik im an sich wunschenswerten Maße

361 Grünert 1984a, S. 32.

362

363

Pross 1974, S. 29.

Anderegg 1968, S. 15.

Vgl. Grünert 1984a, S. 34; Pross 1974, S. 41.

Grinert 1984a, S. 34.

Reichardt 1993, S. 18.

Vgl. Reichardt 1993, S. 18. 
einzugehen, soll doch wenigstens in einem knappen Überblick angedeutet werden, in welchem politischen Symbol-Kontext die Sprache der Mainzer Republik zu lokalisieren ist. Dabei kann nur exemplarisch verfahren werden.

Politischer Machtwechsel bedeutet Eliminierung der politischen Symbolik der alten Machthaber und Etablierung der Symbolik der neuen. Der letztere Vorgang setzte im Deutschland der Revolutionsepoche fruh ein und ging auch in Mainz dem eigentlichen Machtwechsel, den er ankundigte, voraus. Sehr bald nach der Revolution war die Destabilisierung des "Ancien Régime « - auch außerhalb von Frankreich - am Auftauchen der Revolutionssymbolik zu erkennen, wobei die Symbole der Revolution sich oft schneller verbreiteten als deren politische Konzepte: In Mainz wurden beispielsweise schon 1790 , beim restaurativ ausgerichteten $»$ Knotenaufstand,${ }^{368}$ Kokarden in den Revolutionsfarben getragen und die Trikolore mitgefuhrt. Solche Kokarden wurden in Mainz auch in der Folgezeit, also noch vor der französischen Besetzung, in großer Zahl zum Kauf angeboten und fanden beachtlichen Absatz. ${ }^{369}$ Entsprechend waren die Mainzer gerüstet, als 1792 die Stadt übergeben wurde und es zum Machtwechsel kam: Sobald man zum Tor hinaus durfte, pflanzten Reichard, Falciola und ich die Kokarden auf und marschierten ins Lager bei Mombach. ${ }^{370}$

Nach der erfolgten Besetzung von Mainz dominierten dann sogleich die Revolutionsfarben in der Öffentlichkeit: Nicht nur trugen die französischen Soldaten die Kokarde, sondern auch die Administrationsmitglieder, der Bürgermeister, die Mitglieder des Mainzer Jakobinerklubs sowie zahlreiche Bürger, die keine institutionelle Funktion innehatten. Die Trikolore war bei offiziellen Anlässen zu finden, besonders aber im Jakobinerklub, dessen Protokollbuch blau-weiß-rot eingebunden war. ${ }^{371}$ Als modischer Bestandteil der Kleidung und als politisch signifikatives Schmuckelement von Straßen oder Innenräumen (z. B. von Ballsălen) wurden die Revolutionsfarben ebenfalls verwendet. ${ }^{372}$

Das Inventar an Symbolen ging weit über die Revolutionsfarben hinaus: Demonstrative Verwendung fanden die Pike, die Jakobinermütze und der

368 Vgl. oben, S. 16.

369 Vgl. Boos 1901, S. 569; Reichardt 1993, S. 21.

370 Dies berichtet der Kaufmannslehrling und spätere Jakobiner Johann Aloys Becker. (Nach Dumont 1982e).

371 Vgl. Reichardt 1993, S. 21-22.

372 In einem anonymen zeitgenössischen Gedicht hieß es:

Ihr Seidenhändler seyd vergnügt,

Das Band, was euch im Laden liegt;

Wär auch der Vorrath noch so groß,

Werdt ihr nun reißend los. (Zit. n. Reichardt 1993, S. 21). 
Freiheitsaltar, ${ }^{373}$ nicht zuletzt auch revolutionăre Hymnen wie die Marseillaise und das Ça ira. Letztere waren so weit verbreitet, daß sie stellenweise auch nach dem Ende der Mainzer Republik noch unbefangen intoniert wurden. ${ }^{374}$ Von intensiver, wenn auch im Hinblick auf den persuasiven Effekt höchst zwiespältig einzuschătzender ${ }^{375}$ Symbolkraft war auch eine - historisch beispiellose - Bürgerbefragung in der Gestalt eines Roten und eines Schwarzen Buches, in die die Bürger sich alternativ einschreiben sollten. Diese Volksbefragungsaktion, ${ }^{376}$ die M. Neugebauer-Wölk soeben eingehend

373 Vgl. Reichardt 1993, S. 21-30.

374 So beobachtete Goethe unmittelbar nach der Rückeroberung von Mainz beim Mittagsmahl an einer großen Wirtstafel erstaunt, daß man von den gegenwärtigen Musikanten den Marseiller Marsch und das "Ça ira« verlangte [...]. (Goethe 1976 [1822], S. 394-395).

375 Vgl. z. B. die Diskussion bei Dumont 1993a, S. 162-165; Neugebauer-Wölk 1993, S. 61-65.

376 Vgl. den Aufruf, der am 8. November 1792 in der Mainzer National-Zeitung veroffentlicht wurde (MR1, S. 150):

Mainz vom 7. November. Da der Bürger General Custine die Einwohner hiesiger Stadt und Gegend aufgefordert hat, sich zu erklären, ob sie lieber freie Menschen oder Sklaven sein wollen, so werden morgen früh zwei Bücher zu dieser Absicht in dem Saale der Konstitutionsfreunde aufgelegt werden.

Das eine dieser Bücher, das Buch des Lebens, ist in roten Saffian gebunden, mit der Freiheitsmütze und am Rande mit den Nationalfarben geziert und enthält folgenden Anfang:

"Im Namen des Allmächtigen!

Wir Unterzeichnete huldigen dem Gesetze, welches die höchste Gewalt in die Hände des Volks legt und dem Volke sein Recht wiedergibt, diese Gewalt durch Personen ausüben zu lassen, die es sich selbst von Zeit zu Zeit wählt.

Wir erkennen Ereiheit und Gleichheit als die Hauptgrundsätze, worauf eine gute Staatsverfassung gebauet sein muß.

Da das edle Volk der Eranken bereits den Anfang gemacht hat, auf diese Grundsätze eine neue Verfassung zu bauen, so nehmen wir diese Konstitution soweit sie jetzt existiert und so wie wir selbst durch unsre Stellvertreter in Gemeinschaft mit den Bevollmächtigten der fränkischen Nation sie verfassen werden, mit Vergnügen, jedoch unter der einzigen Bedingung an, daß das Gesetz, welches die Zünfte aufhebt, gewisser Ortsverhältnisse wegen nur erst alsdann in unsrer Gegend in Ausübung gebracht werde, wenn die Ursachen aufgehört haben, welche noch zur Zeit die Beibehaltung geschlossener Zünfte für unsern Wohlstand notwendig machen "

Das andere Buch ist in schwarzes Papier gebunden, mit Ketten umwunden und enthält die Überschrift: Sklaverei.

Sämtliche männliche Bürger und Einwohner dieser Stadt und Gegend von 21 Jahren an und darüber werden ersucht, sich entweder das eine oder das andere dieser Bücher zu wählen, um ihre Namen zu unterschreiben, indem es schlech-

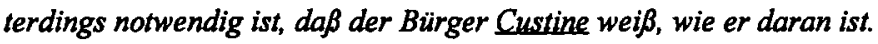


diskutiert hat, ${ }^{377}$ war besonders intensiv von der neuen politischen Symbolik geprägt. So war das eine Buch, das Buch des Lebens, rot eingebunden, mit der Jakobinermultze und am Rande blau-weiß-rot verziert. Das andere Buch, das Buch der Sklaverei, war schwarz eingebunden und mit Ketten umwunden.

Das erfolgreichste Revolutionssymbol überhaupt war jedoch der Freiheitsbaum: ${ }^{378}$

Wie die französischen Arbres de Liberté - politisierte Maibäume, die 1790 von den Bauern des Poitou aufgebracht worden waren, rasch landesweit Nachahmung fanden [..., fanden auch in Mainz und Umgebung die Freiheitsbäume mit deswegen so großen Anklang, weil sie an einen traditionellen Volksbrauch, den der Kerbebäume, anknüpten. 379

Tatsächlich erwiesen sich die Freiheitsbaumpflanzungen - weniger noch wegen des isolierten politischen Symbols als wegen der komplexen Symbolhandlung, die sie begleitete - als höchst geeignetes Vermittlungsinstrument revolutionărer Ideologie: In Mainz selbst wurde 1792/93 zweimal unter größter Beteiligung der Bevőlkerung ein Freiheitsbaum gepflanzt, im Umland kam es bis Januar 1793, also noch in der uberwiegend liberalen Phase der Mainzer Republik, zu über 50 Freiheitsbaumpflanzungen. ${ }^{380}$

Bei diesem Akt politischer Symbolik handelte es sich um eine geschickte Verquickung von Assoziation und Emotion, von überkommenen Rechtsvorstellungen und volkstlumlichen Bräuchen im Dienst einer völlig neuen Ideologie. [...] Zweifellos gehörte die Errichtung von Freiheitsbåumen zu den wirksamsten Mitteln revolutionărer Agitation in den ersten Monaten der Mainzer Republik. ${ }^{381}$

Dazu trug bei, daß das Baumsymbol nicht nur in einen außersprachlichen historischen und aktuellen - Symbol-Kontext gestellt werden konnte, sondern $\mathrm{da} ß$ sich darliber auch zahllose Anknupfungspunkte fur sprachliche Metaphernbildung ergaben. Zu Vergleichen regten vor allem die Attribute eines lebenden Baumes wie Same, Keim, Wuchs, Wurzel, Stamm, Krone, Äste,

Die Subskription ist von morgens 8 bis 12 und dann von 2 Uhr nachmittags bis abends 6 Uhr offen. Wer gar nicht erscheint, erklärt sich stillschweigend für einen Freund der alten Sklaverei und hat sich hernach selbst zuzuschreiben, wenn er wie ein Sklave behandelt wird.

377 Vgl. Neugebauer-Wölk 1993.

378 Vgl. Anderegg 1968; Kuhn 1982; Dumont 1982c, S. 141; Scheel 1984, S. 105109; Keller 1988, S. 136-148, 620-621; Scheel 1989, S. 64-65, 160-161; Dumont 1993a, S. 154-159; Reichardt 1993, S. 25-27.

379 Reichardt 1993, S. 25.

380 Vgl. Dumont 1993a, S. 154-159. Eine Karte der arealen Verbreitung von Freiheitsbäumen findet sich auf S. 196.

381 Dumont 1993a, S. 154 und 159. 
Zweige, Früchte und Schatten an. ${ }^{382}$ Diese wurden zu Bezugspunkten jakobinischer Freiheitsmetaphorik, wie der folgende Redebeitrag anläßlich einer Freiheitsbaumpflanzung zeigt, der die Vorstufe der Metaphernbildung, den expliziten Vergleich, dokumentiert:

Fest und stark breiten sich seine Wurzeln im vaterländischen Boden aus, so wie unsere Liebe zu Freiheit und Gleichheit sich in unseren Herzen ausbreiten soll. Stolz wachse sein Stamm empor, so wie unser Gemeingeist sich emporheben soll! Sein Haupt trotze jedem Windsturme, so wie unser Hang zur Freiheit und Gleichheit den Feinden denselben Trotz bieten soll. ${ }^{383}$

Oben wurde gesagt, daß der politische Machtwechsel sich nicht nur in der Etablierung neuer Symbolik dokumentiert, sondern auch in der Eliminierung der alten. Auch dies läßt sich am Beispiel der Mainzer Republik beobachten. Zum Teil besorgten schon die ehemaligen Machthaber die Eliminierung der eigenen politischen Symbole, wenn sie etwa selbst auf die Verwendung ihrer Hoheitszeichen verzichteten: Wenn auch wohl durch äußere Sicherheitsaspekte veranlaßt, mutet es doch wie ein »Flagge streichen « an, daß der Kurfurst, bevor er vor den herannahenden Franzosen aus Mainz flüchtete, sein Wappen vom Wagen abnehmen ließ:

Unter so bedenklichen Umständen, wo keine Truppen nahe sind, welche die Stadt vertheidigen können, ist die ganze courageuse Noblesse und Geistlichkeit sammt den Emigrierten und ihren Weibern gestern und vorgestern mit Sack und Pack geflüchtet. Der Churfürst kam den 4ten, sah einpacken und fuhr Abends 1/2 10 (mit den Wappen vom Wagen abgekratzt) in der Stille davon. ${ }^{384}$

Zum weit uberwiegenden Teil waren es jedoch die Jakobiner, die die Symbole des "Ancien Régime" aus dem offentlichen Leben entfernten. Dies wurde nicht selten demonstrativ und publikumswirksam inszeniert wie bei der Zerschlagung des sogenannten Butterwecks auf dem Marktplatz, ${ }^{385}$ eines altstädtischen Gerichtszeichens, auf dem die fur den Handel verbindlichen Maße eingraviert waren. Gemäß dem Vorschlag Georg Wedekinds wurde dieser Gerichtsstein am 3. November 1793 zerschlagen und an seiner Stelle der erste Mainzer Freiheitsbaum gepflanzt.

Georg Forsters unten wiedergegebener brieflicher Kommentar ist in unserem Zusammenhang weniger als Beleg für das unmittelbare historische Geschehen von Belang, sondern primăr als Beleg für die instrumentalistische Haltung, die Forster - immerhin eine der zentralen Gestalten der Mainzer Re-

382 Kuhn 1982, S. 190.

Rede des Bürgers Heller bei der Freiheitsbaumpflanzung in Frankenthal. Vgl. zu diesem und anderen Beispielen Kuhn 1982, S. 189-191.

385 Vgl. Scheel 1984, S. 105-109; Reichardt 1993, S. 18-19. 
publik - dieser Symbolhandlung gegenuber einnahm: Die komplexe Symbolhandlung wird nicht etwa ihrer historischen Substanz wegen befurwortet Forster spricht hier distanzierend von einer Kleinigkeit, von einer alten Sage -, sondern wegen ihrer vermuteten persuasiven Potenz. Ganz in der Art eines kuhl kalkulierenden modernen politischen Persuasionsstrategen wird die Aktion befirwortet, weil angenommen wird, daß sie Aufsehen mache, daß sie wirke, und zwar gerade aufgrund eines Informationsdefizits, das der Adressatenschaft unterstellt wurde.

Heut Nachmittag will man den Stein am Gerichtshause ausgraben, den vor 300 Jahren Kurfürst Diether von Isenburg dahin legen und mit eisernen Reifen und Ketten umgeben ließ, wobei er sagte: ich leg euch da einen Butterweck hin, wenn ihn die Sonne zerschmilzt, so sollt ihr eure Rechte und Freiheiten wieder haben. Die Ceremonie unter Begleitung von militairischer Musik wird Aufsehen machen, zumal wenn sie mit Errichtung eines Freiheitsbaumes verbunden ist, wie mans vorhat. Das Volk hängt doch an alten Sagen, und solche Kleinigkeiten wirken. ${ }^{386}$

Gerade auch bei dieser Zeremonie der Zerschlagung des Gerichtssteins handelte es sich, wie R. Reichardt gezeigt hat, um eine im Rahmen des französisch-deutschen Kulturtransfers zu sehende analoge Symbolhandlung, da hiermit der Bastille-Mythos aufgenommen wurde. In Anlehnung an die Bastille-Zerstörung wurden auch in Mainz die Trümmer des Gerichtssteins eingesammelt. Nationalgardisten trugen sie in jeden Haushalt mit dem Kommentar, das Bruchstuck solle zum ewigen Gedăchtnis aufbewahrt werden. Ebenso existierte der Plan, das von dem Gerichtsstein gewonnene Metall in Münzen umzuprägen, die die Initialen $F$. G., für Freiheit und Gleichheit, tragen sollten. ${ }^{387}$

Andere Akte der Eliminienung kurfürstlicher Symbole können nur genannt werden: Auf dem Rückweg von der Zerstörung des Butterwecks wurde beispielsweise noch ein anderes Denkmal der Barbarei, der sogenannte Burgfrieden, abgehauen und zernichtet. ${ }^{388}$ Oder bei der zweiten Freiheitsbaumpflanzung, am 13. Januar 1793, erfolgte eine feierliche Verbrennung von nachgebildeten Symbolen des »Ancien Régime«, die von als Sklaven kostümierten Personen getragen wurden:

Sechs unter Bedeckung von bewaffneten Mainzer und Frankenbürgern herbeigeschleppte Sklaven brachten jetzt einer Krone und Szepter, ein anderer den Reichsapfel, ein dritter Ordenskreuze und andere kindische Unterscheidungszeichen, noch andere einen Haufen alter Adelsbriefe und Ahnentafeln herbei. Eine

386 Brief an Ludwig Ferdinand Huber vom 3. November 1792. (Forster 1989 [1792], Bd. 17, S. 231).

387 Das Eisen wurde aber nicht eingeschmolzen, weil man seine wirkliche Funktion und historische Bedeutung noch rechtzeitig erkannte. Vgl. Scheel 1984, S. 108.

388 Mainzer National-Zeitung vom 8. November 1793. (MR1, S. 107). 
lichte Flamme loderte auf dem Altare der Freiheit empor; man entriß den Sklaven diese scheußlichen Insignien der Feudalität; der Bürger Maire und die Munizipalen, mit ihren dreifürbigen Schärpen geziert, warfen sie in die Flammen und ließen sie vom Feuer verzehren. ${ }^{389}$

Die jakobinischen Akte der Symbolsetzung und -ersetzung waren im übrigen nicht minder umstritten als ihre politischen Konzepte, und mit zunehmender Dauer der Mainzer Republik waren auch die jakobinischen Symbole immer öfter Gegenstand gegenrevolutionärer Initiativen. Waren die anfänglichen Freiheitsbaumpflanzungen - zum allergrößten Erstaunen der kurfürstlichen Institutionen - auf großen Zuspruch bei der Bevolkerung gestoßen, so wich diese anfängliche Zustimmung zunăchst der Zurückhaltung und - nachdem die neuen Behörden auf diese Zurückhaltung mit Dirigismus reagiert hatten zuletzt dem Widerstand.

Eine solche Kontroverse entzindete sich beispielsweise an der Frage der Beseitigung von Wappen an offentlichen und privaten Gebäuden. Nachdem General Custine moniert hatte, in Mainz seien allenthalben noch feudale Symbole zu finden, obwohl nach dem fränkischen Gesetze alle Monumente der Feudalität aufgehoben ${ }^{390}$ seien, verordnete die Munizipalität am 17. Januar 1793, daß, falls die Eigentümer der mit Wappen versehenen Häuser binnen acht Tagen die an ihren Höusern sich befindenden Wappen nicht freiwillig abmachen lassen werden, man solche von Obrigkeits wegen auf ihre Kösten abnehmen werde. ${ }^{391}$ Die Hauseigentumer widersetzten sich dieser Verordnung: Teils, indem sie kunsthistorische Argumente ins Feld führten, teils, indem sie die Wappen nur kaschierten, nicht aber entfernten. Als die Munizipalităt dann aber ihrer Ankündigung gemäß zur Tat schritt, setzte sie sich dem Vorwurf des Vandalismus aus. Im Gegensatz zu den sehr positiv aufgenommenen, in Gestalt von Volksfesten abgehaltenen Freiheitsbaumpflanzungen zeigte sich dieser Versuch der Symboleliminierung, je länger er andauerte, als

keineswegs geeignet, revolutionäre Gesinnungen zu kräftigen. Wenn Maurermeister Johannes Roos mit seinen Gesellen auf Grund der Munizipalitătsverordnung vom 17. Januar daranging, die Wappen von den adligen Häusern herunterzuschlagen, die natürlich beträchtlichen kulturhistorischen und künstlerischen Wert besaßen, dann war ein gehơriges $\mathrm{Maß}$ an Gesinnungsreinheit vorauszusetzen, um mit diesem barbarischen Vorgehen einigermaßen zurechtzukommen. ${ }^{392}$

389 Der Volksfreund vom 15. Januar 1793. (MR1, S. 534).

390 MR1, S. 570.

391 MR1, S. 571.

392 Scheel 1989, S. 165. 
Im Zuge der hinhaltenden, nicht nur in Mainz erfolgreichen, ${ }^{393}$ von kunsthistorischen Argumenten gestlitzten Strategie der betroffenen Bürger, die vortrugen, die Wappen seien als Zierde der Gebäude schützenswert, entspann sich in der Folge auch ein beachtenswerter semantischer Konflikt: Matthias Metternich operierte in seinem Bürgerfreund als semantischer Stratege, indem er versuchte, die Wortbedeutung von Zierde gezielt politisch zu verengen: Das Wort sei so zu verstehen, daß es auf die Zeichen des Despotism ${ }^{394}$ nicht anwendbar sei. Wer so die Außenseite der Sklaverei noch schön, noch zierlich finden kann, dessen Herz und Seele ist zu keiner Erhabenheit, nicht einmal zum gemeinsten Gefühle der Menschenwürde fähig. ${ }^{395}$

Über bloße Passivităt hinaus kam es in der Folge auch zum aktiven Angriff auf die jakobinischen Symbole, wobei besonders der Freiheitsbaum Gegenstand von Attacken wurde. Diese nutzten nicht selten die durch die Revolutionäre selbst evozierte Symbolik, indem sie sie ins Gegenteil verkehrten. Die Tatsache beispielsweise, daß der von einer Jakobinermütze gekrönte Baum in der ersten Zeit ohne Wurzeln aufgestellt wurde, 396 war fur revolutionskritische Stimmen leicht auszuschlachten: Der bald welke, dürre Baum, im Boden verkeilt, wurde nun höhnisch als Symbol der Revolution akzeptiert, die so als kurzlebiger Revolutionsschwindel erschien. ${ }^{397}$ Eine gegenrevolutionăre Karikatur der Zeit legt einem Juden folgende Charakterisierung des Freiheitsbaumes in den Mund: Nau, wie soll mir's gefallen, s'is außer a Bäumche ohne Wurtzel, un a Kaepla ohne Kopf..$^{398}$

Über solche verbalen Ironisierungen hinaus war der Freiheitsbaum Ziel tätlicher Angriffe. Zur zweiten Freiheitsbaumpflanzung in Mainz kam es beispielsweise nicht zuletzt deshalb, weil Ende 1792 die rote Kappe vom Freiheitsbaum entkommen, der Baum selbst auch umgeworfen ${ }^{399}$ worden war. Wie in Frankreich wurden Freiheitsbaume auch in Deutschland haufig von Royalisten abgehackt, entweder heimlich, oder aber dort, wo sie wieder an die Macht gekommen waren, offiziell. Jakobiner mußten oft den Baum selbst beseitigen und, so in Bobenheim, zur Strafe den Stamm eine bestimmte Zeit auf dem Rücken tragen. Sogar der traditionelle Maibaum geriet bei den Revolutionsfeinden nun in Verdacht, „ein heimliches Freiheitszeichen zu

393 Vgl. Dumont 1993a, S. 358, besonders Fn. 172.

MR1, S. 572.

395 MR1, S. 572.

396 Erst später pflanzte man die Freiheitsbäume tatsächlich, das heißt mit Wurzeln.

397 Vgl. Kuhn 1982, S. 182-186.

398 Deutsche Jakobiner 1982, Bd. 3, S. 88.

399 Protokoll des MJK vom 27. Dezember 1792. (MR1, S. 440). 
$\operatorname{sein}^{4400}$ - ein indirekter Beleg für den nachhaltigen Erfolg der revolutionären Freiheitsbaumpflanzungen.

Wie es sich oben schon angedeutet hat, nahm die Behandlung der Revolutionssymbolik in der Mainzer Republik den gleichen Verlauf wie die gesamte Revolutionierungskampagne. Auf spontane Anfänge folgte Passivităt, dann Widerstand der Bevölkerung, auf diesen wiederum reagierten die neuen Machthaber mit Dirigismus und Repression. Dieser typische Verlauf kann abschließend mit der Behandlung des Revolutionssymbols Kokarde in der Mainzer Republik exemplifiziert werden: Am 29. März 1793 verlangte der Rheinisch-deutsche Nationalkonvent auf Antrag Anton Joseph Dorschs, des Präsidenten der Allgemeinen Administration, ultimativ, daß jedermann Kokarden tragen soll. ${ }^{401}$ In der Zeit der Ausweisung von Mainzern, die sich weigerten, den Eid auf Freiheit und Gleichheit zu schwören, war damit das ehemalige Symbol des begeisterten freiwilligen Bekenntnisses zur Revolution zum Aufenthaltsvisum in Mainz geworden. Der Zusatz Dorschs, daß alle einerlei Kokarden ${ }^{402}$ tragen sollten, verwies dann schon auf die zunehmende Verbreitung der weißen Kokarde, des royalistischen Symbols. Diejenigen, welche die weiße Kokarde oder jedes andere Aufruhrszeichen aufgesteckt haben sollten oder noch aufstecken würden, ${ }^{403}$ wurden sogar mit Dekret des Nationalkonvents vom 19. Mărz 1793 mit dem Tode bedroht - ubrigens unter Aussetzung der rechtlichen Garantien des Strafprozeßrechts. Politische Symbole, die zu Beginn der Mainzer Republik polyfunktional eingesetzt worden waren, nămlich einmal als åußeres Zeichen des Machtwechsels, andererseits aber auch als Zeichen der inneren Identifikation mit diesem, waren also zuletzt auf die erste Funktion reduziert. Unter der Androhung unmittelbarer physischer Gewalt waren sie zur Unterwerfungsgeste geworden, die die Funktion hatte, einen stattgehabten Machtwechsel öffentlich zu ratifizieren.

\subsubsection{Verbale Zeichen}

Sowohl was den Aufbruch zu einer demokratischen Öffentlichkeit als auch was den Niedergang politischer Kommunikation in der Mainzer Republik angeht, stehen in der heutigen Forschung die schriftlich realisierten Texte im Zentrum der Beachtung. Exemplarisch mag I. Stephans Einschătzung angefuhrt werden, nach der die persuasive Aktivität der Mainzer Jakobiner in de- 
ren „revolutionăre[r] Publizistik ${ }^{4404}$ gesehen wird und die Adressaten der Jakobiner stets als „Leser ${ }^{6405}$ verstanden werden. Solche Prädominanz der Literalităt ist jedoch weniger darauf zuruckzufuthren, daß es 1792 ausschließlich die schriftlich realisierten - gedruckten oder geschriebenen - Texte gewesen wären, die die beispiellose Politisierung der Mainzer Bevölkerung bewirkt hätten. Die rezent zu beobachtende Konzentration auf die Literalităt ist vielmehr in erster Linie dem Prinzip "verba volant, scripta manent/ verpflichtet: Die Verschriftlichung von Sprachzeichen ist nicht zuletzt ein Akt ihrer Konservierung, der zeitversetzte Dekodierung und Analyse ermøglicht. ${ }^{406}$

Im realen Kommunikationsgeschehen der Mainzer Republik stand der politischen Kommunikation mittels schriftlich realisierter Texte die direkte politische face-to-face-Interaktion aber zumindest gleichberechtigt zur Seite. Die kommunikativen Verhältnisse in der Mainzer Republik geben daher Anlaß, vor dem Mißverstanndnis zu warnen, idealtypische Konzepte wie die der oralen vs. der literalen Kultur, denen je besondere sprachliche Mittel zuzuordnen seien, ${ }^{407}$ als diskrete Phasen sprachhistorischer Abfolge reisieren zu wollen, die etwa von einer - vor der Verbreitung des Buchdrucks anzusetzenden - Phase der Prä-Literalităt über eine Phase der Literalităt zu einer für die Gegenwart sich andeutenden Phase der Post-Literalităt fuhrten. ${ }^{408}$ Die kommunikative Wirklichkeit war demgegenüber, nachdem die präliterale Phase einer primären, ausschließlichen Oralităt einmal verlassen worden war, stets durch Synchronie von Oralităt und Literalităt geprägt.

Für Frankreich hat B. Schlieben-Lange gezeigt, daß im 18. Jahrhundert eine literale und eine orale Kultur, mit einerseits urbanem, andererseits ruralem Schwerpunkt, zunächst synchron koexistierten. ${ }^{409}$ Diese bloße Koexistenz mutierte dann mit der Popularisierung und Politisierung der Aufklärung in eine Interdependenzbeziehung: Zum einen kam es zu einer Ausweitung der Literalităt, die durch Alphabetisierung immer größere Bevölkerungskreise erreichte. Zum anderen kam es aber auch zu einer Aufwertung der Oralität. Diese wurde - zumindest programmatisch - in Gestalt des rationalen Dialoges und der Diskussion zu einem Mittel, auf ơffentlich-egalitäre, nämlich

\footnotetext{
404 Stephan 1976, S. 101.

405 Stephan 1976, S. 123.

406 Vgl. z. B. Eco 1977, S. 51; Assmann/Assmann 1983, S. 266. Die technische Weiterentwicklung, die dazu fuhrte, daß Sprachzeichen auch ohne Verschriftlichung konservierbar wurden, hat dann auf die Massenkommunikation besonders des zwanzigsten Jahrhunderts bestimmenden Einfluß genommen. (Vgl. McLuhan 1968).

407 Vgl. Ong 1987, S. 42-61; 118-137.

408 Vgl. McLuhan 1968, S. 66-67.

409 Vgl. Schlieben-Lange 1983, S. 64.
} 
diskursive Weise einen vernunftgemaßen Konsens herzustellen. ${ }^{410}$ Beide, die Funktionsausweitung der Oralităt und die gesellschaftliche Durchsetzung der Literalität, gingen in engem Verbund vonstatten. Einerseits vollzog sich die Literarisierung neuer Bevölkerungsschichten zunächst einmal oral:

Die Durchsetzung yon Schriftlichkeit ist paradoxerweise gerade auf Verfahren und Kommunikationsnetze angewiesen, die zum Bereich der Müdlichkeit gehören. [...] Pointiert kőnnte man also sagen, daß der Aufschwung der Schriftkultur im 18. Jahrhundert ohne ein gut funktionierendes Netzwerk oraler Kommunikation nicht möglich gewesen wäre. ${ }^{411}$

Andererseits war aber auch die neue Oralităt weder ihrer Form noch ihrer Funktion nach mit der fruheren, rural dominierenden Oralität vergleichbar. Sie war nicht mehr allein auf die Bewältigung des Alltags gerichtet, sondern auf die sprachliche Konstitution und inhaltliche Bestimmung von Öffentlichkeit.

Die Wahl eines bestimmten, oralen oder literalen, Übermittlungsweges verbaler Zeichen ist durch den Versuch ihrer Emittenten motiviert, die aus den konstitutiven Merkmalen des jeweiligen Übermittlungsweges ${ }^{412}$ resultierenden spezifischen Möglichkeiten zu nutzen, die entsprechenden spezifischen Zwänge hingegen zu vermeiden bzw. durch die komplementäre Wahl eines anderen Weges - mit anderen spezifischen Möglichkeiten und $Z$ wängen - zu kompensieren.

Was die politische Kommunikation angeht, so liegen die Möglichkeiten der Literalităt, besonders nach der Erfindung des Buchdrucks, in der Tatsache, daß die Übermittlung von Texten von der unmittelbaren persönlichen Anwesenheit der Interaktionspartner unabhängig ist. Dadurch können politische Texte „schnell, massenhaft und weit ${ }^{4413}$ verbreitet werden. Die Zwänge der Literalităt liegen demgegenüber in der Notwendigkeit des Vorhandenseins spezieller, im 18. Jahrhundert noch nicht ubiquitărer Produktions(Buch- und Flugschriftendruck), Distributions- (Transportwege und Bezugsmöglichkeit) und Dekodierungstechniken (Alphabetisierung der intendierten Adressaten). Spiegelbildlich erscheinen demgegenüber unter den technischen Bedingungen des 18. Jahrhunderts die Möglichkeiten der Oralität, nämlich ihre Unabhängigkeit von solchen speziellen Techniken und, positiv gewendet, ihre Potenz, in Face-to-face-Kommunikation direkt Einfluß nehmen zu können. Solchen Mőglichkeiten stehen andererseits aber auch auf Seiten der Oralităt bestimmte Zwănge entgegen: zuvörderst die Notwendigkeit der per-

410 Vgl. Schlieben-Lange 1983, S. 65.

411 Schlieben-Lange 1983, S. 66.

412 Vgl. Schlieben-Lange 1983, S. 46-51; Ong 1987, S. 37-60, 97-108, 118-134.

413 Schlieben-Lange 1983, S. 49. 
sönlichen Anwesenheit der Interaktionspartner, woraus ein begrenzter Radius und daraus eine geringere Geschwindigkeit der Textdistribution resultieren. ${ }^{414}$

\subsubsection{Orale Kommunikation}

Die vergleichsweise starke Stellung, die der orale Kommunikationsweg im Sprachhandeln der Mainzer Republik einnahm, ist auf die oben genannten Faktoren zurlickzufuhren. Besonders, daß der literale Kommunikationsweg nur im Rahmen der durch den Alphabetisierungsgrad der Bevölkerung gesetzten Grenzen wirksam werden konnte, beschränkte alle Bemuhungen um die Etablierung und Distribution einer demokratischen Presse. Wie hoch dieser Alphabetisierungsgrad war, ist für das 18. Jahrhundert allerdings nicht leicht $\mathrm{zu}$ ermitteln und daher in der Forschung umstritten. Dem sehr skeptischen Urteil R. Engelsings, man könne es Ende des 18. Jahrhunderts ,als die Regel ansehen [...], daß die Bauern Analphabeten waren, [...] ${ }^{\text {c4 } 15}$ wird neuerdings immer entschiedener widersprochen. ${ }^{416}$ Auf der anderen Seite geht aber auch E. François' Auffassung, die auf der Grundlage von empirischen Erhebungen die These vom vorherrschenden Analphabetismus - zumindest für den Mittelrhein - zur „Legende“4417 erklärt, zu weit. François nimmt „das Unterschreibenkönnen zum Zeichen einer vollstăndigen Alphabetisierung ${ }^{6418}$ und „eine selbst ungelenke Unterschrift [...] als Zeichen für die Fähigkeit zum Lesen [...].“419 Mit Blick auf die sozial- und mediengeschichtliche Forschung der jüngsten Zeit urteilt $P$. von Polenz dagegen vorsichtig abwägend, wenn er den „Anteil der Analphabeten und Halbalphabeten (nur unterschriftsfähig) [...] Ende des 18. Jh. noch auf zwei Drittel bis drei Viertel [...] $]^{\star 420} \mathrm{der}$ Bevölkerung beziffert.

414 Die absolute Dominanz der oralen politischen Kommunikation im zwanzigsten Jahrhundert resultiert aus der Tatsache, daß die positiven Möglichkeiten der Oralität nach wie vor existieren, ohne jetzt, nach der Entwicklung neuer Massenmedien, jedoch durch den Zwang unmittelbarer personaler Anwesenheit der Interaktionspartner begrenzt zu sein.

415 Engelsing 1973, S. 87.

416 U. Maas (1995, S. 249) charakterisiert diese Sichtweise als „Mythos vom schriftfernen Land“. Vgl. auch Knoop 1995; Gessinger 1995.

417 François 1977, S. 299.

418 François 1977, S. 279.

419 François 1977, S. 280. Mit Blick auf die franzðsische Enquête Maggiolo wendet B. Schlieben-Lange (1983, S. 67) ein: „Freilich laßßt sich aus der Tatsache, daß jemand seinen Namen schreiben kann, noch nicht schließen, daß er uber eine allgemeine Lese- und Schreibfahigkeit verfligt." von Polenz 1994, S. 45. 
Auch wenn der Bevölkerungsanteil der An- und Halbalphabeten heute schwer präzise zu ermitteln ist, so läßt sich doch an den Texten der Mainzer Republik indirekt ablesen, daß die Textemittenten damit rechnen mußten und sehr wohl damit rechneten, daß die intendierte Adressatenschaft bei weitem noch nicht in vollem Umfange alphabetisiert war. Dies belegt nicht nur die Tatsache, daß die Beherrschung der grundlegenden Kulturtechniken programmatisch gefordert wurde (Jeder Mensch muß lesen, schreiben und rechnen können, wer das nicht kann, wird alle Tage betrogen ${ }^{41}$ ), sondern dies zeigen auch verschiedene Wahlordnungen, bei denen auf den verbreiteten Analphabetismus explizit Rücksicht genommen wurde. Die von G. Forster entworfene Wahlordnung vom Februar 1792 sah beispielsweise vor [Hervorhebungen J.H.].422

§ 12. Sobald die zum Anfang der Wahl bestimmte Stunde geschlagen hat, nimmt der älteste Mann in der Versammlung, welcher schreiben kann, den Vorsitz; die drei nächsten im Alter, welche schreiben kJnnen, übernehmen das Geschäft der Stimmensammlung [...].

\$ 14. Keiner darf einen geschriebenen Stimmzettel mitbringen, sondern alle sollen ihre Zettel auf dem Tische des Präsidenten schreiben. Diejenigen, welche nicht schreiben können, lassen sich die Namen derer, welchen sie ihre Stimmen geben wollen, von den Stimmensammlern in Gegenwart eines Freundes, welcher lesen kann, aufzeichnen.

$\S 36$. Sobald es auf den bestimmten Morgen acht Uhr geschlagen hat, nimmt jede Urversammlung in einer ihr anzuweisenden Kirche unter dem Vorsitz des ältesten anwesenden Stimmfähigen, welcher schreiben kann, ihren Anfang [...].

Das Wissen um verbreitetes Analphabetentum war für die Textemittenten der Mainzer Republik sicher ein Grund, literaler politischer Kommunikation nicht ausschließlich zu vertrauen. Andererseits läßt sich jedoch ,immer in revolutionären Umbruchszeiten eine Verstärkung der Bedeutsamkeit mündlicher Kommunikationsformen feststellen", ${ }^{423}$ auch in modernen, weitgehend alphabetisierten Gesellschaften. Der Grund dafur liegt - uber die oben diskutierte Funktion der Vermeidung von Kommunikationsrestriktionen hinaus in einer positiven Funktion oraler Kommunikation in der Politik, nämlich der Möglichkeit der unmittelbaren Einflußnahme auf die Adressaten, womöglich sogar die direkte Handlungsauslösung. Daß orale Kommunikation der politischen Aktion sehr viel näher steht als literale, ist besonders für die Französische Revolution herausgestellt worden:

421 Georg Wedekind am 28. Oktober 1792 im MJK. (MR1, S. 76). 
Das Zusammentreffen des Ideals des Dialogs mit der Wirklichkeit oraler Traditionsformen in historisch erstmals bedeutsamen Bevolkerungsschichten [...] führten zu einer historisch in dieser Konzentration vielleicht einmaligen Wirksamkeit oraler Kommunikationsformen. Es entsteht in diesem Zusammenhang eine neue Qualität: Die Nähe von Diskussion und Aktion wird zu einem der tragenden Elemente der Revolution. ${ }^{424}$

Neben dem Wissen um die durch Analphabetismus begrenzte Fähigkeit der Adressaten, literale Texte zu rezipieren, war es zweifellos diese nicht zuletzt aus dem französischen Vorbild gewonnene Einschätzung ihrer revolutionären Potenz, die in der Mainzer Republik zur zeitweiligen Dominanz der Oralität führte. Nicht vergessen werden darf aber auch, daß nicht wenige Aktivisten der Mainzer Republik in der Tradition der Rhetorik standen und diese - wenn nicht in politischer Rede, so doch in Vorlesung oder Predigt - auch angewandt hatten. Dem entsprach auf der anderen Seite ein seit langem geubtes (nur-)auditives Rezeptionsverhalten größerer Bevölkerungsanteile.

Ohne also die Bedeutung individueller oder kollektiver Lektüre politischer Schriften gering veranschlagen zu wollen, kann für die Mainzer Republik von Dominanz der Oralităt doch insofern gesprochen werden, als die weit überwiegende Anzahl derjenigen Situationen, in denen politische Persuasion stattfand, durch Mündlichkeit bestimmt waren. Einige dieser Situationen sollen im folgenden besprochen werden.

An erster Stelle steht derjenige Situationstyp, der alle anderen zu dominieren scheint: Die politische Versammlung. Die zentralen Institutionen der Mainzer Republik, der Jakobinerklub und der Rheinisch-deutsche Nationalkonvent, tagten in öffentlichen Sitzungen, in denen primär mündlich kommuniziert wurde. Gerade der dynamische erste Jakobinerklub, der noch nicht institutionell erstarrt war wie der zweite oder wie der Nationalkonvent, war dabei nicht nur durch die monologische Oralităt von Reden, sondern auch durch die dialogische Oralität des offenen, mitunter konfrontativen $\mathrm{Ab}$ tauschs von Argumenten geprägt. Nicht umsonst waren es diese Reden und Debatten im Jakobinerklub, die Wirkung auf die Bevölkerung ausübten. Um politische Versammlungen handelte es sich auch bei den oben in anderem Zusammenhang erwähnten revolutionären Feiern, besonders den Freiheitsbaumpflanzungen. Diese waren nicht nur geprägt von einer verdichteten, klug eingesetzten revolutionären Symbolik, sondern auch von nicht minder wirksamer sprachlicher, und zwar oraler Kommunikation. Wie exemplarisch der Bericht über die Freiheitsbaumpflanzung in Dirmstein belegt, waren mündliche Kommunikationsformen wie Reden, Singen oder kollektives Rufen integrale Bestandteile des Festablaufs: 
Diese Feierlichkeit eröffnete Bürger Endemann im Schloßhofe mit einer zweckmäBigen Rede, welcher der dortige verdienstvolle Rector mit den, mit dreifarbigen Bändern gezierten Schulkindern, der größte Teil der Inwohner und viele benachbarte Freunde aus Grünstad, Frankenthal, Laumersheim, Gerolsheim beigewohnt haben. Von da ging der Zug mit Musik in das Ort bis zum Rathaus, wo unter dreimaligem Ausrufen "Es lebe die Franken-Nation, es lebe Bürger General Custine und die Wormser Munizipalität! « der Freiheitsbaum aufgerichtet ist. Bürger Frank und er (Lewer), Gemeindeprokurator, hätten sodann Reden an das Volk gehalten, die dortigen Bürger gaben ein ländliches Abendessen, wobei die wohlgebildete Schuljugend einige Freiheitslieder abgesungen hat. ${ }^{425}$

Um eine primär nicht politisch veranlaßte Versammlung handelt es sich beim Gottesdienst, doch wurde auch er in der Mainzer Republik revolutionär-persuasiv genutzt, da sich nicht selten Geistliche beider Konfessionen für die Revolution erklärten und im Gottesdienst die Vereinbarkeit von Christentum und Demokratie demonstrierten. Sowohl bei den zu diesem Zweck vorgetragenen »Freiheits- und Gleichheitspredigten« als auch bei Gebeten für General Custine und die Mainzer Jakobiner handelte es sich um die Nutzung traditioneller oraler Kommunikationsformen, deren potentielle Wirkung um so höher einzuschätzen ist, als die geistlichen Textemittenten auf ihr überlegenes Prestige und einen Vertrauensbonus bei den Adressaten zählen konnten. ${ }^{426}$

Eine weitere Institution, die revolutionäre Inhalte direkt - darstellend und, soweit sprachlich, oral - vermittelte, hatte der Jakobinerklub 1793 mit dem Mainzer National-Bürger-Theater ${ }^{427}$ ins Leben gerufen, eine Neugrlindung, nachdem das renommierte Mainzer Nationaltheater seinen Betrieb nach der französischen Besetzung eingestellt hatte. Überzeugt davon, daß die Schauspielkunst die wirksamste[...] aller Künste $e^{428}$ sei, gingen die Mainzer Jakobiner „einen entscheidenden Schritt uber das Schillersche Konzept von der Bühne als einer "moralischen Anstalt» hinaus"429 und strebten ,die enge Verflechtung der gesellschaftlich-politischen Aktionen mit den assthetischen und kulturellen Intentionen innerhalb der revolutionären Praxis ${ }^{\text {c430 }}$ an. Daß hier besonders der Versuch motivierend war, einen im Vergleich zur politischphilosophischen Argumentation völlig anderen Wirkungsmechanismus zu

425 Wormser Munizipalitătsprotokoll vom 23. November 1792. (Vgl. Dumont 1993a, S. 157).

426 Nicht unăhnlich den Lehrern, die im Unterricht ihre Unterstutzung der französischen Revolution demonstrierten.

427 Vgl. Steiner 1973; Scherpe 1975, S. 184-194; Stephan 1976, S. 165-170; Scheel 1989, S. 164-165; Dumont 1993a, S. 159-161.

428 Hermann Theyer am 20. Januar 1793 im MJK. (MR1, S. 579).

429 Stephan 1976, S. 167.

430 Steiner 1973, S. 83. 
initiieren, demonstriert Hermann Theyers Gründungsaufruf im Jakobinerklub:431

Zwar hat man in Eurer Gesellschaft so viel und so warm für die Grundsätze der Freiheit und Gleichheit gesprochen, daß ich glaube, daß man wenigstens jetzt nichts Wichtiges hinzufügen könne. Aber habt Ihr vergessen, daß, wenn wir auch die Vernunft unsrer Widersacher zum Schweigen gebracht haben, wir noch einen Feind in ihnen besiegen müssen, der um so widerspenstiger und delikater ist, je versteckter seine Motive, je weniger die Mittel und je unzugänglicher die Wege, ihn anzugreifen, sind: ich meine das menschliche Herz. Man kann nicht zweierlei Feinde mit einerlei Waffen schlagen; Abstraktionen sind für die Vernunft, Gefühle für das Herz; durch die kalte Weisheit wird jene, dieses durch das Angenehme der schönen Künste besiegt. Doch - was spreche ich. Ihr seid ohne Zweifel mit mir über die Wahrheit dieses Satzes einig, sonst hättet Ihr nicht erst jüngst Euren lauten Beifall einer Gesellschaft von Freunden gegeben, die sich vereinigt hat, die Herzen ihrer Mitbürger durch eine Kunst zu stimmen, die unwidersprechlich am sichersten und allgemeinsten wirkt: es ist die Schauspielkunst. Eben diese Kunst, welche von der schlauen Despotie nur zu lange zum süßen Mohnsafte umgeschaffen war, unsre für große Dinge gewiß nicht unempfindlichen Seelen in tatenlosen Schlummer einzuwiegen, sei das Gegengift für die von ihr selbst geschlagenen Wunden!

Das Mainzer National-Bürger-Theater, das mit Laiendarstellern arbeitete und kollektiv geleitet wurde, brachte vom 17. Februar bis zum 1. Juli 1793 mehrere neue Stücke ${ }^{432}$ zur Auffuhrung, die auf dem Wege direkter, oraler Kommunikation für Republik und Demokratie warben, indem sie deren Vorzüge herausstellten und das »Ancien Régime« lächerlich zu machen suchten.

Während die bislang angeführten Situationen oraler Kommunikation durch umfangreichere Adressatengruppen gekennzeichnet waren, an die die Textemittenten sich richteten oder innerhalb deren die oralen Kommunikationsprozesse abliefen, ist der letzte hervorzuhebende Situationstyp durch die Kleingruppe, bis hinunter zur Zweier-Gruppe, charakterisiert. Diese revolutionäre Persuasion in der Kleingruppe, in der die Partnerdistanz, auch der Grad an Öffentlichkeit, am geringsten ist, war für das Sprachhandeln in der Mainzer Republik typisch. Nach dem franzősischen Vorbild der lecteurs patriotes oder missionaires patriotes ${ }^{433}$ hatte Custine schon in den ersten Tagen der Mainzer Republik nach "Predigern« der Revolution verlangt. ${ }^{434}$ Auch Eulogius Schneider hatte von den Mainzern gefordert: Sendet Apostel auf die

431 Hermann Theyer am 20. Januar 1793 im MJK. (MR1, S. 577-583, hier S. 578).

432

433

Vgl. Steiner 1973.

Vgl. von Polenz 1994, S. 400.

434 Vgl. oben, S. 69. 
Dörfer und Flecken, prediget laut das Evangelium der Freiheit. ${ }^{435}$ Diese Aufrufe wurden in der Folgezeit durchaus befolgt, ob nun als gezielte Aktivităten des Jakobinerklubs, auch der Zivilbehörden, oder als Initiativen Einzelner, beispielsweise der Zuhörer im Jakobinerklub, die dann als Multiplikatoren für die Weitergabe des Gehörten sorgten. ${ }^{436}$ Zahlreiche Demokraten ließen es sich jedenfalls angelegen sein, den direkten persőnlichen Kontakt zu den oft skeptisch-abwartenden Einwohnern zu suchen und sie durch Information und Appell, in Gespräch und Diskussion fur die Revolution zu gewinnen. Dieses Verfahren wurde nicht nur in der Stadt geübt, sondern gerade auch auf dem Lande. ${ }^{437}$ Mainzer Jakobiner zogen als Volkslehrer, als Emissäre $e^{438}$ des Klubs auf das Land, wo sie von Landjakobinern unterstützt wurden.

So besuchten - gerade auf dem Lande - viele Jakobiner gezielt Märkte und Wirtshäuser, um dort Flugblätter und -schriften zu verteilen. Sie ließen es jedoch nicht bei der bloßen Weitergabe von Propagandamaterial bewenden, sondern verwickelten ihre Mitbürger in politische Diskussionen und suchten sie von der absoluten Notwendigkeit und Richtigkeit der »Fränkischen Konstitution« zu überzeugen. ${ }^{439}$

Alle diese Formen politischer Persuasion stellten für Deutschland im 18. Jahrhundert eine Innovation dar, lediglich vergleichbar mit der weit zurückliegenden Reformations- und Bauernkriegssituation. ${ }^{440}$ Es war unter den Bedingungen des Absolutismus nicht mőglich gewesen, offentlich politische Werbung zu betreiben. Erst jetzt konnte auf die politische Überzeugung der, nun im Sinne der Volkssouveränităt ernst genommenen, Adressaten gezielt werden. Daß dies nicht allein durch Schriften, sondern mündlich geschah,

435 An die Freunde der Freiheit zu Speyer, Mainz und Worms In: Argos, 1. Halbjahr 1792, Nr. 36. (MR2, S. 88).

$436 \mathrm{Vgl}$. Scheel 1989, S. 90.

437 Vgl. zur Landagitation Scherpe 1975, S. 161-171; von Polenz 1994, S. 400.

438 Vgl, z. B. das Protokoll des MJK vom 29. November 1792 (MR1, S. 310): 5. Der Bruder Pabe machte den Vorschlag, daß man diesen Winter hindurch verschiedene Mitglieder von unsrer Gesellschaft ausschicken möge, um das Volk zu belehren und es zu fragen, ob es frei sein wolle oder nicht. [...] 7. Ein Mitglied des Wachthabenden Ausschusses las einen Aufsatz vor, worin er zeigte, was für Mittel man brauchen müsse, das Landvolk über Freiheit und Gleichheit zu belehren. [...] 9. Ferner machte das Mitglied die Motion, daß man bei solchen Emissaires immer einen von den ehemaligen sogenannten gemeinen Leuten mitschicken, sodann einen andern, der lesen und schreiben könne, worüber die Gesellschaft mit der Administration sich besprechen könne. 10. Es wurde die Motion gemacht, daß die Gesellschaft den Emissaires Vorschrift erteilen solle, wo(r)nach sich selbe richten solle $[n]$.

440 Vgl. von Polenz 1994, S. 400. 
machte den Persuasionsversuch nur wirkungsvoller, indem er an traditionelle orale Kommunikationsgewohnheiten anschloß. Die Brisanz jedoch, die die unmittelbare orale Persuasion in Frankreich erlangen konnte, wo stets die Nähe zur revolutionären Aktion gegeben war, fehlte in Mainz. Das Ziel der intensiv betriebenen oralen politischen Persuasion war ja in Mainz letztlich nicht Revolution, sondern Affirmation, wenn auch in diesem Falle Affirmation der Revolution: Es ging hier zunächst um die innere Bejahung, spăter dann um die außerliche Sanktionierung des auf militärischem Wege schon Erreichten.

\subsubsection{Semi-orale Kommunikation}

Orale und literale Kommunikationsformen ergänzten einander in der Mainzer Republik nicht nur in der Form, daß sie - je nach den Rezeptionsmöglichkeiten der Bevölkerung - komplementăr eingesetzt wurden, sondern sie waren in aller Regel eng aufeinander bezogen. Der bevorzugte Weg, revolutionäre Inhalte zu verbreiten, bestand beispielsweise - vor allem auf dem Land - darin, die Revolutionsschriften vorzutragen oder vorzulesen. Dies konnte spontan geschehen, wie es beispielsweise für Dromersheim ${ }^{441}$ oder Sprendlingen ${ }^{442}$ berichtet wird, oder aber auch administrativ angeordnet werden:

Hofmann macht den Vorschlag, [...] daß die Pfarrer die patriotischen Schriften selbst befördern und den Inhalt bekanntzumachen genötigt würden. [...] Meuth [...] macht den Vorschlag, Aufklärungsschriften durch den Schultheiß ablesen zu lassen $[\ldots]^{443}$

Tatsächlich wurden in den oben angeführten Kommunikationssituationen, in denen Oralität dominierte, nur in der Minderheit der Fälle, etwa der spontanen Diskussion oder dem Gespräch, primär orale Texte hervorgebracht. Meist jedoch, ob es sich nun um Reden, Schauspiele oder Lieder handelte, war die Grundlage ein literal vorliegender Text. Die neue, funktional auf den politischen Verband bezogene Oralităt war formal also nicht selten eine sekundäre, das heißt, sie war Oralisierung literaler Texte.

Der entgegengesetzte Fall, die Literalisierung oraler Texte, ist nicht minder häufig zu beobachten. Ein Beispiel hierfur ist das Protokoll, hier z. B. die Protokolle des Jakobinerklubs und des Rheinisch-deutschen Nationalkonvents, ${ }^{444}$ wo das primär gesprochene Wort sekundär verschriftlicht wurde.

441 Vgl. Dumont 1993d, S. 114.

442 Vgl. Keim 1993, S. 131-132.

443 MR1, S. 145-146.

444 Vgl. MR1; MR2. 
Auch solche Literalisierungen ${ }^{445}$ geschahen hăufig, und in persuasiver Intention:

Der Präsident bat den Bruder, seine Rede aufs Büro zu legen, um sie ins Teutsche übersetzen zu lassen. Der Bruder antwortete, daß er solches sogleich nicht könne, weil die Rede für jeden andern unlesbar geschrieben sei, er wolle aber selbige rein abschreiben und sodann der Gesellschaft überliefern. Ein Mitglied begehrte, diese Rede drucken zu lassen. Angenommen. ${ }^{446}$

Sowohl aus der Literalisierung von Oralem als auch aus der Oralisierung von Literalem resultieren spezifische Zwischenformen zwischen Oralität und Literalität, die als Semi-Oralität $t^{447}$ bezeichnet worden sind. In solchen semioralen Kommunikationsformen darf eine Typik der Epoche gesehen werden.

In der Eranzossischen Revolution laufen all diese widersprüchlichen Tendenzen der Aufklärung zusammen und werden nun in der Einheit der Nation und der Egalität der Schichten als widersprüchlich erlebt. Die aus der Revolutionszeit überlieferten Dokumente sind gekennzeichnet durch ein ständiges Oszillieren zwischen Mündlichkeit und Schriftlichkeit. Es ist manchmal unausmachbar, ob im Einzelfall ein schriftlicher oder mündlicher Text am Anfang gestanden hat. Die Verschriftlichungen und Oralisierungen wechseln, mitgerissen von der allgemein empfundenen $\mathrm{Be}$ schleunigung der Zeit, diese vielleicht auch mit tragend, in schneller Folge. ${ }^{448}$

Solche spezifischen, zwischen Literalität und Oralität oszillierenden Kommunikationsformen sind nicht nur furr die Französische Revolution kennzeichnend, sondern bestimmen auch das Kommunikationsgeschehen in der Mainzer Republik. Es sind Formen, die sich unter den technischen Bedingungen des 18. Jahrhunderts, das eine direkte, uberregionale Distribution von

445 Auch das Gegenteil, die bewußte Abwehr von Literalisierung, kommt vor, etwa wenn der Protokollant angewiesen wird, nicht zu protokollieren. In der Mainzer Republik trat auch ein Fall ein, in dem die schon geschehene Protokollierung zurückgenommen wurde, um massiven Streit im MJK zu vertuschen: [...] die Protokolle der beiden fatalen Sitzungen wurden aus unserm Tagebuch herausgerissen und die Gesellschaft gieng froh auseinander. (Brief von Georg Forster am 20./22. Januar 1793 an seine Frau. (Forster 1989 [1793], Bd. 17, S. 309)).

446 Protokoll des MJK vom 17. Dezember 1792. (MR1, S. 385) Weitere Belege: [...] nach dessen Endigung bestieg der B[ürger] CTommissaire] Reipel die Tribüne und hielt eine Rede. Die Gesellschaft ersuchte den B [ruder] Forster und B[ruder] Dorsch, den beruhigenden vortrefflichen Inhalt dieser Rede dem Publikum durch den Druck bekanntzumachen. Angenommen. (Protokoll des MJK vom 6. Januar 1792. (MR1, S. 490)) Es wurde ferner beschlossen, daß die Bürger Metternich, Forster und Hofmann ihre über die Vereinigung gehaltnen Reden [zum] Drucke übergeben sollten [...]. (Protokoll des Rheinisch-deutschen Nationalkonvents vom 21. Mărz 1793. (MR2, S. 463)).

448 Schlieben-Lange 1983, S. 66. 
Oralem noch nicht kannte, als hoch leistungsfahig erwiesen, indem sie in der Kombination die Möglichkeiten des einen Kommunikationsweges nutzten und gleichzeitig die Zwănge des anderen vermieden: Die Literalisierung von Oralem ermoglichte dessen schnelle, massenhafte und uberregionale Distribution. Die Re-Oralisierung von Literalisiertem kompensierte dagegen den verbreiteten Analphabetismus und stellte die in der politischen Kommunikation gewuinschte Direktheit des Emittenten-Adressatenbezuges her. ${ }^{449}$

Die flächendeckende politische Kommunikation der Mainzer Republik war demnach durch die verschränkte, die jeweiligen Distributionsnachteile kompensierende Nutzung oraler und literaler Kommunikationsverfahren gekennzeichnet. Welch intensive Langzeitwirkung ein solches Verfahren auslosen konnte, exemplifiziert F. Dumont mit dem Bericht des preußischen Feldpredigers Samuel Christoph Wagener, der 1794 höchst uberrascht ist, einen rheinhessischen Bauern aus einer Straßburger Rede Dorschs zitieren zu hören:

"Er hat also die Rede gelesen? Wie kam denn die in Seine Hände? « Und die Antwort: »Die Mainzischen Klubisten haben sie, nebst vielen anderen Reden, ausgeteilt unter uns Landleute«. Wagener fragt weiter: "Wenn Er doch noch etwas daraus behalten hätte, und mir erzählen könnte«, worauf der Bauer meint: » $O$, ich habe fast die ganze Rede noch im Gedächtnis, denn was mir gefällt, das lese ich gern zweimalı und fährt fort, Dorschs Definition der »gesetzmäßigen Freiheit« wörtlich wiederzugeben. ${ }^{450}$

\subsubsection{Literale Kommunikation}

Wenn oben herausgestellt wurde, daß der orale Übermittlungsweg sprachlicher Zeichen im politischen Kommunikationsgeschehen der Mainzer Republik dem literalen gleichgestellt werden muß und in wichtigen Kommunikationssituationen sogar dominierte, soll dies die Bedeutung der schriftlich realisierten Texte keineswegs schmälern. Die Tatsache der in der Mainzer Republik verbreiteten Semi-Oralitat konnte sogar belegen, daß Literalität hier nicht unbedingt mit der sonst zu beobachtenden „Reduktion von Interaktionalität ${ }^{\text {‘451 }}$ verbunden war, sondern daß die literal realisierten Texte systematisch zur Grundlage einer intensivierten oralen Interaktion gemacht wurden. Die in wesentlichen Teilen oral vorgetragene Persuasionsoffensive, die in Mainz 1792/93 stattfand, war nur vor dem Hintergrund literal realisierter

449 Über diese Distributions-Vorteile hinaus lassen sich Texte beobachten, die SemiOralität intentional anstreben, etwa um Re-Oralisierung zu erleichtern oder auch bei der Lektlire den Eindruck unmittelbarer Oralităt entstehen zu lassen.

451 Vgl. Beck 1973, S. 85-88. 
Texte durchfuhrbar und ist aus heutiger Sicht auch allein an diesen Texten ablesbar. ${ }^{452}$

Die potentielle und reale Breitenwirkung literaler Texte ging dabei weniger von den an unterschiedliche interne Rezipientenkreise gerichteten (hand)geschriebenen ${ }^{453}$ als vielmehr von den auf externe Wirkung zielenden gedruckten Texten aus. ${ }^{454}$ Sie waren es, die den Mainzer Jakobinern die Demokratie zu garantieren schienen, ${ }^{455}$ und sie sind es, die in der Geschichte der öffentlichen Sprache in Deutschland eine Zäsur markieren. ${ }^{456}$ Die ungeheure Anzahl an Druckschriften, die in Mainz ab Oktober 1792 schlagartig erschienen oder in Umlauf gebracht wurden, hat in der Vergangenheit mehrfach das Interesse der Forschung gefunden, weshalb im folgenden nur das hervorgehoben werden soll, was für den weiteren Argumentationsgang von Bedeutung erscheint. Dabei wird unterschieden zwischen periodischen und unperiodischen Druckschriften.

452 Auskunft uber historische Oralităt vor der Erfindung der Schallaufzeichnung läßt sich nur indirekt erlangen, entweder aufgrund ihrer expliziten Thematisierung in schriftlich uberlieferten Texten oder aber aufgrund ihrer sprachlichen Reflexe in gleichfalls schriftlich überlieferten Texten.

453 Hierher gehören die der verwaltungsinternen Kommunikation dienenden Aktennotizen, Briefe und Protokolle, aber auch die umfangreichen Briefwechsel zwischen Privatpersonen.

454 Die Publizistik der Mainzer Republik ist in vollem Umfang zuletzt leicht zugånglich gemacht worden: Vgl. Stadtbibliothek Mainz (Hrsg.): Die Schriften der Mainzer Jakobiner und ihrer Gegner (1792-1802). Revolutionäre und gegenrevolutionăre Proklamationen und Verordnungen, Reden, Flugschriften, $\mathrm{Ab}$ handlungen, Schauspiele, Gedichte und Lieder, Reiseberichte, Zeitungen und Zeitschriften aus der Zeit der Mainzer Republik (1792/93) und der linksrheinischen Revolutionsbewegung bis zur fruhen Franzosenzeit in Rheinhessen und der Pfalz (1797-1802). Microfiche-Edition. Munchen [usw.] 1993. [= SMJG].

455 Einen Beleg fur solchen Presseoptimismus stellt auch der folgende Text dar, der sich in der neugegrundeten Mainzer Zeitschrift Der fränkische Republikaner (Nr. 2 vom 23. November 1792, S. 11) findet: Es sagte mir neulich ein superkluger und supergelehrter Professor: das republikanische Wesen tauge nichts, oder wenigstens: könne es nicht halten; hievon hätten wir die ältesten Beispiele in der Geschichte von den Römern und Griechen und eben so würde es auch bei den Franken und ihren Nachahmern gehen. Ich antwortete aber diesem superklugen Manne nur mit der einzigen Frage: ob denn auch die Römer und Griechen Drukkereien gehabt hätten? Hierauf schwieg er beschämt, und unsere Unterredung hatte ein Ende.

„Eine wirkliche, kritische politische Őffentlichkeit hat es zur Zeit der Französischen Revolution nur sporadisch in Ansătzen gegeben, vor allem in der »Mainzer Republik« [...]." (von Polenz 1994, S. 40). 


\subsection{Periodische Druckschriften}

Wie oben ${ }^{457}$ gezeigt, war die Ausgangslage des Mainzer Pressewesens ${ }^{458}$ vor der Mainzer Republik unter den Bedingungen des absolutistischen Arkansystems dürttig. Die beiden einzigen, zudem zensierten Periodika waren ein Nachrichtenblatt (Mainzisches Intelligenzblatt, mit kurfürstlichem gnädigsten Privilegium) und eine politische Zeitung (Privilegirte Mainzer Zeitung).

Vollständig verăndert zeigte sich in der Mainzer Republik zunächst das Zeitungswesen: Das Mainzische Intelligenzblatt wurde fortgefuhrt, erschien aber bald nach der Besetzung mit verănderter inhaltlicher Ausrichtung und unter dem modifizierten Titel Mainzer Intelligenzblatt mit provisorischer Genehmhaltung der fränkischen Nation, später dann [...] mit Genehmhaltung der allgemeinen Administration. Auch die politische Zeitung wurde fortgeführt, allerdings unter dem neuen Titel Mainzer Zeitung (ab dem 30. Oktober 1792 Mainzer National-Zeitung) und unter der Leitung von Georg Wilhelm Böhmer, Custines Sekretär, was dem Blatt einen offiziősen Charakter verlieh.

Die Umgestaltung der Mainzer Presselandschaft wurde nicht zuletzt aber durch verschiedene Neugründungen bewirkt. Dies waren zum einen Matthias Metternichs politische Zeitung Der Bürgerfreund, zum anderen vier politische Zeitschriften: Der Patriot (Hrsg.: Georg Wedekind), Der fränkische Republikaner (Hrsg.: Dominikus Meuth und Kaspar Hartmann), Die neue Mainzer Zeitung oder der Volksfreund (Hrsg.: Georg Forster) und Der Kosmopolitische Beobachter (Hrsg.: Anton Fuchs).

Damit hatte sich infolge des politischen Umbruchs die Presselandschaft in Mainz erheblich verandert. Die neuen Presseorgane gingen vor allem aus dem Umkreis des schon am 23. Oktober 1792 gegründeten Mainzer Jakobinerklubs [...] hervor. Gleichwohl vertraten sie im einzelnen unterschiedliche Positionen und richteten sich an verschiedene Zielgruppen. Während Metternich sich mit dem "Bürgerfreund" vor allem an die Landbevolkerung wandte, hatte »Der fränkische Republikaner« den gehobenen Mittelstand im Auge. Und "Der Patriot«, den man "das theoretische Organ der Mainzer Jakobiner" genannt hat, richtete sich an die Gebildeten und Intellektuellen. ${ }^{459}$

Wie J. Wilke und F. Förster in ihrer eingehenden, auch inhaltsanalytisch verfahrenden Untersuchung gezeigt haben, ${ }^{460}$ war die jakobinische Mainzer Presse in mehrfacher Hinsicht innovativ und zukunftsweisend, so daß sie auf

457 Vgl. Kap. 4.1.1 dieser Arbeit.

458 Vgl. die umfassende Darstellung bei Wilke/Förster 1993. Vgl. außerdem z. B. Roth 1930; Zeitin 1935; Dreyfus 1968; S. 484-504; Grab 1969, S. 124-128; Dumont 1993a, S. 138-151.

460 Vgl. Wilke/Förster 1993, S. 176-196. 
verschiedenen Gebieten als Vorlăuferin der modernen Presse anzusehen ist. Dies gilt furr die Ansătze zu Pressefreiheit und zu einem im 18. Jahrhundert noch neuen journalistischen Selbstverstăndnis, zum anderen aber auch für die formale Organisation und die inhaltliche Ausrichtung der Blätter: Neu ist in der Mainzer Presse nicht nur der Leserbrief, sondern beispielsweise auch eine einsetzende kritische Berichterstattung über die Innen-, besonders auch die Lokalpolitik. Gerade im Übergang von einer referierenden Berichterstattung zum Meinungsjournalismus ,klindigte sich einer der bedeutsamsten pressehistorischen Umbrüche an. ${ }^{\text {"461 }}$

Aufgrund der ins Auge springenden Modernität ist es besonders hervorzuheben, daß die große Anzahl von Zeitungen und Zeitschriften nicht aus wahllos sich überlagernden publizistischen Aktivitäten resultierte, sondern $\mathrm{da} ß$ eine ausgeprägte Zielgruppenorientierung festzustellen ist. Auf die verschiedenen Bevölkerungsgruppen, die die Mainzer Jakobiner als potentielle revolutionăre Akteure und somit als Adressaten der prorevolutionären Persuasion ausgemacht hatten, war jeweils ein eigenes Periodikum ausgerichtet. Wie die Graphik 2 zeigt, war die jakobinische Presse gleichwohl nur von kurzer Dauer. Noch vor dem Verbot vom 17. April $1793^{462}$ hatten alle Zeitschriften ihr Erscheinen eingestellt, danach durfte nur noch das Intelligenzblatt erscheinen. Als Gründe für dieses rasche »Pressesterben« sind ein mangelnder Absatzmarkt und mangelnde Nachfrage genannt worden. ${ }^{463}$ Vor allem aber dürfte das sich verändernde politische Klima in der Mainzer Republik dafür verantwortlich gewesen sein. Aufklärerisch-persuasiv motiviert, war die Gründung von Periodika ein typisches Ergebnis der ersten, optimistisch-liberalen Phase der Mainzer Republik. Als diese dann in ihre autoritäre Phase gelangte, wurde ein im Entstehen begriffener kritischer Journalismus zerrieben zwischen den Propagandaansprüchen der Besatzungsmacht einerseits und dem Glaubwürdigkeitsverlust bei der Bevölkerung andererseits. Die Kriegsphase war dann geprägt von politischem Dirigismus und materieller Not, so daß fur die beiden politischen Zeitungen, die bis dahin uberlebt hatten, kein Raum mehr war. Auch was die Presse anbetrifft, blieb die Mainzer Republik also letztlich Episode, eine Episode freilich, die aufgrund ihrer publizistischen Modernität vorausweist auf sehr viel spătere publizistische Strukturen.

461 Wilke/Förster 1993, S. 188.

462 Vgl. oben, S. 89.

463 Vgl. Wilke/Forster 1993, S. 173. 


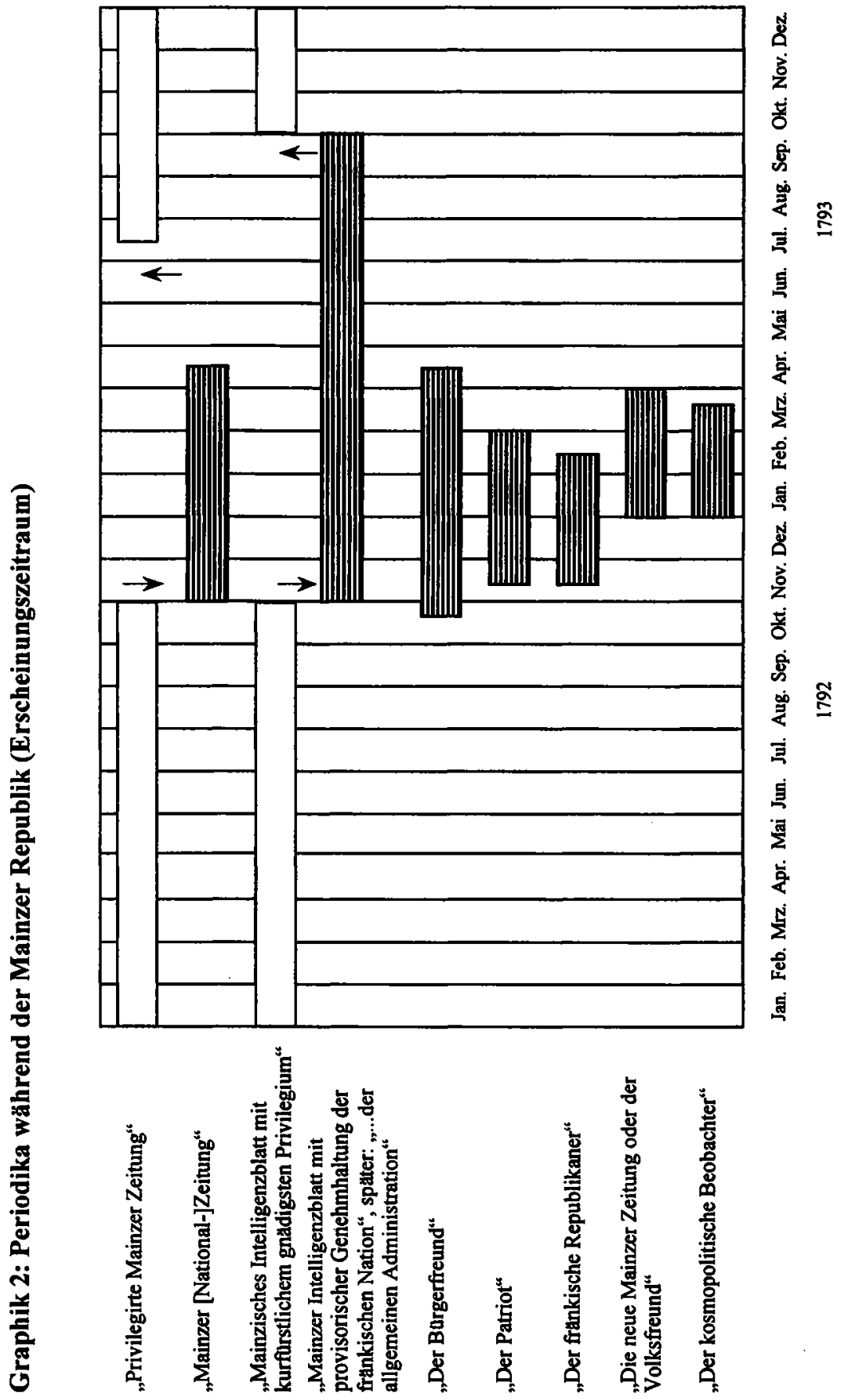


Die [...] Veränderungen in der Mainzer Presse waren tiefgreifend und brachten in mehrererlei Hinsicht etwas Neues. Aber diese Veränderungen wurden nach der Wiederkehr des absolutistischen Systems ruckgăngig gemacht und damit hinfällig. Auch sie blieben Vorzeichen einer noch ausstehenden Zukunft. ${ }^{464}$

\subsection{Unperiodische Druckschriften}

Neben diesen sieben Periodika erschien in der Mainzer Republik eine Vielzahl prorevolutionärer Flugschriften. ${ }^{465}$ Es handelte sich hier einmal um Reden aus dem Mainzer Jakobinerklub, die durch sekundäre Publikation einer weiteren Öffentlichkeit bekannt gemacht werden sollten, dann aber auch um revolutionäre Texte, die zum primären Zweck der selbständigen Publikation verfaßt worden waren. Auch Flugblätter mit revolutionären Gedichten bzw. Liedern, dann Plakate mit Bekanntmachungen, Aufrufen oder Verordnungen und nicht zuletzt revolutionăre Katechismen und Kalender erschienen als selbständige Druckschriften. Die Forschung hat sich mit dieser Publizistik der Mainzer Republik verschiedentlich befaßt, so daß uber den Autoren- und Rezipientenkreis der Veröffentlichungen sowie uber ihre Produktions-, Distributions- und Rezeptionsbedingungen Wesentliches bekannt ist. ${ }^{466}$ Es kann daher in unserem Zusammenhang auf diese Ergebnisse verwiesen werden.

Autoren der revolutionären Flugschriften waren zu Beginn die Angehörigen der franzősischen Armee, namentlich General Custine. Dessen Sekretär Georg Wilhelm Böhmer hatte allerdings schon früh die Funktion eines "Ghostwriters ${ }^{467}$ so daß schon in der Anfangsphase auch Deutsche maßgeblich als Autoren hervortraten. Mit der Gründung des Jakobinerklubs, der Ankunft von Propagandisten der Revolution aus Straßburg und der Einsetzung neuer Orts- und Gebietsverwaltungen wurde der Anteil der deutschen Autoren dann immer stärker.

Der Rezipientenkreis dieser Veröffentlichungen war der allerbreiteste und umfaßte nicht mehr nur die stădtischen Eliten wie die Universitătsmitglieder und die Großkaufleute, sondern bezog auch die Bauernschaft im größeren Umkreis von Mainz mit ein. Um einen solch breiten Rezipientenkreis erreichen zu können, wurden die einzelnen Veröffentlichungen von den Mainzer Druckereien teilweise in hohen, für die damalige Zeit in extrem hohen Stuickzahlen aufgelegt. Die von Cotta Ende 1792 verfaßten, an die Landbevölkerung gerichteten Persuasivtexte Von der Staatsverfassung in Frankreich zum

\footnotetext{
464 Wilke/Forster 1993, S. 195.

465 Die Mikrofiche-Edition der Mainzer Stadtbibliothek fuhrt 140 prorevolutionäre Flugschriften auf. Vgl. SMJG, Teil 2, S. 26-44.

466 Vgl. z. B. Pelzer 1989; Dumont 1993a, S. 145-151; Dumont 1993d; Keim 1993.

467 Vgl. Dumont 1993d, S. 118.
} 
Unterrichte für die Bürger und Bewohner im Erzbisthume Mainz und den Bisthümern Worms und Speyer ${ }^{468}$ und Wie gut es die Leute am Rhein und an der Mosel jetzt haben können ${ }^{469}$ wurden beispielsweise „in riesigen Mengen gedruckt, je 5000 als Plakate und je 4500 als Flugschriften im Oktavformat bei den damaligen Auflagen eine geradezu astronomische Ziffer! “470 In noch höherer Auflage - vermutlich 100.000 Exemplare 471 - wurde das am 19. November 1792 in Paris beschlossene franzősische Hilfeversprechen für alle Völker aufgelegt und verteilt.

Die Preise für die Druckschriften waren sehr günstig, so daß diese auch von den unteren Bevölkerungsschichten erworben werden konnten: Flugblätter kosteten meist nichts. Flugschriften wurden teils ebenfalls kostenlos abgegeben, kosteten ansonsten aber zwischen 2 und 8 Kreuzer. Der Bezugspreis für Zeitungen lag monatlich zwischen 8 und 24 Kreuzern. Zum Vergleich: Ein Laib Brot von 4,5 Pfd. kostete ca. 10 Kreuzer. 472

Eine derartige Preisgestaltung war natürlich nur bei einer Subventionierung der Druckkosten möglich. Diese erfolgte zum Beispiel durch den Mainzer Jakobinerklub, dessen Mitglied der Buchbinder Jakob Zech war:

Ein Mitglied schlägt vor, die Rede des Vorsprechenden auf Kosten der Gesellschaft drucken zu lassen [...]; unterstützt und angenommen. ${ }^{473}$

Bruder Zech habe verschiedene Reden auf Kösten der Gesellschaft drucken lassen, die Gesellschaft solle demnach bestimmen, ob der Ök[onomie]aus[schuß] sich deshalb mit $B[$ ruder $]$ Zech benehmen solle; unterstützt und angenommen. ${ }^{474}$

Auch die französische Armee finanzierte den Flugschriftendruck, und zwar nicht nur, wenn sie ihn selbst veranlaßt hatte, sondern nicht selten auch dann, wenn er auf Veranlassung des Jakobinerklubs erfolgt war:

Hälin macht den Vortrag, daß die Reden des Wetekind zum zweiten Male aufgelegt und auf Kosten der Gesellschaft verteilt werden sollen. Böhmer versichert, daß Custine dieses zahlen werde. Der Vorschlag wurd also angenommen. ${ }^{475}$

Außerdem standen die neu eingesetzten Verwaltungen zur Finanzierung des Flugschriftendruckes bereit. So stellte die St.-Rochus-Hospitaldruckerei, die die oben genannten Flugschriften Cottas in hoher Auflage gedruckt hatte, die

\footnotetext{
468 Vgl. MR1, S. 295-298.

469 Vgl. MR1, S. 323-326.

470 Dumont 1993d, S. 124.

471 Vgl. Dumont 1993d, S. 124.

472 Vgl. Dumont 1993a, S. 150-151, bes. Anm. 235.

473 Protokoll des MJK vom 1.1.1793. (MR1, S. 472).

474 Protokoll des MJK vom 3.1.1793. (MR1, S. 479).

475 Protokoll des MJK vom 7.11.1792. (MR1, S. 145).
} 
Kosten dafür der Mainzer Munizipalität in Rechnung. ${ }^{476}$ Wenn Broschüren nicht kostenlos verteilt wurden, sondern gegen ein geringes Entgelt, konnte der Mainzer Jakobinerklub bei diesem Verfahren sogar noch einen Gewinn verbuchen, der teilweise wohltätigen Zwecken zugefuhrt wurde. ${ }^{477}$

Die Distribution der so gedruckten Flugschriften erfolgte auf vielgestaltigen Wegen, die in ihrer Komplementarität zuletzt eine flächendeckende Verbreitung ermöglichten: Selbst im abgelegeneren ländlichen Raum konnte man Gaststätten und Privathäuser finden, die mit demokratischen Schriften gleichsam tapeziret ${ }^{478}$ waren. Grob zu unterscheiden sind zunächst zwei Verfahren, nämlich die Distribution durch Privatinitiative und diejenige durch staatliche Verordnung.

Im Zentrum der - allerdings staatsnahen - Privatinitiativen stand auch hier häufig der Jakobinerklub: Die Mainzer Stadtbevolkerung zu erreichen, war nicht schwer, aber auch die Landbevölkerung wurde systematisch mit revolutionären Schriften versorgt. Flugschriften wurden regelmäßig von »Volkslehrern«, die in revolutionärer Mission von Mainz aus aufs Land zogen, dort in großer Menge verteilt, zum Beispiel anläßlich der beliebten Freiheitsbaumpflanzungen, aber auch in Gaststätten. In Mainz selbst erreichte man die Landbevölkerung auf dem Wochenmarkt, wo beispielsweise die Ehefrau des demokratisch-prorevolutionär eingestellten Buchbinders Zech bei den Bauern revolutionăre Flugschriften gegen Naturalien eintauschte. ${ }^{479}$ Auch die zahlreichen Arbeiter, die zur Sicherung und Erweiterung der Festungsanlagen in Mainz eingesetzt waren und bei denen es sich meist um Landbewohner handelte, erwiesen sich als Multiplikatoren, indem sie die ihnen übergebenen Schriften mit in ihre Heimatgemeinden nahmen und dort einem großßeren Kreise zugänglich machten. ${ }^{480}$ Andererseits waren in vielen Fällen die Landbewohner auch selbst aktiv, indem sie sich in Mainz, beispielsweise im Jakobinerklub, gezielt Zugang zu Flugschriften verschafften und diese in ihren Heimatgemeinden verteilten: Auch die Bauern gehen in den Klub und kaufen mit Begierde die Impressa. ${ }^{481}$

476 Vgl. Scheel 1981, S. 144-145.

477 Bruder Rulfs verlangt, dieselbe zum Vorteil der Armut drucken zu därfen; unterstützt und angenommen. (Protokoll des MJK vom 1.1.1793. (MR1, S. 472)) Die Gesellschaft beschlok, die Rede auf eigne Kösten drucken zu lassen und den Überschuß oder Nutzen davon der Kasse des Wohltätigenausschusses zukommen zu lassen. (Protokoll des MJK vom 14.1.1793. (MR1, S. 542)).

478 So charakterisierte ein Nachbar die Wohnung des Dromersheimer Krämers Krebs. (Vgl. Dumont 1993d, S. 114).

479 Vgl. Keim 1993.

480 Vgl. Dumont 1993d, S. 118-119.

481 Ein revolutionskritischer Autor in seinem Bericht an den Wiener Hof. (Zit. $n$. Dumont 1993d, S. 119). 
Von Beginn der Mainzer Republik an erfolgten Produktion und Distribution von Flugschriften auch auf staatliche Initiative hin, zunächst derjenigen des franzősischen Militărs, später derjenigen der neuen Verwaltungen. Diese administrative Aktivităt wurde ab Ende November 1792 absichtsvoll verstärkt, als man daran ging, die Propagandatătigkeit stärker staatlich zu kontrollieren und dazu auch die bis dahin herrschende Pressefreiheit restriktiver zu fassen. Im Anschluß an die Weisung zur Pressefreiheit, die die Allgemeine Administration am 21.11.1792 erlassen hatte, ${ }^{482}$ wurde die Distribution der revolutionären Flugschriften jedenfalls staatlich normiert:

Im Sinne und auf der Basis dieser Weisung setzte nunmehr eine von den neuen Behörden gesteuerte Propaganda ein, die bisher ausschließlich dem mit keinen Machtmitteln ausgestatteten Klub überlassen gewesen war. So ordnete die Allgemeine Administration am 24.11. [1792] an, die von Cotta und Pape verfaßte Aufklärungsschrift "Von der Staatsverfassung in Frankreich« als Plakat und Flugschrift an die Gemeinden des Erzbistums Mainz und der Bistumer Worms und Speyer zur Verlesung von der Kanzel, zum Affigieren und zur Verteilung zu versenden. ${ }^{483}$

Die Anweisung an die Gemeinden lautete:

Im Namen der Frankenrepublik Die Gemeinde erhält in den Anlagen mehrere Abdrücke von der Staatsverfassung von Frankreich zum Unterricht für die Bürger und Bewohner im Erzbistum Mainz und den Bistümern Worms und Speyer mit der Weisung, daß jeder Seelsorger in der Gemeinde diesen Unterricht vor der Predigt auf der Kanzel ablesen, ein Exemplar in den Rats- und Gerichtshöusern affigiert und die übrgen Exemplarien unter die Gemeindsbürger ausgeteilt werden, dann, wie dieses befolget worden, anhero einberichten sollen. ${ }^{484}$

Diese neue, administrativ systematisch gesteuerte und uberwachte Revolutionierungskampagne hatte eine noch größere Verbreitung der Schriften und ihrer Inhalte zur Folge als zuvor, eine Tatsache, die nicht zuletzt durch die "gleichsam obrigkeitliche Autorităt", ${ }^{485}$ mit der die Inhalte der Revolution nun verbreitet wurden, bewirkt wurde. Die Rezeption der Druckschriften erfolgte dann oft entsprechend den oben ausgefuhrten Bedingungen der ReOralisierung, hăufig in ländlichen Diskussionszirkeln, in denen die revolutionären Schriften aus Mainz vorgelesen und debattiert wurden. Diese lokalen "Klubs« spielten eine wichtige Rolle in der Meinungsbildung der Bevölkerung, indem dort die Aufsătze der Mainzer Jakobiner durch Oralisierung - im Falle der gedruckten Reden durch Re-Oralisierung - zugleich popularisiert und einer breiten Diffusion entgegengefuhrt wurden.

482 Vgl. oben, S. 86f.

483 Scheel 1981, S. 144.

484 MR1, S. 295.

485 Dumont 1993d, S. 123. 


\subsection{Textsorten in der Mainzer Republik}

Die für die Mainzer Republik charakteristische, aus einem neu sich herausbildenden Konzept politischer Öffentlichkeit resultierende Etablierung und intensive Nutzung einer Vielfalt von »Kanälen« politischer Kommunikation diente, was die Sprachzeichen angeht, vorrangig der Übermittlung von Texten.

Der Terminus »Text« bezeichnet eine begrenzte Folge von sprachlichen Zeichen, die in sich kohärent ist und die als Ganzes eine erkennbare kommunikative Funktion signalisiert. ${ }^{486}$

Im Text ist diejenige linguistische Einheit zu suchen, in der die politischen Intentionen der Kommunikationspartner sprachlich realisiert werden. Diese Ebene der Texte von derjenigen der Kommunikationskanäle und -situationen in der Mainzer Republik abzuheben, ist nicht obsolet: Obwohl dem gewăhlten oder vorgegebenen Kommunikationskanal ein gewisser Einfluß auf die Struktur der mit seiner Hilfe ubermittelten Texte nicht abgesprochen werden kann, sind es im einzelnen doch oft sehr unterschiedliche Texte von mitunter geradezu gegensätzlicher politischer Funktion und sprachlicher Struktur (z. B. GEDICHT vs. VERORDNUNG), die auf ein und demselben Kommunikationskanal (z. B. Zeitung) transportiert werden.

Texte als die primären kommunikativen Einheiten stehen nicht isoliert, sondern sind Ausprägungen bestimmter Sprachhandlungsmuster. ${ }^{487}$ Diese sind zutreffend als Textsorten ${ }^{488}$ bezeichnet worden, wobei der Terminus ${ }^{489}$ allerdings den analytischen Akt der Textklassifikation akzentuiert und damit die faktische Priorităt der Sprachhandlung vor der Sprachhandlungsklassifikation verwischt. Da diese Sprachhandlungsmuster in den meisten Fällen nicht kodifiziert, sondern lediglich einer temporären Stabilisierung durch interne Normen der Sprecher- und Schreibergemeinschaft unterworfen sind, unterliegen sie - in der Folge sozialer Veränderungen oder in deren Vorbereitung - dem Wandel. Eine Geschichte dieser Sprachhandlungsmuster, d. h.

486 Brinker 1988, S. 17.

487 Mit G. Beck (1973, S. 73) k8nnen Textsorten als „Verwendungsweisen mündlicher und schriftlicher Sprachäßerung, welche zu mehr oder minder festen gesellschaftlich sanktionierten Sprech-/Schreibhandlungsmustern geworden sind", gefaßt werden.

$488 \mathrm{Vgl}$. zu den unterschiedlichen Ansătzen der Textsortenklassifikation zusammenfassend Rolf 1993, S. 81-141.

$489 \mathrm{Vgl}$. zu der terminologischen und begrifflichen Variation des Textsortenkonzepts Rolf 1993, S. 43-46. 
der Textsorten, erscheint somit - auch über den hier behandelten Gegenstand hinaus - als lohnendes Vorhaben der Historiolinguistik.

Wir erkennen deshalb die Notwendigkeit zur Erweiterung des Forschungsprogramms der Sprachgeschichte hin zur Kommunikationsgeschichte. In ihr muß sich eine Texttypengeschichte mit einer Geschichte der funktionalen Sprachvarietăten [...] verbinden. ${ }^{490}$

Textsortenhistorische Fragen sind in der zurückliegenden Forschung vor allem anhand zahlreicher Einzelprobleme in unterschiedlichsten sprachhistorischen Konstellationen untersucht worden. ${ }^{491}$ Eine zusammenhängende Textsortengeschichte ist dagegen lange Zeit Programm geblieben. Erst P. von Polenz' "Deutsche Sprachgeschichte ${ }^{492}$ bezieht in eine Gesamtdarstellung der neuzeitlichen deutschen Sprachentwicklung kommunikationsund textsortenhistorische Fragen systematisch ein.

Besonders die tiefgreifenden und relativ rasch sich vollziehenden Veränderungen im Textsortenspektrum sind es, die als markante sprachhistorische Diskontinuitatten die Textsortengeschichte einer Sprache periodisieren. Die Mainzer Republik stellt einen solchen bedeutenden sprachhistorischen Einschnitt dar. Der Versuch der Mainzer Jakobiner, in Mainz 1792 eine politische Öffentlichkeit zu schaffen und diese politisch zu prägen, mußte sie zur Entwicklung und Realisierung von innovativen Sprachhandlungsmustern, also Textsorten, fuhren. Das sich herausbildende Textsortenspektrum der Mainzer Republik unterschied sich dann vom zuruckliegenden Textsortenspektrum des »Ancien Régime« so markant, daß sogar von einer textsortenhistorischen Zäsur gesprochen werden kann. Diese innovativen Textsorten hatten zwar nach dem Ende der Mainzer Republik - zunächst während eines kurzfristig restituierten Absolutismus, dann in der napoleonischen Zeit und schließlich in der Restauration - furs erste keine Chance auf Realisierung und damit auf unmittelbare Tradierung, jedoch wurden sie in Vormärz und Revolution wiederbelebt und finden sich in größeren Teilen auch heute noch, bzw. wieder, als zentrale Elemente in der Sprache der politischen Öffentlichkeit.

So innovativ diese Kommunikationsformen in Mainz 1792/93 auch in Erscheinung traten, sie waren doch nicht ohne jede Prăzedenz. Im Gegenteil, der überwiegende Teil der Textsorten, die 1792 in Mainz die im Entstehen begriffene politische Öffentlichkeit prägten, laßt sich direkt oder indirekt auf bekannte Muster zuruckführen: Dies heißt einmal, daß Textsorten, die auch im "Ancien Régime» schon gebräuchlich waren, modifiziert wurden, indem

490 Steger 1984, S. 191. Vgl. Schenker 1977.

491 Vgl. den Überblick bei Steger 1984, S. 192-200.

492 Vgl. von Polenz 1991, S. 3; von Polenz 1994. 
man sie neuen, nämlich politischen Funktionen dienstbar gemacht und damit in einen neuen Sprachhandlungstyp ubergeführt hat. Als Muster für die in der Mainzer Republik innovativen Textsorten kommen zum anderen auch historisch weiter zuruckliegende deutsche Texte und und nicht zuletzt auch europäische Texte aus der Zeit der Mainzer Republik in Betracht. In diesem Zusammenhang darf zum einen an die Publizistik der Fruhen Neuzeit erinnert werden: Mit dem Blick auf ein breites Publikum wurde schon wăhrend der Reformation und der Bauernkriege ein Spektrum von teilweise neuen Kommunikationskanälen genutzt (Flugschriften) und auf diesem Hintergrund in persuasiver Intention eine Fulle von Textsorten realisiert. ${ }^{493}$ Eine textsortenhistorische Traditionslinie, die diesen ersten Entwicklungsschub deutscher Öffentlichkeitssprache mit der Mainzer Republik in unmittelbare Verbindung brächte, ist jedoch nicht zu belegen.

Das wichtigste Vorbild der in der Mainzer Republik realisierten Sprachhandlungstypen ist dagegen die Textproduktion des revolutionären Frankreich, ein Textsortenpotential, das in der Mainzer Republik verschiedenen Textemittenten sehr geläufig war und deshalb konkret musterbildend werden konnte. $\mathrm{Zu}$ diesen Textemittenten gehörten natürlich einerseits die Franzosen, die in militärischer oder administrativer Funktion in Mainz waren, dann die Propagandisten, die aus Straßburg nach Mainz geholt worden waren, nicht zuletzt aber auch die Mainzer Jakobiner, die meist uber intensive Kenntnisse der französischen Revolutionsliteratur verfugten. Dieser im engeren Sinne interferenzlinguistische Aspekt ist in der Vergangenheit besonders von romanistischer Seite behandelt worden. ${ }^{494} \mathrm{Er}$ ist auch Gegenstand laufender romanistischer Forschungsprojekte ${ }^{495}$ und kann deshalb hier ausgeklammert werden. Es geht in der vorliegenden Arbeit um die Innovationen der politischen Sprache in Mainz 1792/93 und um die Mechanismen, mit denen diese von jakobinischer Seite popularisiert wurden, nicht um die - zweifellos höchst lohnende - Rekonstruktion eines franzठssisch-deutschen „Kulturtransfers“، ${ }^{496}$

Im folgenden soll ein Überblick gegeben werden über diejenigen Textsorten, die sich in der Mainzer Republik im Relevanzbereich »Politik« in Texten greifen lassen. Analog zu W. Dieckmanns Unterscheidung von Funktionsund Meinungssprache ${ }^{497}$ wird dabei unterschieden zwischen den politischen Relevanzbereichen »Ideologie« und »Institution«.

493 Vgl. z. B. Guchmann 1974; Schwittala 1983; von Polenz 1991, Kap. 4.8, H-N.

Vgl. z. B. Neugebauer-W8lk 1985; Reichardt 1988b; Abdelfettah 1989; Kramer 1990; Reichardt 1991; Kramer 1992; Musolff 1992; Reichardt 1993.

495 Vgl. Reichardt 1993.

496 Vgl. Reichardt 1993.

497 Vgl. Dieckmann 1975, S. 81. 


\subsubsection{Textsorten im Relevanzbereich »Ideologie«}

Die Textsorten im Relevanzbereich "Ideologie« sind zweifellos diejenigen, die das Textsortenspektrum der Mainzer Republik am markantesten kennzeichnen, auch weil sie sich am schärfsten von denjenigen des "Ancien Régime«, in Mainz der kurfürstlichen Zeit also, abheben. Die große Anzahl von Texten, die hier entstanden ist, zeichnet sich durchgangig durch die informativ-persuasive Sprachfunktion aus. ${ }^{498}$

Hierher gehören vor allem die auf den verschiedenen Wegen oraler Kommunikation (Einzel- und Kleingruppen)/mission", Versammlung, Feier, Theater, Gottesdienst, Schulunterricht) realisierten Textsorten politische REDE, PREDIGT, GEDICHT und LIED, dann aber auch die dialogisch angelegten Textsorten GESPRÄCH, DISKUSSION und SCHAUSPIEL.

Gleichfalls zu nennen sind die auf den verschiedenen Wegen literaler Kommunikation (periodische und unperiodische Druckschriften) distribuierten Texte, wozu einmal sekundäre Literalisierungen der oben genannten oralen Texte gehören, dann aber auch primär literal realisierte Texte wie ZEITUNGSNACHRICHT, ZEITUNGSKOMMENTAR, DENKSCHRIFT, STELLUNGNAHME, WIDERLEGUNG oder REISEBERICHT. Einige dieser Textsorten waren gezielt auf Re-oralisierung angelegt, so z. B. KATECHISMUS, KALENDER und FABEL.

Bemerkenswert an diesem Spektrum ideologiesprachlicher Textsorten in der Mainzer Republik ist, daß praktisch keine Texte aufzufinden sind, die von der poskativen Sprachfunktion, der Funktion des an die Regierenden gerichteten Begehrens, geprägt gewesen wären. ${ }^{499}$ Auch Texte integrativer Funktion sind im Vergleich zu denjenigen persuasiver Funktion relativ selten. Dieses Faktum ist das Ergebnis des verschiedentlich erwähnten Umstandes, daß die Mainzer Jakobiner sich eben nicht in der Situation des Unterdrickten befanden, dessen Ziel die Destabilisierung etablierter Macht sein muß, sondern in der Situation desjenigen, der die Macht schon errungen hat und dem es folglich um die Stabilisierung des Erreichten geht. Die Adressaten der Texte wurden also nicht als potentielle Mitstreiter im revolutionären Kampf gegen die aktuelle Obrigkeit angesprochen, sondern als Bevölkerung, die letztlich in passiver Rolle als "Untertanen «, nun allerdings einer revolutionăr sich verstehenden Regierung, verblieben waren. $\mathrm{Da}$, wie es oben ausgedrückt wurde, das Ziel der »Revolutionäre« in Mainz also nicht Revolu-

498 Vgl. oben, S. 44-46.

499 Einige ideologiesprachliche Texte, die von dieser poskativen Funktion geprăgt sind, richten sich an die realiter nicht mehr an der Macht befindliche kurfürstliche Regierung, der poskative Gestus ist also in diesen Texten eine rhetorische Figur im Kontext eines funktional persuasiven Textes. 
tion, sondern Affirmation, wenn auch Affirmation der Revolution, war, findet im Textsortenspektrum seinen Ausdruck, und zwar als Dominanz der informativ-persuasiven Funktion.

Mit dominant persuasiver Funktion imponieren im Relevanzbereich "Ideologie» mehrere Textsorten, die zwar auch vor 1792 schon existiert hatten, die nun jedoch in der Mainzer Republik einen tiefgreifenden Funktionswandel erlebten. Es handelt sich hierbei um literarische Textsorten wie GEDICHT, LIED, SCHAUSPIEL, KATECHISMUS, KALENDER oder FABEL. ${ }^{500}$ Diese Textsorten, denen zuvor keine (offen) politische Funktion zugekommen war, wurden nun von den Sprechern in der Mainzer Republik politisch instrumentalisiert, indem sie auf ein außersprachliches Ziel, die Beeinflussung der Mainzer Bevolkerung im Sinne der Revolution, ausgerichtet wurden. Dieser Umstand hat die literaturwissenschaftliche Forschung dazu motiviert, von »operativer Literatur« zu sprechen, eine geglückte Terminologisierung, die den Funktionswandel der Textsorten akzentuiert. ${ }^{501}$

Diese Gruppe von politisch (um-)funktionalisierten literarischen Textsorten gibt im ubrigen auch Gelegenheit, davor zu warnen, einer Unterscheidung von "literarischen « und "Gebrauchstextsorten« allzu viel klassifikatorische Schärfe zuzutrauen. Wenn E. Rolf beispielsweise nach intensiver Diskussion resümiert: „Gebrauchstexte haben [...] so etwas wie Funktionswert, literarische Texte aber haben einen Eigenwert", 502 so ist darauf hinzuweisen, daß es sich bei der operativen Literatur der Mainzer Republik um literarische Texte mit politischem Funktionswert handelt, also um Überlagerung und Mischung von Textfunktionen. Dieser Funktionswert der operativen Literatur in der Mainzer Republik ist nicht gering zu veranschlagen. Die Autoren nutzten bewußt und mit gewissem Erfolg einen Kontrafaktur-Effekt: Indem bekannte Textmuster politisch mum-funktionalisiert« wurden, konnte man Adressaten erreichen, die politische Denkschriften nicht rezipiert hätten. Ein solcher Wirkungsmechanismus gilt mit Sicherheit für den (nun revolutionär ausgerichteten) KALENDER, der in vielen bäuerlichen Häusern traditionell die einzige Lektüre war, dies gilt für die zahlreichen Kontrafakturen traditioneller LIEDER, dies gilt fur das SCHAUSPIEL, das mit antiaristokratischen Komödien sowohl das Unterhaltungsbedürnis ansprach als auch der revolutionären Persuasion diente. Auch die - allerdings seltener anzutreffende - revolutionăre PREDIGT gehört hierher.

500 Vgl. Grab 1969; Steiner 1973; Segeberg 1974; Scherpe 1975; Stephan 1976; Steiner 1977; Stephan 1980; Scherpe 1982; Stephan 1982; Scherpe 1983; Neugebauer-Wolk 1985; Grab 1989; Neugebauer-Wölk 1989; Scherpe 1989.

502 Rolf 1993, S. 128. 
Mit besonderem Nachdruck soll zuletzt auf eine Textsorte hingewiesen werden, die in der Mainzer Republik eine uber Mainz hinausreichende Innovation darstellt, die politische VOLKSREDE: Die ersten offentlichen politischen Reden in Deutschland wurden namlich 1792 in Mainz gehalten. ${ }^{503}$ Damit wurde eine Textsorte begründet, die - nach längerer Unterbrechung im 19. Jahrhundert wiederbelebt wurde, rasch zunehmende Bedeutung erhielt und bis auf den heutigen Tag von beachtlichem Gewicht fur die politische Entscheidungsfindung geblieben ist. Die politische VOLKSREDE war an eine zumindest zeitweise Etablierung einer politischen Öffentlichkeit gebunden, und insofern war an sie vor der Mainzer Republik in Deutschland nicht zu denken. Nachdem dann aber mit der Mainzer Republik eine politische Öffentlichkeit geschaffen worden war, wurde die politische Rede möglich, und sogleich so häufig realisiert, daß man sie als die dominierende Textsorte bezeichnen kann. Die Mainzer Demokraten sind primăr durch eine Vielzahl von persuasiv intendierten Reden im Jakobinerklub und bei anderen Versammlungen ins Bewußtsein einer Öffentlichkeit getreten, die durch diese Reden erst geschaffen wurde. Es bildete sich somit eine Textsorte heraus, deren textuelle Realisierung die Bedingung ihrer eigenen Existenz, die Öffentlichkeit, zugleich hervorbrachte und damit konstituierte.

Die Reden der Mainzer Republik bilden ein bemerkenswertes Korpus, weil sich hier die Herausbildung und die Verănderung persuasiver Strategien in einem relativ kurzen Zeitraum beobachten lassen. Gerade aufgrund der abrupten, von außen ermöglichten Veränderung der kommunikativen Bedingungen in Mainz war die in Entstehung begriffene politische Öffentlichkeit in mancher Hinsicht ein dynamisch sich veränderndes Experimentierfeld. Emittenten und Adressaten politischer Texte erprobten sowohl ihre neuen Rollen als auch neue kommunikative Strategien, die sie zum Teil erst situationsadäquat entwickeln mußten, um sie dann in innovativen Textsorten zu realisieren. Hier läßt sich das oben vorgestellte Faktorenmodell nach Hannappel/Melenk mit Gewinn heranziehen: Die Äußerung ist immer das Ergebnis einer bestimmten kommunikativen Strategie, und diese entwickeln Sprecher in Abhängigkeit von ihrer Situationseinschätzung, ihrer Adressateneinschätzung und ihrem Sprach- und Sachwissen.

Die Redner im Jakobinerklub, bei denen es sich oft um Professoren der Universităt handelte, hatten am Anfang die Adressateneinschătzung, daß die Mainzer, nur erst aufgeklärt, sich umgehend zur Revolution bekennen würden. Als verbale Strategie standen ihnen zunächst die Textsorten zur Verfügung, in denen sie geubt waren. Das waren die wissenschaftliche Abhandlung

503 Vgl. Grünert 1984b, der mit Forsters Rede vom 15.11.1792 im MJK seine Textsammlung zur politischen Rede in Deutschland beginnen läßt. Vgl. von Polenz 1994, S. 396-397. 
und, als oral realisierte Textsorte, die Vorlesung. Die Sprache der Freiheit war daher in der ersten Zeit der Mainzer Republik die Sprache des Katheders. Die Professoren der Mainzer Universităt mußten im Jakobinerklub erst zu Volksrednern werden, zunächst ähnelten ihre Reden aufklärerischen Vorlesungen. Eine gewisse Ausnahmestellung nimmt auch hier Georg Forster ein. Wie P. von Polenz nachgewiesen hat, ${ }^{504}$ wies Forsters Rede Über das Verhältnis der Mainzer gegen die Franken ${ }^{505}$ schon alle Varianten moderner politischer Rede auf, wenn auch in anderer quantitativer Verteilung als später.

Der Mainzer Medizinprofessor Georg Wedekind jedoch, der in den ersten Wochen fast zu jeder Sitzung eine Rede hielt, war zunächst noch ganz einem universităr geschulten Deduktionsstil verhaftet:

Unser Mainzer Staat war bis itzt eine elektive Monarchie er stand unter dem fast unumschränkten Willen eines nicht vom Volke, sondern von einer gewissen Anzahl von adeligen Geistlichen gewählten Fürsten. Hier bemerke ich gleich folgende große Fehler in unserer Verfassung. a) Jede Regierung ist fehlerhaft, welcher ein Regent vorsteht, das heißt, alle Monarchien taugen nichts. Die Beweise sind: 1) Ein einzelner Mensch ist an sich zur Führung einer Regierung untauglich, weil $[\ldots]^{506}$

Die Mittel der Aufklärung waren ihm die Wahrheit und eine gerade Sprache:

Übrigens kann ich Euch nicht unerinnert lassen, daß die gerade Sprache des freien Mannes den verwöhnten Ohren der Höflinge und aller der Leute, die uns nie genau sagen, was sie wollen, sondern uns nur immer raten lassen, was sie eigentlich sagen wollen, [...] mißfällig ist. Wir werden aber alle bald finden, daß wir unsere Ohren an eine solche gerade Sprache gewöhnen müssen, weil unser gemeinsames Interesse Offenherzigkeit erfordert und weil wir als freie Männer auch keine Ursache haben, mit unserer Uberzeugung hinter dem Berge zu halten. Das einzige, wofür wir uns fürchten müssen, ist die Lüge; ${ }^{507}$

Wedekind sollte sich täuschen. Nicht die Ohren gewöhnten sich an den wissenschaftichen Argumentationsstil, sondern die Jakobiner mußten aufgrund der ausbleibenden Breitenwirkung ihre Adressateneinschătzung korrigieren und andere Persuasionsstrategien entwickeln. Bezeichnend dafür ist die vollkommen veränderte Einschătzung der Notwendigkeiten politischer Rede, die Wedekind etwa vier Monate später in seiner Anweisung An junge Volksredner artikuliert:

Lerne, junger Mann, der Du auf das Volk würken willst, lerne vorher auf einzelne Menschen würken! Schaden sogar können Deine Wahrheiten, wenn Du den Zeit-

504 Vgl. von Polenz 1988. 
punkt verfehlst. [...] Durch Vernunft allein richtest Du so wenig bei dem Publikum, als bei Individuen, gegen Vorurtheil etwas aus, wenn $D u$ nicht irgend einen andern im Menschen liegenden Affekt zum nahen Bewußtsein bringen kannst. Mit diesem treibst $D u$ dem Menschen sein Vorurtheil aus und Deine Gründe sagst Du daru, weil man doch so gern will, daß es heiße, man habe nach Vernunft gehandelt. ${ }^{508}$

Die hier nicht ohne Zynismus gepriesene Persuasionsstrategie prägte dann die späteren Reden der Mainzer Jakobiner. Ein zweiter jakobinischer Redestil war durch den expliziten Ausdruck von Bewertungen gekennzeichnet, wobei in reichem Maße von Metaphern Gebrauch gemacht wurde:

Worms und Mainz waren die Orter, wo die ausgearteten Kinder Frankreichs die Dolche schärften, mit denen sie die Eingeweide ihres Mutterlandes zerfleischen wollten, und diese Bewohner waren Sklaven unter dem schändlichsten Drucke eines ausschweifenden Fürsten und seines Hofgesindels. Doch Retter Custine kam, und die frevelnde Rotte der Aufrührer floh, und die biedern Mainzer können nun frei ihr Haupt erheben. Eben dieser Saal, in welchem die Feinde des Volkes von dessen Schweiße schwelgten, aus welchem die Sprache der Wahrheit verbannt war und in dem oft die höllischen Entwürfe zur Unterjochung der Völker gebrütet wurden, ist nun in einen Tempel der Freiheit und Gleichheit umgewandelt worden. ${ }^{509}$

Die agitatorische Strategie erreichte die Mobilisierung der Gesamtbevölkerung jedoch so wenig wie die rationale. Eher war hierzu eine dritte Strategie geeignet, die - vergleichsweise modern - stark adressatenorientiert vorging: „Der semantische Stratege entwickelt [...] Hypothesen über Einstellungen, Vorurteile, Wissen und Informationsdefizite seiner Adressaten. Davon hängt es dann ab, welche Aspekte des Sachverhalts [...] thematisiert und als cha-

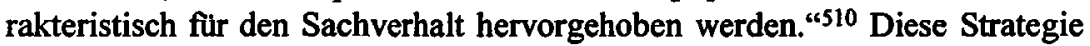
prägte beispielsweise die Texte Friedrich Christoph Cottas, die er für die Landagitation entwarf. ${ }^{511}$ Tatsächlich fanden die Ideen der Jakobiner unter

508 In: »Der Patriot《. (SMJG 170-174/41-40).

509 Anton J. Dorsch am 4.11.1792 im MJK. (MR1, S. 114).

510 Klein 1989b, S. 15.

511 Als Beispiel kann hier kein Redetext vorgelegt werden, jedoch verdeutlicht der auf orale Vermittlung angelegte "Handwerker- und Bauern-Kalender des alten Vaters Gerhard «, die Übertragung eines französischen, von Jean Marie Collot d'Hebois verfaßten Vorbildes, die kommunikative Strategie. Cottas Kalender ist ein für die Landagitation exemplarischer Text, in dem das Bemühen zum Ausdruck kommt, durch katechetisch-dialogische Struktur, einfache Wortwahl und pastoralen Ton den vermuteten Rezeptionsmőglichkeiten der Landbevőlkerung entgegenzukommen:

Erstes Gespräch. Von der Konstitution

Vater Gerhard pflegte immer zu seinen Mitbürgern zu sagen: $O$ wie schön, wie gut ist doch die Konstitution von Frankreich! Die macht uns und unsre Kinder glüklich! 
der Landbevơlkerung vergleichsweise viel Anklang. Es wäre jedoch voreilig, dies allein auf die sprachliche Persuasionsstrategie zuruckzufuhren. Mindestens ebenso wichtig war, daß die materielle Situation der Landbevölkerung sehr viel dramatischer war als die in der Stadt, so daß revolutionäre Werbung hier einen wesentlich fruchtbareren Boden vorfand.

\subsubsection{Textsorten im Relevanzbereich »Institution«}

Gegenüber der im politischen Relevanzbereich »Ideologie» dominierenden Oralităt dominiert umgekehrt die Literalität bei den Textsorten des politischen Relevanzbereiches »Institution«. Die Textsorten im politischen Relevanzbereich "Institution" sind ORDNUNG, ERKLÄRUNG, BEKANNTMACHUNG, ANWEISUNG, ERLASS, VERORDNUNG, PROKLAMATION, DEKRET, INSTRUKTION und ULTIMATUM, um zunächst diejenigen zu nennen, bei denen eine regulative Sprachfunktion im Vordergrund steht. Graphik 3 veranschaulicht dabei, wie hoch alleine die Anzahl von PROKLAMATIONEN war, welche die militärischen und zivilen Administrationen in den neun Monaten der Jahre 1792/93 in Mainz in Umlauf brachten.

Auch regulative Texte werden, ähnlich wie die persuasiven, in der Intention distribuiert, das Handeln der Adressaten zu beeinflussen. Auf der Grundlage des Besitzes politischer Macht geht es den Emittenten regulativer Texte jedoch uber die bloße Beeinflussung hinaus um die verbindliche Steuerung des Adressatenhandelns. In diesen Zusammenhang ist in der Mainzer Republik auch der politische EID auf Freiheit und Gleichheit zu stellen. Nach einer ersten Phase des freiwilligen Bekenntnisses zur Revolution diente er 1793 primăr der Ratifizierung des stattgehabten Machtwechsels, wurde durch regulative Akte der neuen Machthaber verbindlich eingefordert und war im Falle der Weigerung von harten Sanktionen bedroht.

Nachbar Andreas kam herbei, indem er sich hinter dem Ohr krazte, und ließ sich mit Gerhard in folgendes Gespräch ein:

Vater Gerhard, sagte er, was ist denn das, die Konstitution, oder wie ihr es heist? Ich weiß wohl so ungefähr, was ihr damit sagen wollt, und ich habe sie von Grund meines Herzens lieb und in Ehren, aber das Wort da verstehe ich doch nicht recht. Warum heißt man denn all das Gute, was man seit 4 Jahren in Paris gemacht hat und noch macht, die Konstitution?

Lieber Nachbar, antwortete Vater Gerhard, das Wort Konstitution bedeutet Einrichtung einer Sache, die Verbindung der Theile einer Sache oder eines Körpers, wo alles so beschaffen ist, so steht, so zusammen paßt, daß man davon dem Körper eine lange Dauer versprechen darf. (Cotta 1793, S. 1-2) Vgl. hierzu Neugebauer-Wolk 1985; Neugebauer-Wolk 1989. 
Graphik 3: Proklamationen in der Mainzer Republik

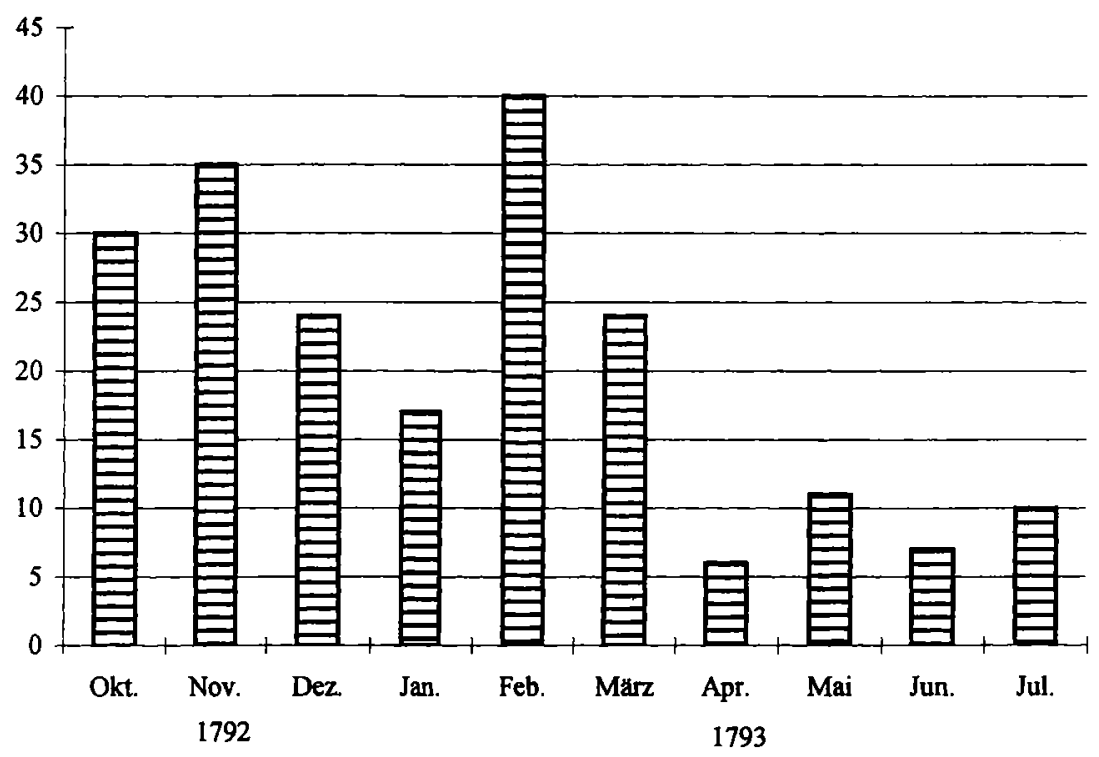

Andererseits sind auch im institutionensprachlichen Bereich Textsorten mit primär informativer Funktion realisiert worden, wobei es sich hier um die Textsorten VERZEICHNIS, MELDUNG, BERICHT, PROTOKOLL, URKUNDE, BESCHLUSS u. a. handelte, die allerdings in der Mainzer Republik nicht innovativ waren, sondern auch zu kurfurstlicher Zeit schon das Verwaltungshandeln begleiteten.

Vollkommen neu sind 1792/93 hingegen diejenigen Textsorten, die im Zusammenhang mit den soeben etablierten, dem Demokratieprinzip verpflichteten Institutionen wie dem Rheinisch-deutschen-Nationalkonvent standen oder aber in den verschiedentlich durchgeführten Volksbefragungen und Wahlen eine Funktion erhalten haben. Innovativ sind in diesem Zusammenhang sowohl die Textsorte bzw. Textsortensequenz $z^{512}$ PARLAMENTSDEBATTE als auch die in diesem Rahmen realisierten Textsorten DEBATTENBEITRAG, MOTION (ANTRAG), BESCHLUSS, PROTOKOLL. Um

512 Dabei kann die Diskussion, ob Textsequenzen wie die Parlamentsdebatte als Textsorten klassifiziert werden sollten oder aber ob sie lediglich als Sequenzen einzeln als Textsorten zu klassifizierender Texte zu begreifen wären, in unserem Zusammenhang außer Betracht bleiben. Vgl. Rolf 1993, S. 27-35. 
ebenso innovative, gleichfalls ubrigens "polytop“513 strukturierte Textsorten handelt es sich bei der VOLKSBEFRAGUNG und der WAHL.

Nicht nur diese letzteren institutionensprachlichen Textsorten erwiesen sich in der Mainzer Republik als innovativ. Auch bei der ersten Textsortengruppe, die durch die regulative Funktion gekennzeichnet ist, lassen sich nämlich im Vergleich zu den kurfurstlichen regulativen Texten beträchtliche Innovationen konstatieren, und zwar vor allem eine Überlagerung der regulativen durch die persuasive Textfunktion: Es war eben nicht so, daß im Herbst 1792 nur ein Elitentausch stattgefunden hätte und nun einfach neue Machthaber befugt gewesen wären, die funktional immer gleichen regulativen Texte zu formulieren und ihre Befolgung einzufordern. Der Umstand, daß die Franzosen als neue Machthaber ein vollig neues politisches Selbstverständnis besaßen, wird - zumindest zu Beginn der Mainzer Republik - auch in Texten regulativer Funktion greifbar.

Ein Beleg hierfür ist die Art und Weise, wie in den Texten einerseits die politische Legitimitätsbasis der Machthaber, andererseits der Adressatenbezug markiert wurde. Die kurfürstlichen Verordnungen beriefen sich explizit auf das Gottesgnadentum als Legitimitătsbasis:

Wir Friderich Karl Joseph, von Gottes Gnaden des heiligen Stuhls zu Mainz Erzbischof, des heil. römischen Reichs durch Germanien Erzkanzler und Kurfürst, auch Fürst und Bischof zu Worms [...]. ${ }^{514}$

Die Adressaten fanden sich an gleicher Stelle als Bürger, meist jedoch als Unterthanen angesprochen, von denen Gehorsam gefordert wurde. Vergleicht man damit eine ebenfalls als regulativ einzustufende Bekanntmachung der Allgemeinen Administration in der Mainzer Republik, ${ }^{515}$ so wurden die Adressaten dort als Bürger, Einwohner oder Bewohner, besonders aber als Mitbürger angesprochen, eine Bezeichnung, die eine egalitäre Einstellung zum Ausdruck bringt. Wenn dann die Legitimitătsbasis der Mitglieder der Allgemeinen Administration formuliert wird, ist offensichtlich, daß die neuen Machthaber sich einem vőllig neuen Legitimitätsprinzip, der Volkssouverănităt nämlich, verpflichtet fuhlten:

Erinnert euch Mitbürger, daß wir Bürger sind, wie ihr; daß jeder Vorsteher des Volks von euch bezahlt wird, und daß ihm die heilige Pflicht obliegt, eure Vorstellungen mit Bereitwilligkeit zu hören, dieselben mit Unparteilichkeit zu prüfen, und mit der strengsten Gewissenhaftigkeit nach den Gesetzen Recht zu sprechen. [...]

513 Rolf 1993, S. 29.

514 Proklamation vom 25.7.1793. (Die Publizistik der Mainzer Jakobiner und ihrer Gegner 1993, S. 258).

515 Vgl. unten, S. 159. 
wenn wir ja einen Vorzug vor euch haben: so ist es das süße Bewußtseyn, als eure Beamte für das Wohl und die Freiheit unserer geliebten Mitbürger zu arbeiten. ${ }^{516}$

Vor dem Hintergrund dieser Selbstverpflichtung der neuen Machthaber auf das Prinzip der Volkssouveränităt ist das Faktum zu interpretieren, daß in der Anfangszeit der Mainzer Republik kaum regulativ intendierte Texte auszumachen sind, die politisch monofunktional wären. In dieser Frühphase der Mainzer Republik sind die regulativen Texte fast stets durch persuasive Elemente überlagert. Auch wo Herrschaft artikuliert wird, soll offensichtlich deutlich gemacht werden, daß es sich um legitime, um "Volks»-Herrschaft handelt.

Ein prominenter Beleg fur einen solchen Text ist Custines Aufruf an die gedrückte Menschheit in Deutschland [...] vom 23./25. Oktober 1792. ${ }^{517}$ Hier ist zwar die regulative Funktion klar zu erkennen, da der General aus der Machtposition heraus spricht und verkündet, wie er die Verhältnisse einzurichten gedenkt. Andererseits dient aber der weit überwiegende Teil des Textes der Persuasion der Bevolkerung, die mit dem Argument des Selbstbestimmungsrechtes für die Revolution gewonnen werden soll.

\subsubsection{Textfunktionskonflikte in der Mainzer Republik}

Daß Texte eine interne Überlagerung von Funktionen zeigen, ist keine Seltenheit. Eine solche ist kommunikativ so lange unproblematisch, wie für die Adressaten eine Hierarchie der Textfunktionen erkennbar bleibt. ${ }^{518}$ Dies war in der Mainzer Republik allerdings nicht immer gegeben. Ein typisches Beispiel hierfür ist das oben angefuhrte ${ }^{519}$ Dekret zur Pressefreiheit: Dort wurde in Abs. [1] Pressefreiheit als wahre Schutzwehr freier Völker gegen alle Arten des weltlichen und geistlichen Despotismus verkundet, und die Adressaten ermunterte man, sich an dieses unverweigerliche Recht zu erinnern und alle desfalls noch vorwaltenden Zweifel und Bedenklichkeiten, welche noch von dem sonst eingerissenen Mißbrauche der willkürlichen Gewalt in ihren Gemütern haften möchten, gänzlich aus dem Wege zu räumen. Schon Abs. [2] widerrief dann aber die Zusicherungen des ersten Absatzes, indem zum einen normiert wurde, daß angeblich volksfeindliche Schriften von dieser "Pressefreiheit" nicht geschutzt sein sollten, und indem man zum zweiten sogar vor Strafandrohung nicht zurlickschreckte: Die Verkäufer und Ver-

516 Vgl. unten, S. 159.

517 Vgl. oben, S. 50f.

518 Vgl. Rolf 1993, S. 39-40: „Illokutionenhierarchie“.

519 Vgl. oben S. 87. (MR2, S. 144). 
breiter derselben seien als Feinde des allgemeinen Wohls anzusehen und zu bestrafen.

Dieser Text ist, anders als der Aufruf Custines, nicht nur von einer Überlagerung von Textfunktionen geprägt, sondern von einem regelrechten Textfunktionskonflikt. Als Textfunktionskonflikt wird ein Phänomen angesprochen, das der Mainzer Republik durchaus nicht exklusiv eignet, hier aber eindrucksvoll zu beobachten ist: Der außersprachlich bedingte Widerstreit von Funktionen ein und desselben Textes. Wenn hier in einem einzigen Text Pressefreiheit zuerst emphatisch verkundet und sodann praktisch wieder aufgehoben wird, so ist darin zunächst ein textinterner Widerspruch zu sehen. Dieser textinterne Widerspruch läßt sich zunächst wohl auf das Motiv zurückfuhren, die Einschränkung, bald die De-facto-Abschaffung der Pressefreiheit, die als zentrale Errungenschaft der Revolution gefeiert worden war, zu verschleiern. Dieses Bemühen läßt sich aber nur verstehen vor dem Hintergrund eines textexternen Widerspruchs, nämlich des Spannungsverhältnisses von Besatzungsregime und revolutionärer Mission. Was Custine in seinem Aufruf noch glaubte verbinden zu können, was aber nur hătte harmonisiert werden können, wenn die Mainzer sich sofort und unisono der Revolution angeschlossen hătten, erwies sich, wie oben gezeigt worden ist, ${ }^{520} \mathrm{im}$ Verlauf der Jahre 1792/93 immer mehr als Antinomie: Der fundamentale Gegensatz zwischen den Interessen der franzosischen Besatzungsmacht, die Mainzer einerseits $\mathrm{zu}$ kontrollieren und andererseits $\mathrm{zu}$ »revolutionieren «. Diese Antinomie war nur unter Preisgabe eines der beiden Interessen auflösbar. Solange diese Konsequenz aber nicht gezogen wurde, entstand eine gewissermaßen paradoxe Kommunikationssituation, in der paradoxe, funktional widersprüchliche Texte produziert wurden.

Solche Texte entstanden besonders in den späteren Phasen der Mainzer Republik, als sich immer mehr eine Politik des "Zwanges zur Freiheit" durchsetzte, die, wie auch die Jakobiner wußten (Der Zwang ist der Freiheit entgegen ${ }^{521}$ ), eine einzige Paradoxie darstellte: G. Forster, vielleicht der hellsichtigste, skeptischste unter den Akteuren, formulierte das Paradoxon explizit, indem er, wie oben zitiert, beklagte, die Mainzer wollten durchaus ohne den gnädigsten Befehl des Herrn Generals nicht frei seyn [...]. .22

Die Texte, die dann im Rahmen dieser Politik des "Zwanges zur Freiheit» - Gegner sprachen vom "Despotismus der Freiheit" - entstanden, sind - auf der Grundlage der textexternen - von greifbarer textinterner Widersprüchlichkeit gepragt [Hervorhebungen J.H.]:

$520 \mathrm{Vgl}$. oben, S. 28f.

521 Georg Wedekind am 30.10.1792 im MJK. (MR1, S. 83).

522

Brief an Huber vom 4. Dezember 1792. (Forster 1989 [1792], Bd. 17, S. 257). 
Der Tag ist gekommen [...] wo man zwischen Frelheit oder Sklaverei whlen muß. Wenn Ihr Euch frei erklärt, so behaltet Ihr unsere Freundschaft. Wollt Ihr Sklaven sein, dann sollt lhr auch als solche von uns behandelt werden [...]. ${ }^{523}$

$[B]$ efiehlt nicht ein Gesetz [...], daß alle Bürger der Länder, wo die siegreichen Waffen der Franken durchdringen, schworen mussen, den Grundsätzen der Freiheit und Gleichheit getreu zu sein, daß die nicht Schwörenden des Landes verwiesen, als Feinde der Republik behandelt und deren Vermögen in Beschlag genommen werden. [...] Schwört jetzt, da euer Vaterland in Gefahr ist, und hocherfreuet werden die Franken euch als Brüder umarmen, für euch wie Löwen fechten und für euch sterben, wenn es sein muß. Und ihr, die ihr aus Trotz nicht schwören wollt, weil ihr saget, daß die Franken euch die Freiheit aufdringen wollen leget diesen Wahn ab. Die biederen Franken geben euch ja die Wahl zwischen ihrer Freundschaft und ihrem Hafb! Wenn ihr den letzteren wählt und euch also öfentlich für ihre Feinde erklärt, könnt ihr sie tadlen, daß sie euch als solche behandlen? Sie dringen niemandem die Freiheit auf, ein so kostbares Geschenk muß nicht aufgedrungen werden; nein, sie lassen euch frei, ihr freiwillig zu huldigen; wer aber niederträchtig genug ist, lieber ein Sklave sein zu wollen, der darf nicht durch seine vergiftete Gegenwart die Gesellschaft freier Menschen verpesten. Einigkeit ist das größte Glück des Freien, und ein Mensch, der öffentlich sagt, ich will nicht frei sein, würde nur durch seine Grundsätze diese Einigkeit zerstören. Sie erklären sich als Feinde der Freien, und also hat die Gesellschaft das Recht, das Vermögen dieser Feinde in Beschlag zu nehmen. ${ }^{524}$

Es gelingt den Emittenten in diesen Texten nicht, die politische und kommunikative Paradoxie auf der Textebene auch nur zu verschleiern. Das Ausmaß, in dem diese Texte kontradiktorisch waren, untergrub zunächst die kommunikative, in der Folge aber auch die politische Glaubwürdigkeit der Textemittenten. Die weitere Entwicklung innerhalb der Mainzer Republik führte dementsprechend zu einer Auflösung der politischen Antinomie, indem das Kontrollinteresse der Besatzungsmacht die revolutionär-demokratische Mission verdrängte: Das Dekret der Allgemeinen Administration vom 17. April 1793, das den Druck von Zeitungen und Flugschriften untersagte und die Zensur wieder einfuihrte, ist im Unterschied zur hier diskutierten Verordnung frei von textinternen Widerspruchen. ${ }^{525}$ Damit hatte man dann aber nicht nur die Textfunktionskonflikte beseitigt, sondern zugleich die Option auf Demokratie. Auf diese hatten die Textfunktionskonflikte - in all ihrer Widersprüchlichkeit - nämlich indirekt verwiesen.

523 „Proklamation der Konventskommissäre vom 21.2.1793, das Konventsdekret vom 31. Januar und die Umtriebe zur Verzögerung der Wahlen in Mainz betreffend.« (MR2, S. 248).

524 Aufruf von Charles-Jean Rougemaitre an die Mainzer Bürger, den Eìd für Freiheit und Gleichheit abzulegen. (3.3.1793) (MR1, S. 791f).

525 Vgl. oben, S. 89. 